\title{
POLYMER TRANSCRYSTALLIZATION INDUCED BY CARBON NANOTUBE AND GRAPHENE FIBERS
}

\author{
A Thesis \\ presented to \\ the Faculty of California Polytechnic State University, \\ San Luis Obispo
}

\begin{abstract}
In Partial Fulfillment
of the Requirements for the Degree

Master of Science in Polymers and Coatings
\end{abstract}

by

John Abdou

June 2015 
(C) 2015

John Abdou

ALL RIGHTS RESERVED 
TITLE:

AUTHOR:

DATE SUBMITTED:

COMMITTEE CHAIR:

COMMITTEE MEMBER:

COMMITTEE MEMBER:
Polymer Transcrystallization Induced by Carbon Nanotube and Graphene Fibers

John Abdou

June 2015

Shanju Zhang, Ph.D.

Assistant Professor of Chemistry

Philip Costanzo, Ph.D.

Associate Professor of Chemistry

Trevor Harding, Ph.D.

Professor of Materials Engineering 


\begin{abstract}
Polymer Transcrystallization Induced by Carbon Nanotube and Graphene

Fibers

John Abdou
\end{abstract}

Carbon nanomaterials provide applications in a wide variety of roles, including as reinforcing materials, thermal and electrical conductors, and optical absorbers. While their benefits can be applied as bulk materials, their implementation into polymer materials as fillers allows for efficient enhanced properties with a small amount of material. These blended materials, referred to as nanocomposites, integrate the beneficial properties of both the polymer and carbon nanomaterials to create cheap solutions to construction and product development that bulk materials could not accomplish. However, major challenges must be overcome to allow for their adoption in industry. Among these problems is the interfacial interactions between the nanomaterials with the polymer matrix. Weak interactions between fillers and polymer can cause the fillers to aggregate out of the polymer phase and greatly reduce the transfer of load, heat, or electricity from the polymer to the filler. As a result, studies must be done to understand and improve these interactions. In order to study these interactions, transcrystals can serve as a model for observing the interface between polymer and filler. Transcrystals are oriented lamella, which are linearly-organized folded polymer chains, forming from a heterogeneous nucleation site at a substrate or a fiber. Transcrystals formed from fibers can 
greatly improve the mechanical strength and thermal stability of the polymer due to increased ordering of polymer chains as well as the load and heat transfer from the polymer to the fiber. Transcrystallization has been well studied with carbon nanotube fibers and other fibers, like nylon and polytetrafluoroethylene.

Graphene is one such filler that can provide substantial benefits due to its high strength, thermal conductivity, and electrical conductivity, but the interactions between these materials have not been studied extensively. Because of this, graphene remains an untapped solution in polymer composite products. In order to study these interactions, this study reports the transcrystallization of isotactic polypropylene in the presence of reduced graphene oxide fibers. Carbon nanotube-induced transcrystals were studied alongside the reduced graphene oxide fibers to compare differences in structure between the two fibers and provide better understanding for the applications of both interfaces in composite development. The kinetics of this transcrystallization was also studied for both fibers to better understand this process as well as to compare the nucleating abilities of both fibers. The fold surface free energies and interfacial free energy differences were calculated to provide a quantitative means of comparison between the two interfaces. This study provides a foundation for creating graphene-polymer composites as well as the transcrystals produced can serve as reinforced materials to be implemented in high-performance products. 


\section{ACKNOWLEDGMENTS}

I would like to express the deepest gratitude to my thesis committee chair, Dr. Shanju Zhang, for his guidance and support during my studies and research. Dr. Shanju Zhang is a great professor and advisor who was always there to guide me during my research as well as encourage me to challenge myself and take advantage of opportunities during my time at Cal Poly.

I would like to express my appreciation to Dr. Phillip Costanzo and Dr. Trevor Harding for their time and advising during my research.

I would like to thank Greg Braggin, Justin van Staden, Karina Reynolds, and other members of Zhang research group, for their help and support during my project.

I would like to give a special thank you to Dr. Raymond Fernando, Dr. Eric Jones, Dr. Dane Jones, and Dr. Katherine Chen, who have all gave me support to this research work.

Lastly, none of this research would have happened without the following funding agencies: National Science Foundation, Cal Poly Extramural Funding Initiative, and Bill Moore Student Fellowship. 


\section{TABLE OF CONTENTS}

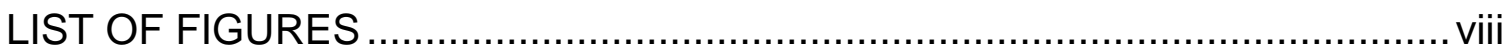

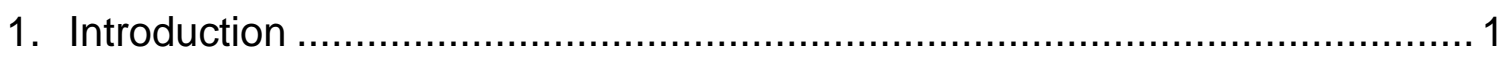

1.1. Graphene, Graphene Oxide, and Carbon Nanotubes............................ 1

1.2. Graphene-Polymer and Carbon Nanotube-Polymer Composites ............. 4

1.3. Polymer Crystallization Theory ......................................................... 12

1.4. Motivation and Research Plan .............................................................. 24

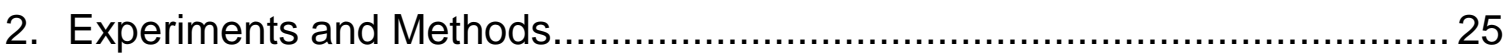

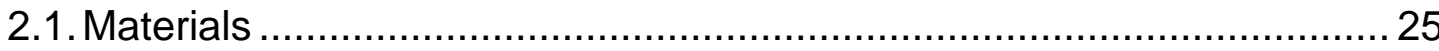

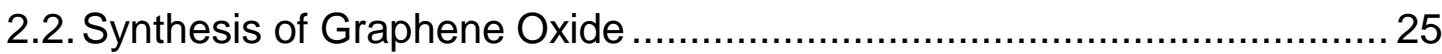

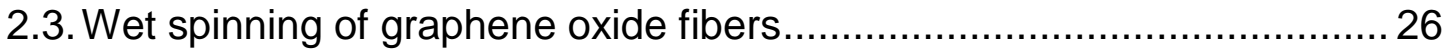

2.4. Preparation of carbon nanotube fibers............................................. 27

2.5. Preparation of single fiber composites ............................................. 27

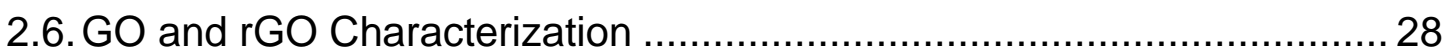

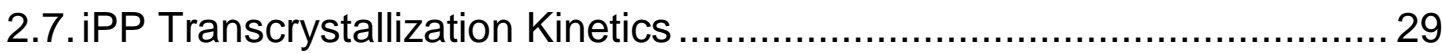

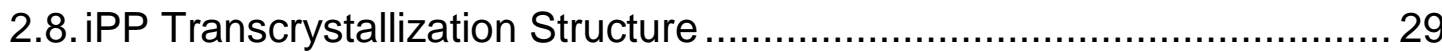

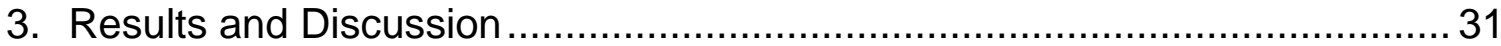

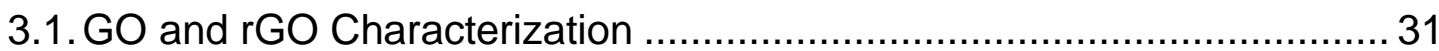

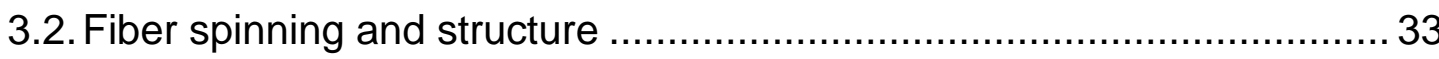

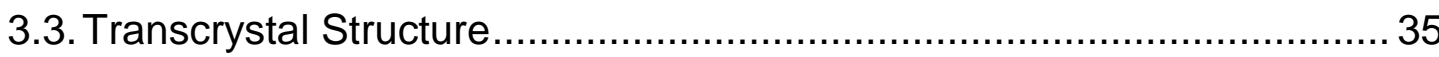

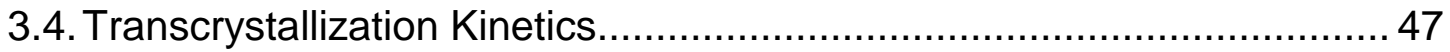

3.5. Transcrystal Interface and Morphology ................................................. 53

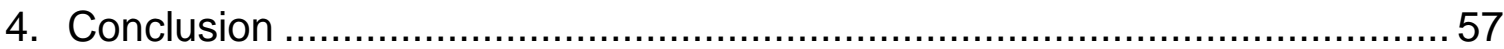

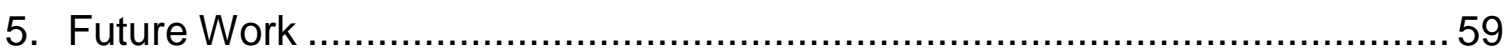

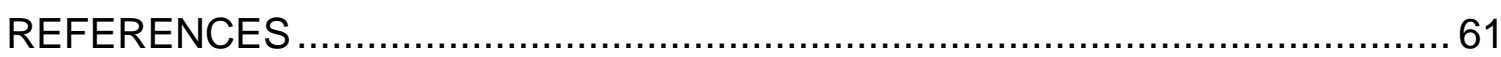




\section{LIST OF FIGURES}

Figure Page

Figure 1. Chemical structures of (a) graphene and (b) graphene oxide. .............2

Figure 2. Chemical structures of (a) SWNT and (b) MWNT. ........................ 3

Figure 3. The three structures of polymer composites............................... 5

Figure 4. Covalent binding process of polymer to $\mathrm{GO}$ by functionalizing GO with ATRP initiator and reacting with styrene, butyl acrylate, or methyl methacrylate. 7

Figure 5. Applications of polymer-carbon nanomaterial composites.................. 9

Figure 6. Oriented polymer helices packed onto the surface of a graphene sheet. 10

Figure 7. Polarized optical microscopy micrograph of isotactic polypropylene-carbon nanotube transcrystals. 11

Figure 8. Illustration of polymer lamellae. 12

Figure 9. Illustration of the initial stem deposition in polymer crystallization.

Figure 10. a) Illustration of activation energy in lamella crystal formation and b) illustration of the formation of stems and folds in lamella crystal formation.

Figure 11. Crystal growth model where oriented lamellae form across the surface.

Figure 12. iPP/CNT transcrystallization kinetics. a) Transcrystalline layer thickness plotted in relation to time with varying temperatures and b) logarithm of the growth rate plotted as a function of $1 / T c \Delta T$. 17

Figure 13. The growth rate curves of crystallization of the three regimes. 18

Figure 14. Diagrams of three regimes from Lauritzen-Hoffman theory.............. 23

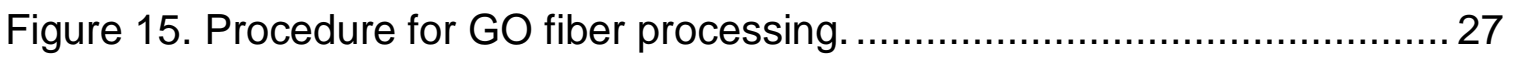


Figure 16. Process for forming iPP transcrystals using melt crystallization.

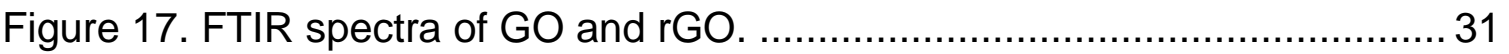

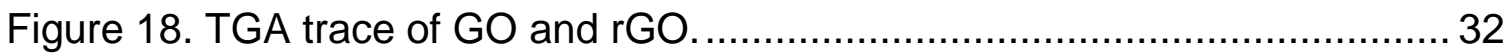

Figure 19. POM micrographs of drop-cast GO LC texture under crossed polarizers rotated at (a) $0^{\circ}$ and (b) $45^{\circ}$. The scale bar represents $200 \mu \mathrm{m} . \ldots \ldots . . .33$

Figure 20. POM micrographs of the GO fiber under crossed polarizers at (a) $0^{\circ}$ and (b) $45^{\circ}$ relative to the transmitted light. The scale bar represents $250 \mu \mathrm{m}$

Figure 21. SEM micrographs of (a) GO fiber, (b) twisted GO fiber, (c) tied GO fiber, and (d) CNT fiber. The scale bar represents $25 \mu \mathrm{m}$ in

(a) and $20 \mu \mathrm{m}$ in (b), (c), and (d).

Figure 22. POM micrograph of iPP crystallized over a GO fiber at $132^{\circ} \mathrm{C}$ under crossed polarizers. The scale bar represents $250 \mu \mathrm{m}$.

Figure 23. POM micrographs of (a) iPP/rGO transcrystals and (b) iPP/CNT transcrystals under crossed polarizers and crystallized at $130^{\circ} \mathrm{C}$. The scale bar represents $250 \mu \mathrm{m}$.

Figure 24. Schemes of the microstructures of (a) positive, (b) mixed, and (c) negative transcrystals. 38

Figure 25. POM micrographs of iPP/CNT transcrystals crystallized at $124^{\circ} \mathrm{C}$ at crystallization times of (a) $0 \mathrm{~min}$, (b) $1.5 \mathrm{~min}$, (c) $3 \mathrm{~min}$, and (d) 4.5 min under crossed polarizers. The scale bar represents $250 \mu \mathrm{m}$.

Figure 26. POM micrographs of iPP/CNT transcrystals crystallized at (a) $124^{\circ} \mathrm{C}$ and (b) $132^{\circ} \mathrm{C}$ under crossed polarizers. The scale bar represents $200 \mu \mathrm{m}$

Figure 27. POM micrographs of (a) iPP/rGO transcrystals and (b) iPP/CNT transcrystals crystallized at $132^{\circ} \mathrm{C}$ under crossed polarizers. $\beta$-transcrystals indicated by the arrows. The scale bar represents $250 \mu \mathrm{m}$. 40

Figure 28. XRD patterns of the transcrystallized iPP with indexed peaks. 42 
Figure 29. POM micrographs of the melting of iPP $\beta$-transcrystals over an rGO fiber crystallized at $132^{\circ} \mathrm{C}$. Sample at (a) room temperature with retarding plate, (b) $155^{\circ} \mathrm{C}$ with retarding plate, (c) $161^{\circ} \mathrm{C}$ with retarding plate, and (d) $161^{\circ} \mathrm{C}$ without retarding plate. The scale bar represents $250 \mu \mathrm{m}$.

Figure 30. POM micrographs of the melting of iPP $\beta$-transcrystals over a CNT fiber crystallized at $132^{\circ} \mathrm{C}$. Sample at (a) room temperature with retarding plate, (b) $155^{\circ} \mathrm{C}$ with retarding plate, (c) $160^{\circ} \mathrm{C}$ with retarding plate, and (d) $160^{\circ} \mathrm{C}$ without retarding plate. The scale bar represents $250 \mu \mathrm{m}$.

Figure 31. POM micrographs of the melting of iPP/CNT transcrystalline double layer crystallized at $132^{\circ} \mathrm{C}$. Sample at (a) room temperature,

(b) $165^{\circ} \mathrm{C}$, (c) $170^{\circ} \mathrm{C}$, and (d) $175^{\circ} \mathrm{C}$, and (e-f) $180^{\circ} \mathrm{C}$. The scale bar represents $200 \mu \mathrm{m}$.

Figure 32. The plots of (a) rGO and (b) CNT transcrystal (TC) thickness versus time at different crystallization temperatures.

Figure 33. Plot of $\ln (\mathrm{G})$ of transcrystals on $r G O$ and $C N T$ fibers versus $1 /(T \Delta T) .50$

Figure 34. Induction times of iPP transcrystals on rGO and CNT fibers at different crystallization temperatures. 52

Figure 35. Plot of $\ln \left(1 / \mathrm{t}_{\mathrm{i}}\right)$ versus $1 /\left(\mathrm{T} \Delta \mathrm{T}^{2}\right)$ for $\mathrm{rGO}$ and $\mathrm{CNT}$ transcrystals.......... 52

Figure 36. SEM micrographs of (a) the overall structure of the iPP/rGO transcrystals and spherulites, (b) the transcrystalline lamellae, and (c) the boundary between the transcrystalline layer and spherulites. TC and S denotes transcrystals and spherulites, respectively. The scale bar represents $10 \mu \mathrm{m}$ in (a) and $800 \mathrm{~nm}$ in (b) and (c). 54

Figure 37. Scheme of the microstructures of iPP transcrystalline lamellae. 55

Figure 38. SEM micrographs of (a) the overall structure of the iPP/CNT transcrystals and (b) the iPP/CNT transcrystalline lamellae. The scale bar represents $10 \mu \mathrm{m}$ in (a) and $5 \mu \mathrm{m}$ in (b) 56

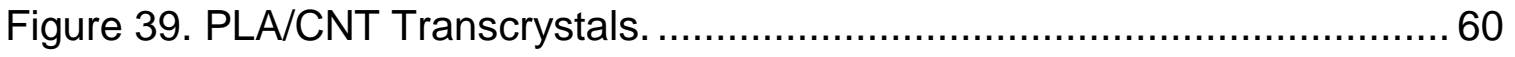

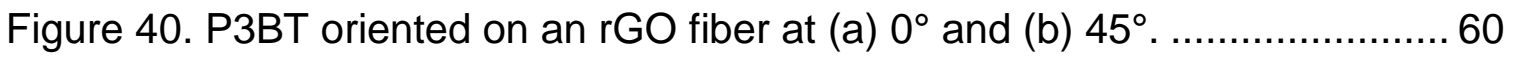


1. Introduction

1.1. Graphene, Graphene Oxide, and Carbon Nanotubes

Carbon nanomaterials encompass a wide variety of forms, including graphene sheets and nanoribbons and carbon nanotube fibers. The unifying feature of all of these materials is that they are made up of carbon atoms in various structures. No single carbon nanomaterial has a clear advantage over another with their strengths dependent on the application.

Graphene is a two-dimensional monolayer of $\mathrm{sp}^{2}$-hybridized carbon atoms in a honeycomb-like lattice shown in Figure 1a. The Nobel Prize-winning discovery of monolayer graphene production in 2004 has significantly impacted the state of materials research because it is the strongest material discovered by researchers. ${ }^{1}$ Due to its structure made up of $\pi$-bonds and delocalized electrons, graphene has many favorable properties, including high tensile strength, excellent thermal conductivity and stability, and electrical conductivity. ${ }^{2-}$ ${ }^{4}$ Single layers of graphene can exhibit tensile strength as high as $130 \mathrm{GPa}$ and current densities six orders of magnitude higher than copper. ${ }^{5}$ Because of these properties, research into graphene has uncovered various potential applications in semiconductors, sensors, optoelectronic devices, and in composites as reinforcing agents. However, graphene remains costly as high-grade graphene requires production processes that are either high cost or low yield, such as chemical vapor deposition and epitaxial crystal growth. ${ }^{6}$ To overcome this problem, low concentrations of graphene can be blended with polymers to create high-performance, low-cost composites that draw from the properties of both the 
polymer and graphene. However, due to the strong interactions between graphene sheets, graphene cannot be dispersed in a polymer phase due to the aggregation of the graphene and resulting weak interactions between graphene sheets and the polymer.

(a)

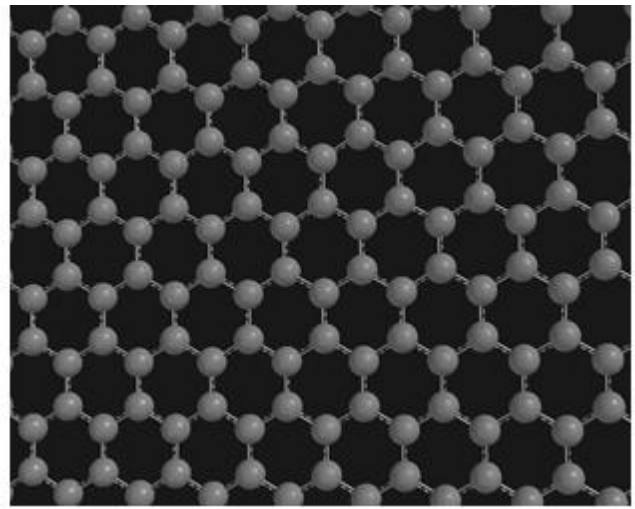

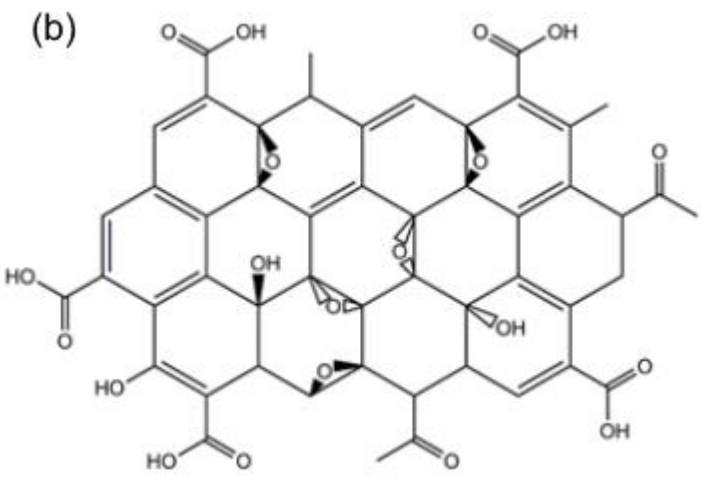

Figure 1. Chemical structures of (a) graphene and (b) graphene oxide.

Academic and industrial composite research has increasingly focused on graphene oxide (GO). GO are graphene nanoplatelets with acid functional groups displayed in Figure 1b and serves as an intermediate in graphene synthesis. GO can be easily formed through the acid treatment, exfoliation, and oxidation of graphite flakes, a process referred to as the Hummers method. ${ }^{7,8}$ Upon reduction of GO, structures similar to graphene are obtained with similar properties to graphene. GO reduction is one method for a cheap means of graphene production due to the cheap reagents and large scale preparation of the material. Furthermore, GO can be dispersed in water and common organic solvents due to its acid functional groups, making it an effective target in composites. GO can also be processed into films and fibers, allowing for flexible implementation into raw materials and composites. ${ }^{9-12}$ Upon the formation into 
reduced graphene oxide ( $\mathrm{rGO}$ ) fibers, the fibers exhibit strong mechanical properties with tensile strengths as high as $500 \mathrm{MPa} .{ }^{10}$ It must be noted that GO synthesis has little control over the size and dimensions of the sheets.

Furthermore, because of the oxygen functional groups, GO has a higher amount of defects on the surface that reduce the performance of the material, making it a weaker material than both graphene and carbon nanotubes. ${ }^{5}$

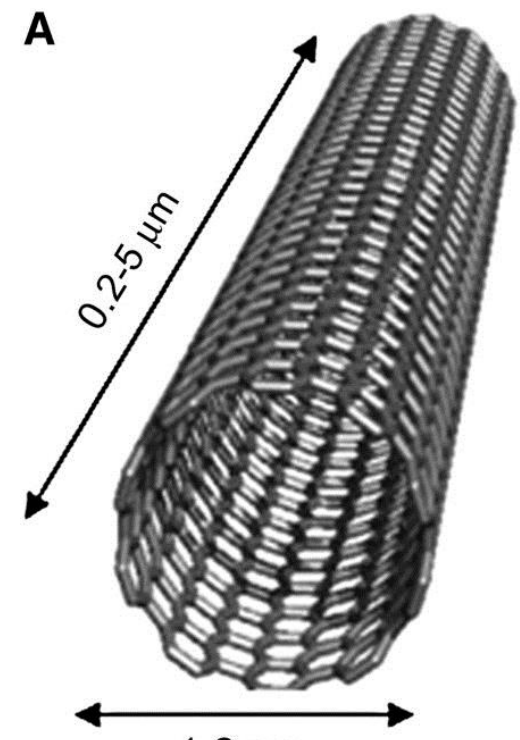

$1-2 \mathrm{~nm}$

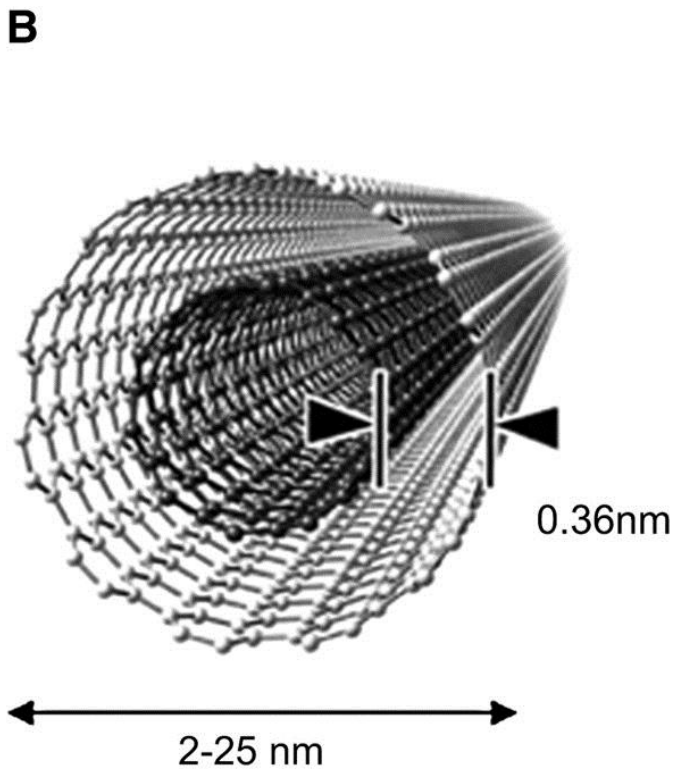

$2-25 \mathrm{~nm}$

Figure 2. Chemical structures of (a) SWNT and (b) MWNT. ${ }^{13}$

Carbon nanotubes (CNTs) are continuous rolls of single or multiple layers of graphene sheets, which are designated as single-walled and multi-walled CNTs (SWNTs and MWNTs) as shown in Figure 2. These nanotubes are exceptionally strong, reaching tensile strengths up to ranges of 11-63 GPa and current densities about 1000 times that of metals. ${ }^{5}$ Similar to graphene, they also exhibit exceptional thermal and electrical properties. However, like graphene, carbon nanotubes also have strong interactions with each other, 
making it difficult to disperse in polymers and solvents and making it difficult to implement carbon nanotubes in composites without the use of high energy and expensive processing. ${ }^{14}$ Carbon nanotubes can be dispersed through functionalization of the surface of the nanotubes or the addition of surfactants to disperse them. These two solutions also have their drawbacks as functionalization decreases the properties of the CNTs as the functional groups serve as defects while surfactants can migrate and cause the nanotubes to aggregate while the polymer dries into a solid matrix. ${ }^{5}$

\subsection{Graphene-Polymer and Carbon Nanotube-Polymer Composites}

Carbon-based polymer composites are a growing focus in research today and provide new solutions in engineering and product development. Composites are created by mixing carbon nanofillers into a polymer matrix to create high performance materials. Polymer composites have different structures, which can affect the state of the interactions between the polymer and filler. There are three major structure types of composites that depend on how the filler is dispersed in the polymer as shown in Figure 3: a) phase-separated microcomposites, which have the polymer interact on the exterior surface of the layered filler, b) intercalated nanocomposites, which the layers of filler are separated enough to allow for the polymer to cover each layer, and c) exfoliated nanocomposites, where the layers are separated entirely and dispersed throughout the polymer phase. These composite structures depend on the type of filler used and the fabrication process. 


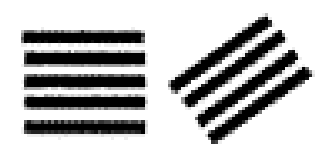

Layered silicate

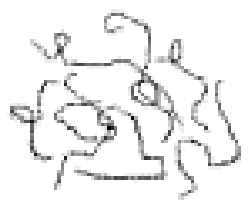

Polymer

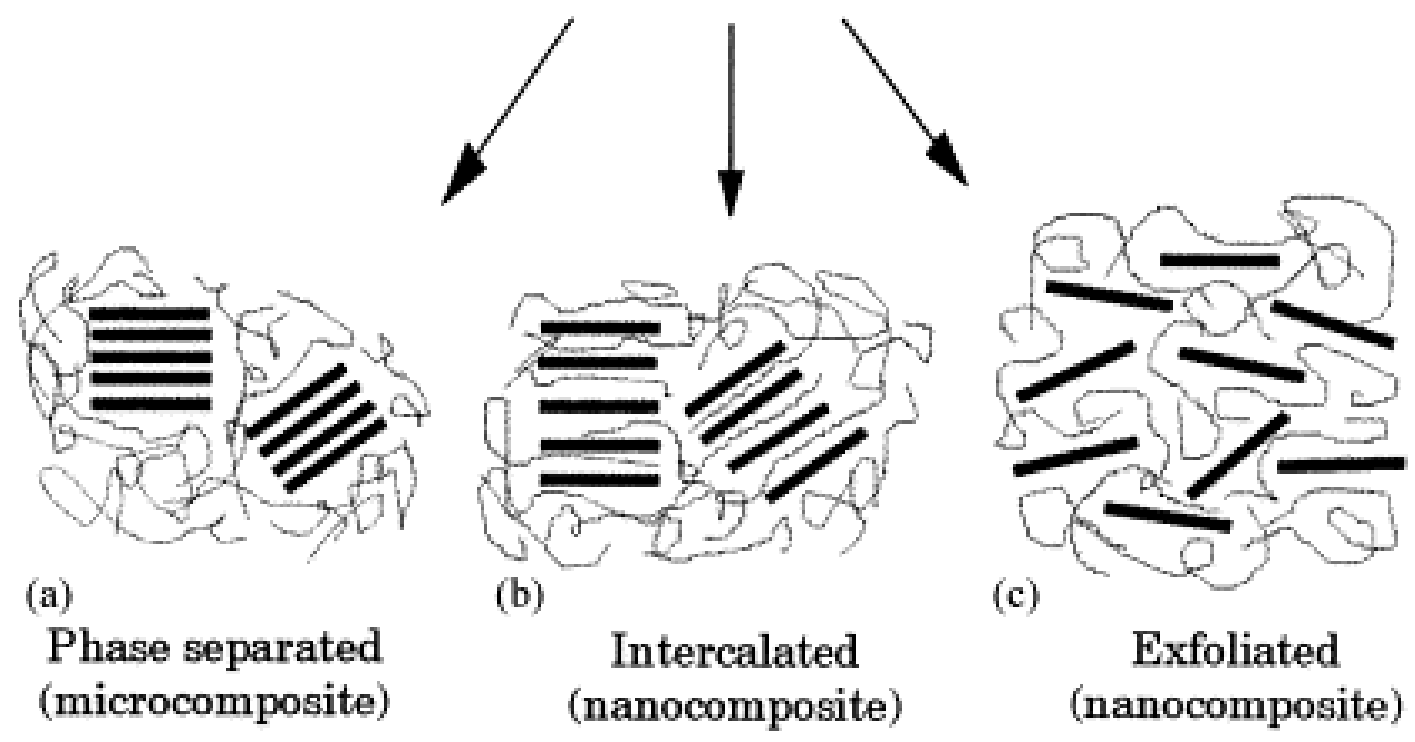

Figure 3. The three structures of polymer composites. ${ }^{15}$

The basic fabrication process for composites involves the dispersion of the filler in the polymer phase. Graphene and carbon nanotube nanocomposites can be implemented with polymer through four major methods: solution mixing, melt mixing, in situ polymerization, and covalent bonding with the polymer. ${ }^{16}$ In solution mixing, the carbon nanomaterial is suspended in solution with or without surfactant and mixed with the dissolved polymer through stirring or shear mixing. After mixing, the composites are precipitated either through evaporating the solvent to form a film or the addition of a solvent that the polymer is not soluble in, causing the polymer to aggregate and cover the nanofiller surface. The resulting composites are then extracted and dried. This process allows for facile production of nanocomposites with good dispersion of the filler and has been 
widely studied, but it requires an exfoliation step in the case of graphene composites to allow for the mixing of the graphene sheets and is more costly due to the use of solvent. Melt mixing is a more cost effective approach that uses no solvents. It involves the mixing of the nanofiller in powder form with the polymer melt at high shear rates. This process has some disadvantages due to the requirement of prior exfoliation for graphene, the poor dispersion of the carbon nanomaterials in the polymer, and the high temperatures needed to melt the polymer causing premature reduction of graphene oxide to reduced graphene oxide. In situ polymerization has advantages over the previous two methods in terms of producing highly dispersed nanocomposites without the need of an exfoliation step. The process creates nanocomposites through the mixing of the filler in pure monomer or monomer solution and then polymerizing the monomer. In the case of graphene oxide, the sheets separate and the monomer intercalates the graphene oxide suspended in the liquid phase, producing intercalated graphene-based nanocomposites. Lastly, the covalent binding approach of making carbon-based nanocomposites involves functionalizing graphene oxide or carbon nanotubes with an initiator or catalyst and mixing the functionalized carbon nanomaterial with monomer to allow for the grafting of polymer chains onto the surface of the graphene sheets as shown in Figure 4. Regardless of the method of fabrication, the result is polymer chains aligned and organized onto the surface of the filler. These interactions between polymer and filler act to transfer stress, heat, or electrons from the polymer matrix to the 
graphene sheet or carbon nanotube surface. This occurrence is observed in studies with graphene and carbon nanotube nanocomposite research.
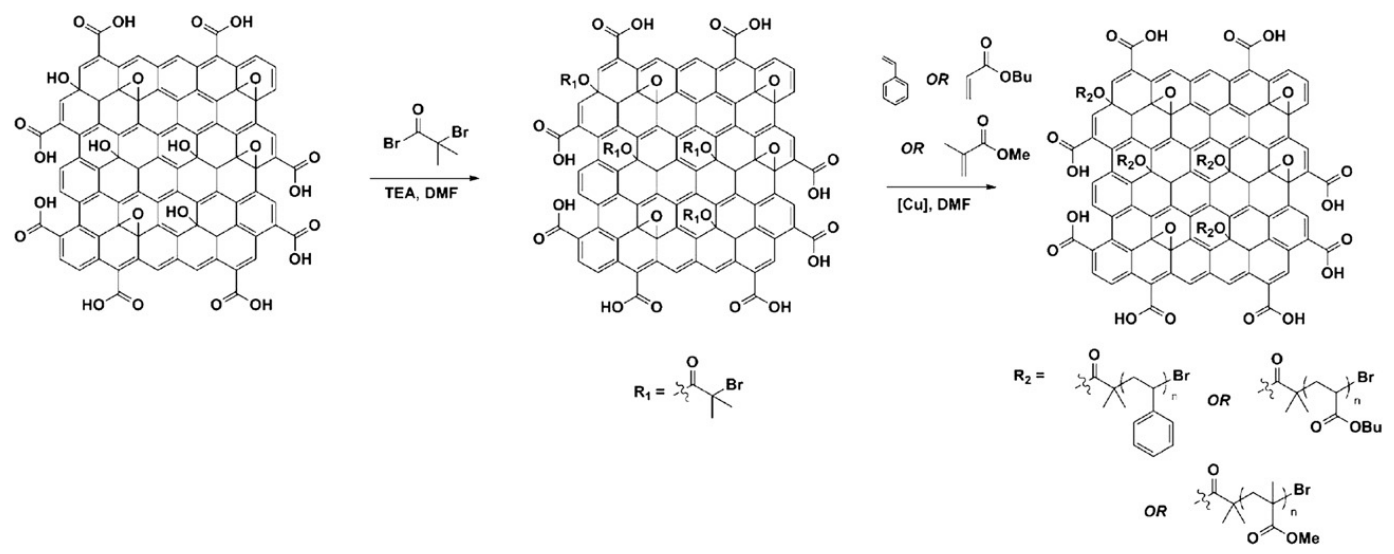

Figure 4. Covalent binding process of polymer to $\mathrm{GO}$ by functionalizing $\mathrm{GO}$ with ATRP initiator and reacting with styrene, butyl acrylate, or methyl methacrylate. ${ }^{16}$

Poly(vinyl acetate) (PVAc) was reinforced using graphene oxide. ${ }^{17}$ Solution mixing was used to produce the nanocomposites by stirring PVAc powder into a $1 \mathrm{mg} / \mathrm{mL}$ GO solution exfoliated through sonication with $0.5 \%$ sodium dodecylbenzenesulfonate (SDBS) surfactant and reduced with hydrazine. The solution was then applied to glass plates and dried to obtain films. The tensile strength showed greater improvements at lower loadings of graphene with the $0.6 \%$ rGO sample showing the greatest change in properties from pure PVAc. At this concentration, the composite exhibits a tensile strength and elongation at break of $42 \mathrm{MPa}$ and $150 \%$ in comparison to $17 \mathrm{MPa}$ and $220 \%$ of pure PVAc, resulting in a stronger, but still ductile material.

Blends of polyaniline (PANI) with varying concentrations of GO and rGO displayed modified conductivity. ${ }^{18}$ The nanocomposites were produced through the in situ anionic polymerization of PANI with dispersed GO, reduced with 
hydrazine, collected through filtration, and then washed with water. The electrical performance of the composites were compared to PANI, GO, and rGO. The composite conductivity reached up to $231.3 \mathrm{~S} / \mathrm{m}$ observed for PANI loaded with $10 \%$ GO due to the $\pi-\pi$ stacking of PANI with the GO sheets. In comparison, PANI, GO, and rGO have conductivities of $10.6,0.8$, and $277.2 \mathrm{~S} / \mathrm{m}$, respectively. PANI-GO composites provide a low cost solution for high conductivity materials without the need for reduction of graphene oxide.

CNT composites show similar applications to graphene composites. Poly(vinyl alcohol) (PVA) mixed with CNT at $60 \%$ weight were spun into robust fibers by a modified coagulation spinning process. ${ }^{19}$ SWNTs were injected into a cylindrical pipe with flowing PVA coagulation solution and drawn into fibers. These composite fibers had demonstrated a maximum tensile strength of 1.8 GPa, comparable in strength to spider silk.

Poly(3,4-ethylenedioxythiophene):poly (styrenesulfonate) (PEDOT:PSS) composite films were studied using MWNTs. ${ }^{20}$ The composites were fabricated by dispersing MWNTs in a $1 \%$ aqueous solution of PEDOT:PSS using ultrasonication and then forming films with solution by spin coating. The resistances of the films were measured and compared to a pure PEDOT:PSS film. At $0.3 \%$ wt MWNT, the resistance of the film was $734 \Omega$ while the pure film was around $980 \mathrm{k} \Omega$. This improvement in resistance is due to the high conductivity of the MWNTs enhancing the PEDOT:PSS.

Because of this interfacial transfer of load, heat, and electricity, composites can be used to create lightweight materials that are strong or 
conductive with a wide variety of applications, including aerospace components, car parts (Figure 5), and solar cells. However, despite these beneficial properties, industry has yet to incorporate graphene composites into products. This is due to the fact that the interface between graphene and polymers is not well-understood.

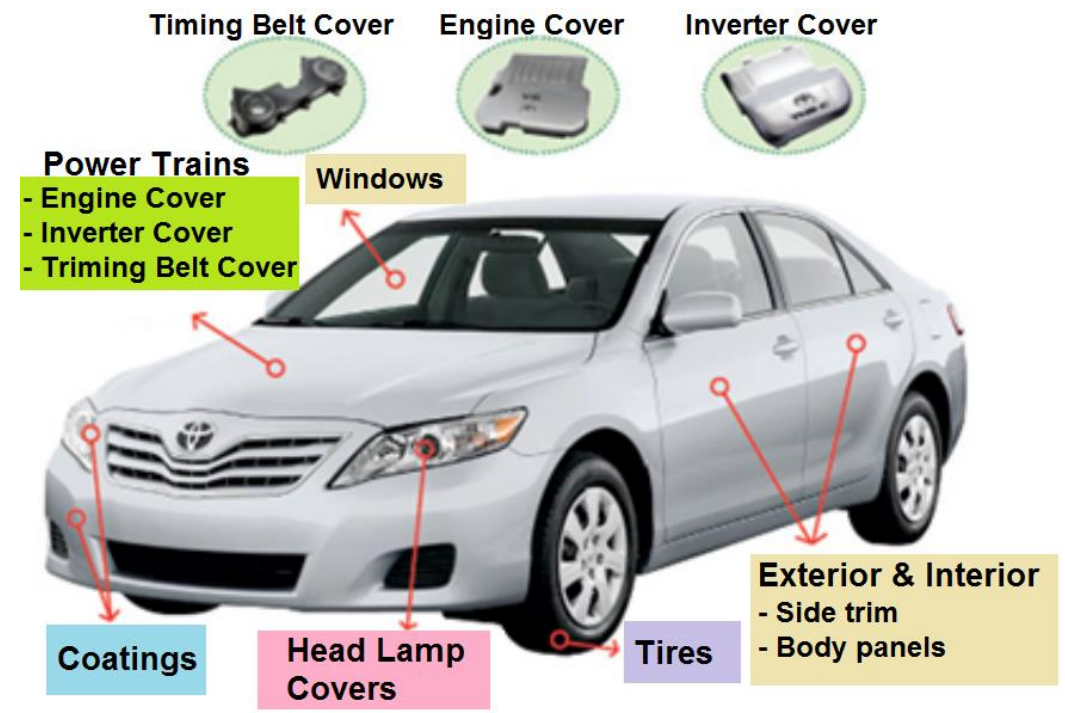

Figure 5. Applications of polymer-carbon nanomaterial composites. ${ }^{21}$

The nature and strength of the interfacial interactions between the polymer and filler affects the interfacial adhesion and load transfer from the polymer matrix to filler, acting as a major contributing factor to composite performance. ${ }^{22-}$ ${ }^{24}$ To improve the performance of composites, research in improved interfacial interactions between the polymer and carbon fillers have been performed using both chemical and physical methods. ${ }^{14,25}$ These methods include the oriented crystallization of polymer to a nanofiller surface, such as is the case in Figure 6. Upon oriented crystallization, the crystal size, chain packing, and chain mobility of the oriented polymer crystals are significantly different from those in the bulk. 
The interfaces between these polymer crystals and filler surface result in enhanced interfacial adhesion and stress transfer ${ }^{26-28}$ However, it remains challenging to directly visualize the interfacial morphology on the nanofillers without high-resolution experimental methods.

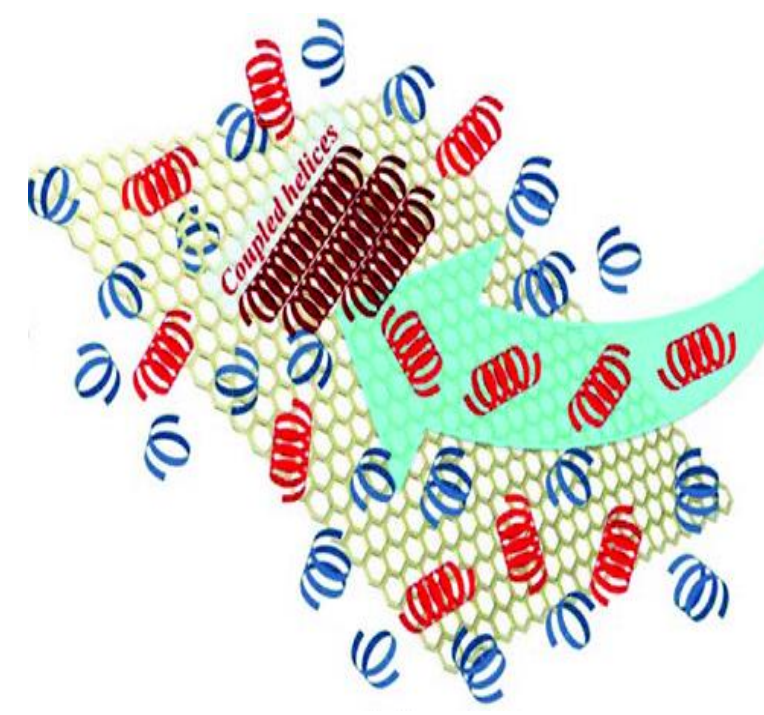

Figure 6. Oriented polymer helices packed onto the surface of a graphene sheet. $^{29}$

It is important to create composites at larger scales to be able to observe these interactions. Fiber-reinforced composites are one possible method to accomplish this. Fiber-reinforced composites make use of fillers in the fiber form. Usually, these composites feature oriented crystallization over the fiber surface, termed transcrystals. In transcrystals, polymer lamellae nucleate and grow from the fiber or substrate surface as seen in Figure 7. During this process, the fiber acts as a nucleation site and orientation template for the polymer chains, which changes the structure of the polymer crystals from those found in the bulk. ${ }^{30}$ Due to the increased order and transfer of stress and heat from the polymer to the 
fiber, transcrystals have notably higher tensile strength and melting temperatures. ${ }^{31}$ Recently, carbon nanotube (CNT)-induced polymer transcrystallization has been reported. ${ }^{22,31}$ Fibers made from SWNTs or MWNTs were embedded in isotactic polypropylene (iPP). ${ }^{31,32}$ Single-fiber pull-out tests demonstrated that the interfacial shear strength of CNT fiber/iPP composites was $300 \%$ higher than that of carbon fiber/iPP composites. ${ }^{32}$ The tensile tests showed that the strength and modulus of CNT fiber/iPP composites were $200 \%$ higher than those of the control iPP. ${ }^{31}$ This process has been studied for carbon nanotube, Kevlar, nylon, Teflon, and single carbon fibers, but graphene oxide fibers have never been studied. ${ }^{6,31,33-35}$ Graphene oxide can be processed into fibers, reduced, and incorporated into a polymer to induce transcrystals. This process can be studied and compared with CNT fiber-induced transcrystals in terms of structure and kinetics.

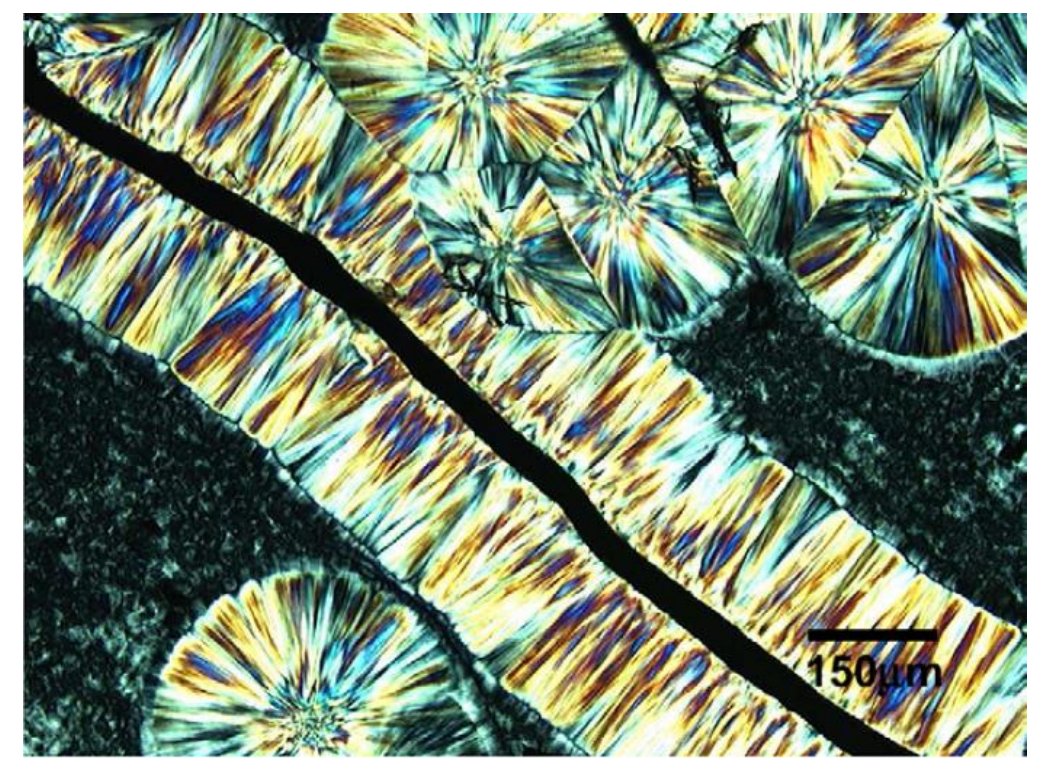

Figure 7. Polarized optical microscopy micrograph of isotactic polypropylenecarbon nanotube transcrystals. ${ }^{31}$ 


\subsection{Polymer Crystallization Theory}

During the crystallization of semicrystalline polymers, polymer coils undergo chain folding, where polymer segments align and fold over each other, resulting in polymer crystals called lamellae as shown in Figure 8. By introducing organic or inorganic reinforcements to the polymer, the crystallinity and morphology of the polymer crystals can be changed. ${ }^{30}$ An example of this is in polymer transcrystallization where a fiber or substrate is introduced to the polymer during crystallization and acts as a heterogenous nucleation site for oriented crystallization.

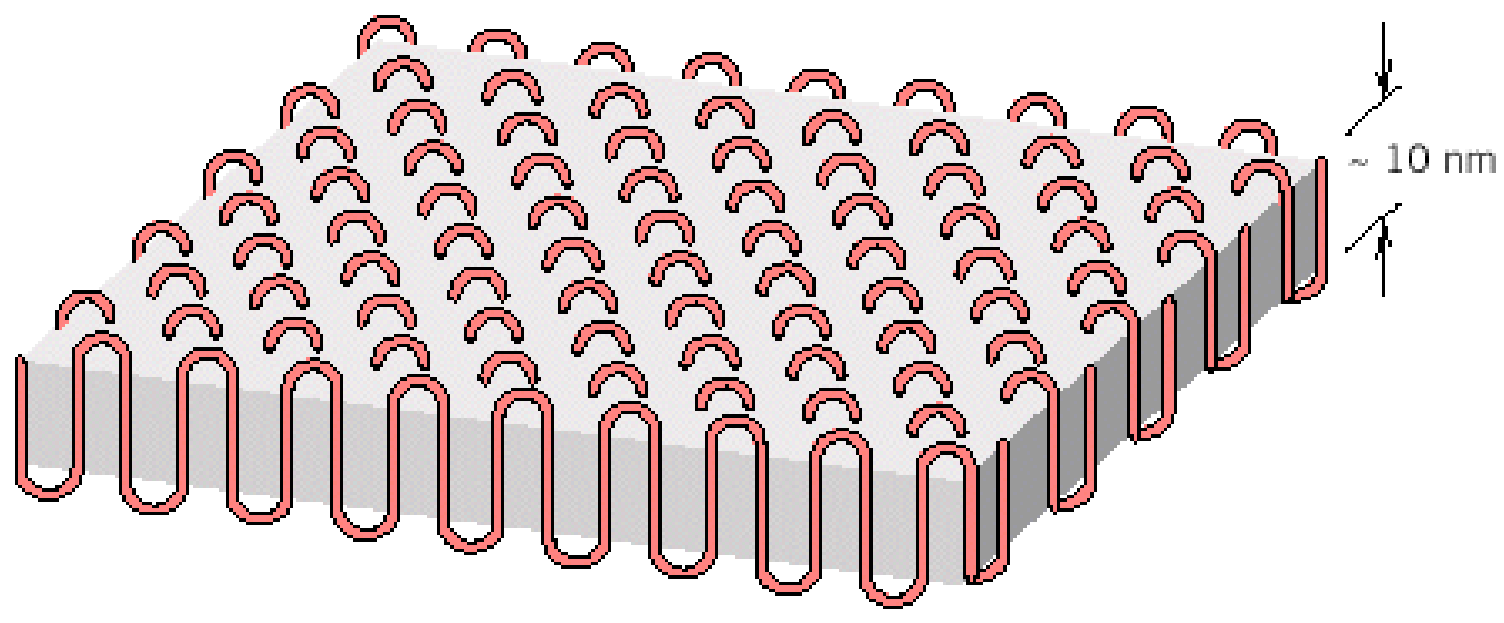

Figure 8. Illustration of polymer lamellae.

The model used to understand the formation of lamellae is the LauritzenHoffman theory of secondary nucleation. This model is the first analytical method to simulate the formation of chain folded lamellae from the threedimensional random coil state based on thermodynamics. ${ }^{36}$ According to the theory, the alignment of polymer chains reduces the Gibbs free energy of the 
polymer. As a result, the growth rate of the polymer crystals can be linked to free energy values that measure the energy needed to form a crystal.

Before crystallization occurs, all the polymer chains are considered to be amorphous. Secondary nucleation occurs through the migration of a polymer segment to an existing nucleation site. In the case of heterogeneous nucleation, this site is found on a fiber, substrate, or any other particle or molecule not made up of the crystallizing polymer. The polymer chain then spreads and extends to create an activated state, $\Delta \Phi^{*}$, in which segments of the polymer, indicated by the black dots on Figure 9, align to the nucleation site of the fiber or substrate. After a period of time, the polymer chain is fully elongated to completely align with the substrate, creating a full stem and concluding secondary nucleation. It should be noted that in Figure 9, the rates of attachment of the polymer chain to the substrate and elongation of the polymer are $A_{0}$ and $A_{0}$ ', respectively, while the reverse rates are $B_{1}{ }^{\prime}$ and $B_{1}$, respectively. Crystal formation then continues with the coiled portion of the remaining attached polymer chain folding and repeating the same process as nucleation with formation of the activated state and elongation of the polymer chain into another stem adjacent and parallel to the initial stem. The energy required to form these stems is displayed in Figure 10a. The step with the greatest barrier of activation energy is the formation of the first activated state because of the difference in surface energy between the polymer and fiber or substrate. After the first stem is formed, the subsequent stems require less activation energy as the formation of lamella becomes more favorable. The end result is a sequence of folded lamellae across the nucleation 
site surface as found in Figures $10 \mathrm{~b}$ and 11. Upon reaching the end of the substrate or another nucleation site, another layer begins and the process repeats with the crystals growing outward and perpendicular to the surface of nucleation in the direction of the vector $\mathrm{G}$ in Figure 11. The terms for the rates of nucleation, lamellar growth across the surface, and radial lamellar growth are i, g, and $\mathrm{G}$, respectively.

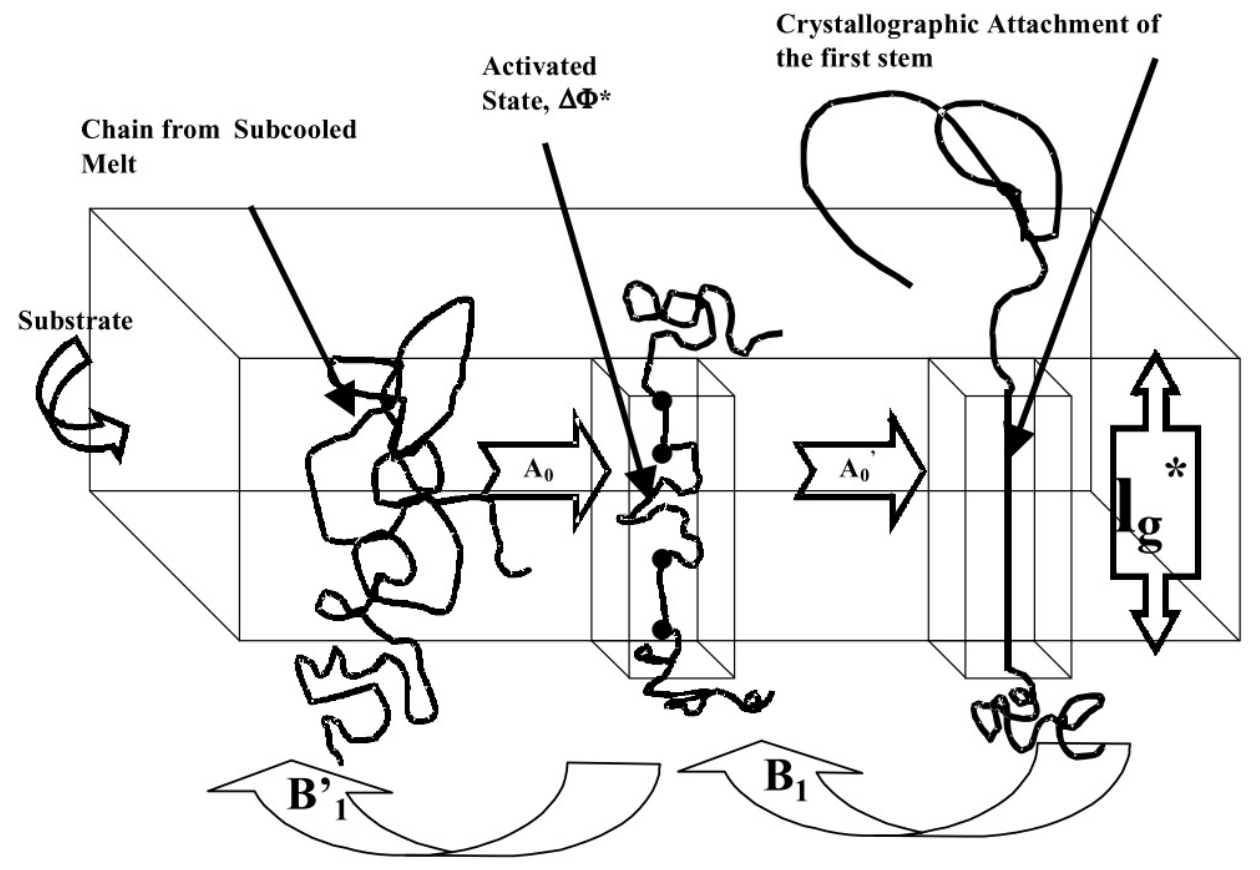

Figure 9. Illustration of the initial stem deposition in polymer crystallization. ${ }^{37}$ 

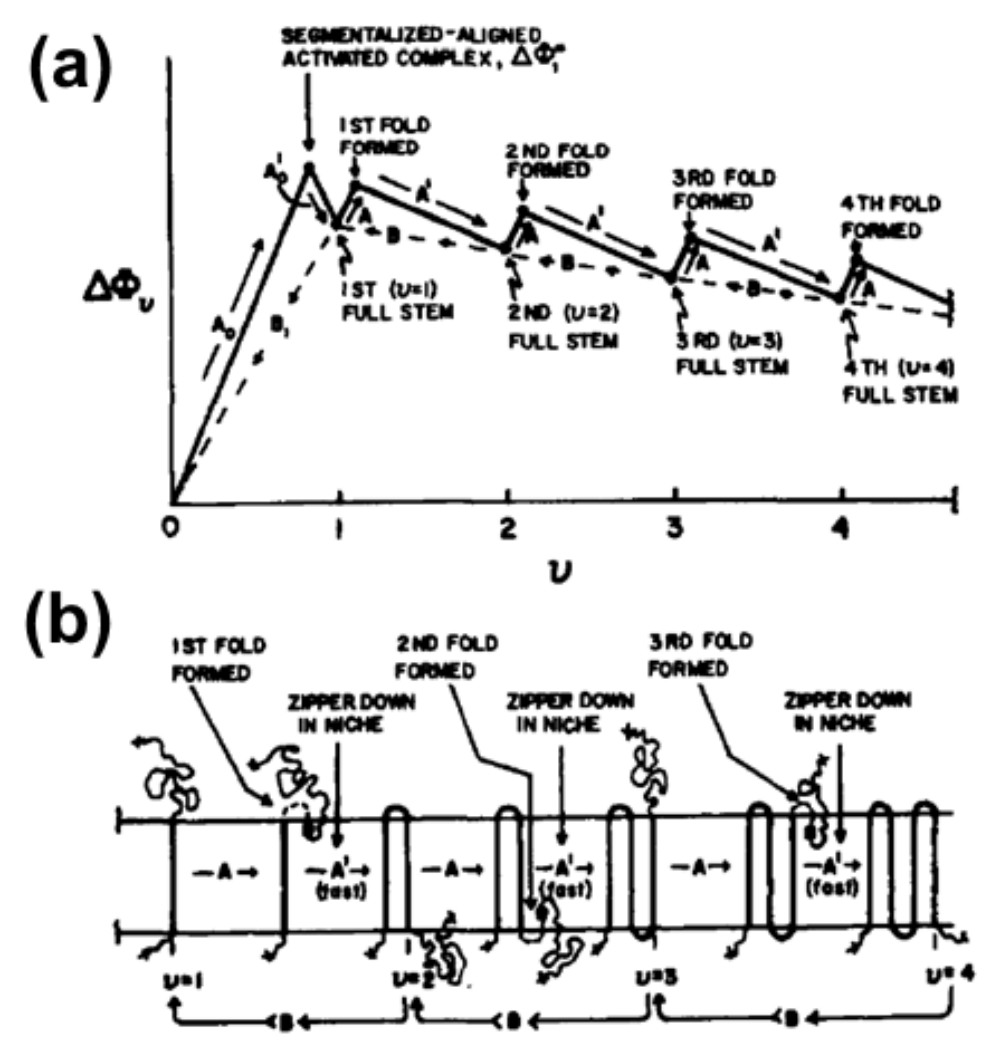

Figure 10. a) Illustration of activation energy in lamella crystal formation and b) illustration of the formation of stems and folds in lamella crystal formation. ${ }^{38}$

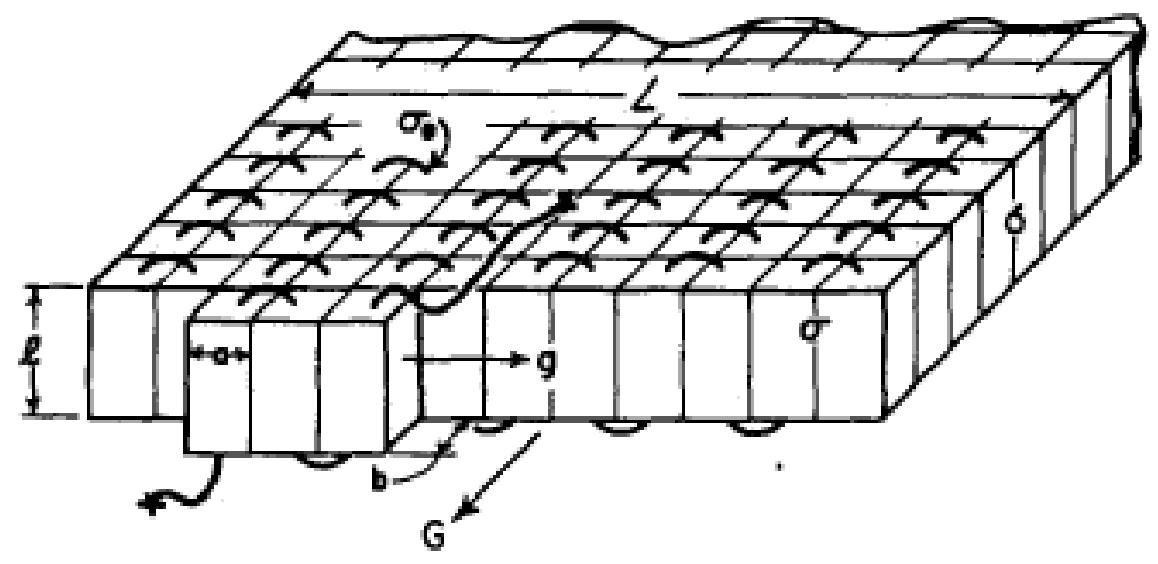

Figure 11. Crystal growth model where oriented lamellae form across the surface. $^{39}$ 
The growth of polymer transcrystals are linear functions of time as indicated in Figure 12a. As the crystallization temperature decreases, the growth rate increases due to the promotion of nucleation at lower temperatures, allowing for the faster formation of crystals. The growth rates plotted as a function of temperature can be used to determine the nucleation parameter, a constant related to the surface free energies of crystallization. LauritzenHoffman theory provides a mathematical model for the polymer diffusion and chain folding activity in polymer crystallization. According to Lauritzen-Hoffman, the growth rate of the crystallization is related to the nucleation parameter, $\mathrm{K}_{\mathrm{g}}$, as shown Equation $1^{38}$

$$
\mathrm{G}=\mathrm{G}_{0} \exp \left(\frac{-\mathrm{U}^{*}}{\mathrm{R}\left(\mathrm{T}_{\mathrm{c}}-\mathrm{T}_{\infty}\right)}\right) \exp \left(\frac{-\mathrm{K}_{\mathrm{g}}}{\mathrm{T}_{\mathrm{c}} \Delta \mathrm{T}}\right)
$$

where $G_{0}$ is the pre-exponential factor that contains all temperature-independent parameters, $U^{*}$ represents the activation energy for the polymer segment transport to the crystal surface in $J, R$ is the universal gas constant, $T_{c}$ denotes the isothermal crystallization temperature in $\mathrm{K}, \mathrm{T}_{\infty}=\mathrm{T}_{g}-30\left(\mathrm{~T}_{g}\right.$ is the glass transition temperature), $\Delta T=T_{m}{ }^{0}-T_{c}\left(T_{m}{ }^{0}\right.$ is the melting temperature at equilibrium), and $\mathrm{K}_{\mathrm{g}}$ is the nucleation constant that is determined by the fold surface free energy in $\mathrm{K}^{2}$. The first exponential term in Equation 1 represents the diffusion process of the polymer chain segments in melt, while the second exponential term is associated with the thermodynamic driving force of chainfolding during the heterogeneous nucleation process. 

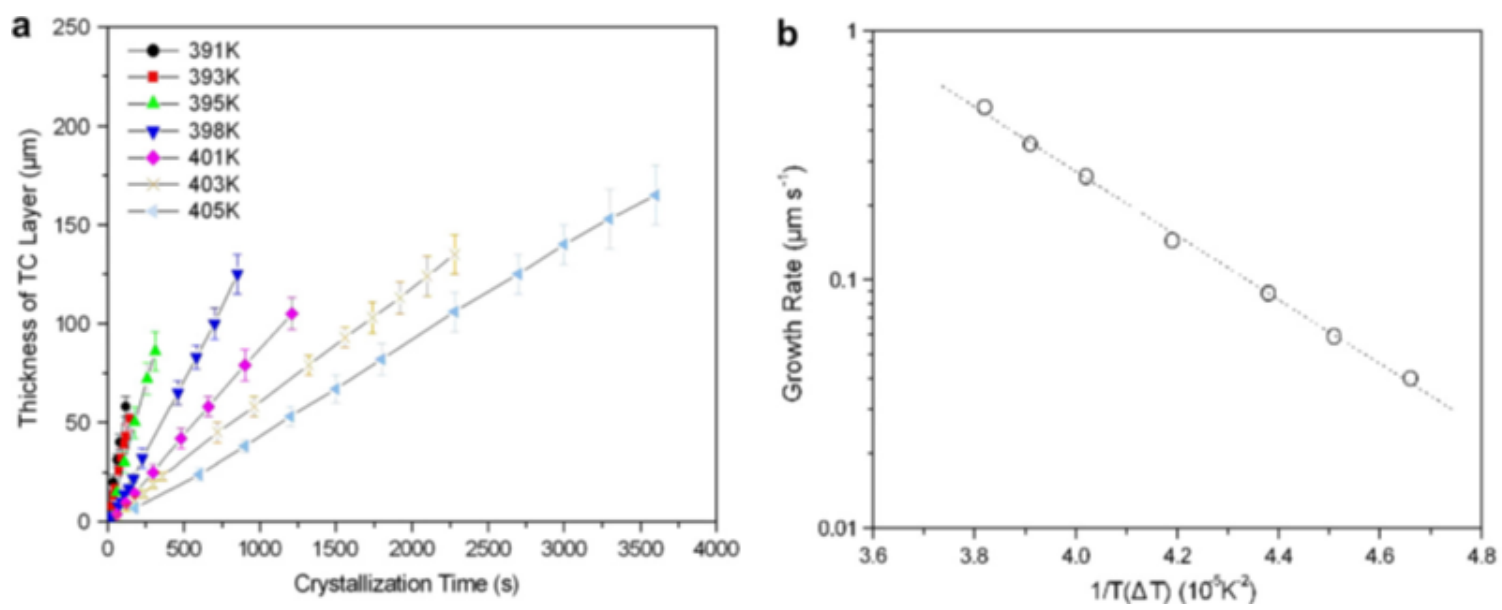

Figure 12. iPP/CNT transcrystallization kinetics. a) Transcrystalline layer thickness plotted in relation to time with varying temperatures and b) logarithm of the growth rate plotted as a function of $1 / T_{c} \Delta T^{31}$

In this regard, the growth rate $(\mathrm{G})$ of the $\mathrm{TC}$ interphase is mainly dependent on $1 / T_{c} \Delta T$. Equation 1 is then simplified and expressed by Equation 2

$$
\ln G=-\frac{\mathrm{K}_{\mathrm{g}}}{\mathrm{T}_{\mathrm{c}} \Delta \mathrm{T}}+\text { constant }
$$

Equation 2 provides a linear relationship between the reciprocal of temperature and the natural logarithm of the growth rate so that slope is equal to $\mathrm{K}_{\mathrm{g}}$ as indicated by Figure $12 \mathrm{~b}$. The $\mathrm{K}_{\mathrm{g}}$ is directly related to the surface free energies of the polymer crystals and is determined by Equation $3^{40}$

$$
\mathrm{K}_{\mathrm{g}}=\frac{4 \mathrm{~b}_{0} \sigma \sigma_{\mathrm{e}} \mathrm{T}_{\mathrm{m}}^{0}}{\mathrm{k}_{\mathrm{B}} \Delta \mathrm{h}_{\mathrm{f}}}
$$

where $b_{0}$ denotes the thickness of single molecular layer in the polymer crystals in $\mathrm{m}, \sigma$ and $\sigma_{\mathrm{e}}$ are the lateral and fold surface free energies in $\mathrm{J} / \mathrm{m}^{2}$, respectively, $\mathrm{k}_{\mathrm{B}}$ is the Boltzmann constant, and $\Delta \mathrm{h}_{\mathrm{f}}$ represents the heat of fusion per unit volume of the polymer crystals in $\mathrm{J} / \mathrm{m}^{3}$. The fold surface free energy is the 
energy per area need for the polymer to form a folded surface while the lateral surface energy is the energy per area to form the surface at the edge of the transcrystal as shown in Figure 11. Fold surface free energy is independent of temperature while lateral surface free energy is affected by temperature. Through the use of growth rate curves, the fold surface free energy, $\sigma_{e}$ can be determined through the calculation of $\sigma \sigma_{e}$ from Equation 3 and the estimation of $\sigma$ through Equation $4^{41}$

$$
\sigma=\propto \Delta \mathrm{h}_{f}\left(a_{0} b_{0}\right)^{1 / 2}
$$

where $\alpha \approx 0.1$ and $a_{0}$ is the width of the polymer chain stem in $\mathrm{m}$. With $\sigma$ and $\sigma_{e}$ obtained, the formation of transcrystals on different surfaces can be compared in terms of energy required per area. However, it should be noted that Equation 3 applies to a certain temperature range called a regime.

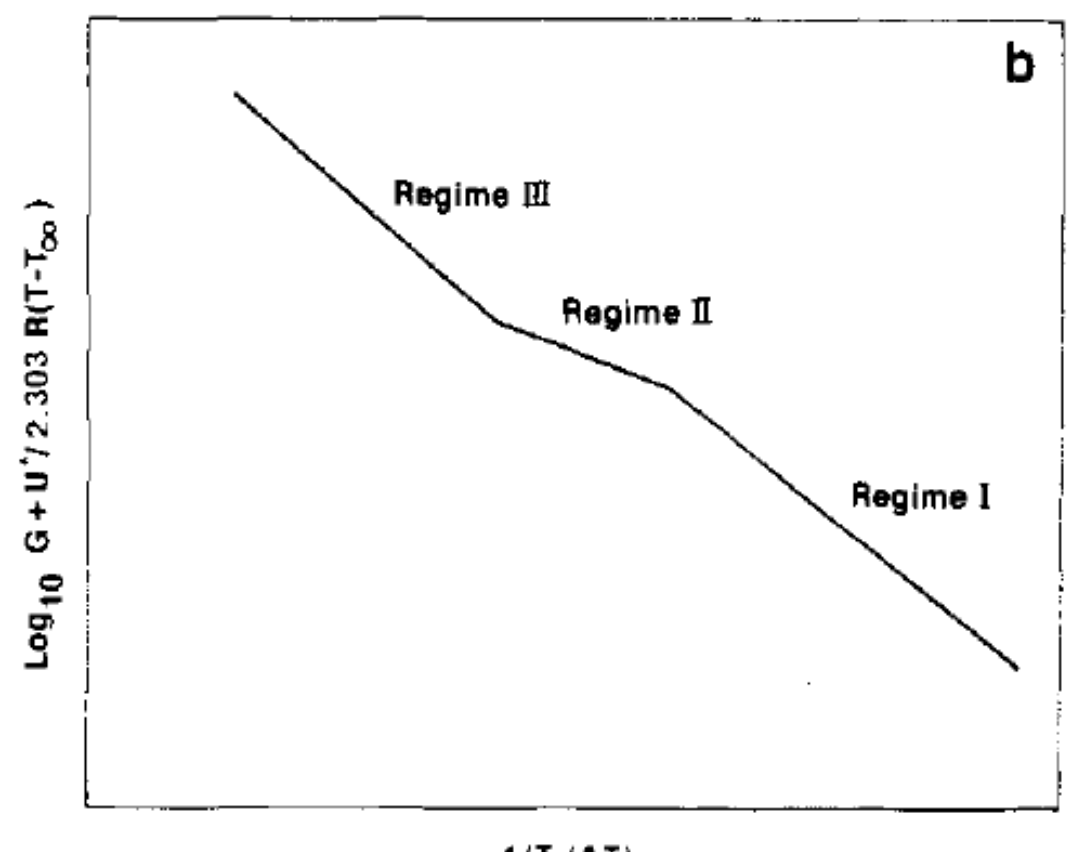

$1 / T(\Delta T)$

Figure 13. The growth rate curves of crystallization of the three regimes. ${ }^{41}$ 
The behavior of growth rate curves is determined by the crystallization temperature. Within certain temperature ranges called regimes (referred to as I, II, and III), the nucleation density changes, leading to changes in relationship between growth rate and nucleation rate along with changes in the growth rate curves as shown in Figure 13. Regime I occurs at high temperatures close to the melting point and have slow growth rates while Regime III occurs at lower temperatures and with higher growth rates. These regimes have been supported in theory and experimental results. At regime I, the growth rate, $\mathrm{g}$, is far greater than the nucleation rate, i. As a result, a single nucleation at the surface quickly forms a layer of crystals before a new nucleus forms, causing the overall growth rate, $G_{1}$, to directly relate to the nucleation rate. The rate of nucleation at regime I is dependent on temperature and decreases with increasing temperature, causing the growth rate to be inversely related to temperature as shown in Equation $5^{41}$

$$
\mathrm{G}=i b_{0} L
$$

where $L$ is the length of the substrate.

At regime $\mathrm{II}, \mathrm{i}$ increases to be close in value to $\mathrm{g}$, resulting in the formation of multiple nucleation sites on the surface before a crystal layer is complete. The growth rate at regime $\|, \mathrm{G}_{\|}$, is directly related to both $\mathrm{g}$ and $\mathrm{i}$ as displayed in Equation $6^{41}$

$$
\mathrm{G}=\left(i b_{0} g\right)^{1 / 2}
$$

This results in a decrease in the slope of the growth curve as $G \alpha\left(i^{*} g\right)^{1 / 2}$. 
Lastly, at regime III, the nucleation sites grow closer together and approach a mean distance equal to about several times the stem width, $\mathrm{a}_{0}$. This is reflected through i being much greater than $\mathrm{g}$. As a result, the growth of the crystal is primarily accomplished through nucleation as growth of crystals across the substrate surface terminates quickly. This results in the growth rate at regime III, $\mathrm{G}_{\mathrm{III}}$, to be directly proportional to nucleation rate again as in Equation $7^{41}$

$$
\mathrm{G}_{I I I}=i b_{0} L^{\prime}
$$

where L' is the distance between the nucleation sites. The formation of crystal layers for each regime is shown in Figure 14.

The overall growth rates at each regime can be calculated through the following formulae ${ }^{41}$ :

$$
\begin{aligned}
& \mathrm{G}_{I}=\mathrm{G}_{0_{I}} \exp \left(\frac{-\mathrm{U}^{*}}{\mathrm{R}_{\left(\mathrm{T}_{\mathrm{c}}-\mathrm{T}_{\infty}\right)}}\right) \exp \left(\frac{-\mathrm{K}_{\mathrm{g}_{I}}}{\mathrm{~T}_{\mathrm{c}} \Delta \mathrm{T}}\right) \\
& \mathrm{G}_{I I}=\mathrm{G}_{0_{I I}} \exp \left(\frac{-\mathrm{U}^{*}}{\left.{\mathrm{R}\left(\mathrm{T}_{\mathrm{c}}-\mathrm{T}_{\infty}\right)}\right)}\right) \exp \left(\frac{-\mathrm{Kg}_{I I}}{\mathrm{~T}_{\mathrm{c}} \Delta \mathrm{T}}\right) \\
& \mathrm{G}_{I I I}=\mathrm{G}_{0_{I I I}} \exp \left(\frac{-\mathrm{U}^{*}}{\mathrm{R}\left(\mathrm{T}_{\mathrm{c}}-\mathrm{T}_{\infty}\right)}\right) \exp \left(\frac{-\mathrm{Kg}_{\mathrm{g}_{I I I}}}{\mathrm{~T}_{\mathrm{c}} \Delta \mathrm{T}}\right)
\end{aligned}
$$

In the case of $\mathrm{K}_{\mathrm{g}}$ calculation, Equation 3 applies to regimes I and III while Equation $11^{41}$ applies to regime II

$$
\mathrm{K}_{\mathrm{g}_{I I}}=\frac{\mathrm{K}_{g_{I}}}{2}=\frac{\mathrm{K}_{g_{I I I}}}{2}=\frac{2 \mathrm{~b}_{0} \sigma \sigma_{\mathrm{e}} \mathrm{T}_{\mathrm{m}}^{0}}{\mathrm{k}_{\mathrm{B}} \Delta \mathrm{h}_{\mathrm{f}}}
$$


Another factor of nucleating ability is the interfacial fold surface free energy difference, $\Delta \sigma$. This factor measures the energy needed to create the first stem. It relates to three basic factors as shown in Equation $12^{42}$

$$
\Delta \sigma=\gamma_{c s}+\gamma_{c m}-\gamma_{m s}
$$

where $\gamma_{c s}$ is the crystal-substrate interfacial free energy, $\gamma_{c m}$ is the crystal-melt surface free energy or the lateral surface free energy, and $\gamma_{m s}$ is the meltsubstrate interfacial free energy. In summary, $\Delta \sigma$ relates to the surface tension between the fiber, polymer crystal, and polymer melt and serves as an indicator for comparing the nucleating ability of heterogeneous nucleation sites. With lower $\Delta \sigma$, the site is more favorable for nucleation.

The nucleation rate can be used to calculate $\Delta \sigma$ using Equation 13

$$
i=i_{0} \exp \left(\frac{-U^{*}}{R\left(T_{c}-T_{\infty}\right)}\right) \exp \left(\frac{-\Delta G^{*}}{k_{B} T}\right)
$$

Where $\Delta \mathrm{G}^{*}=\frac{-16 \sigma \sigma_{e} \Delta \sigma T_{m}^{0}}{\left(\Delta T \Delta h_{f}\right)^{2}}$. Upon taking the logarithm of Equation 9, the formula can be simplified to Equation 14 and 15

$$
\begin{gathered}
\ln i=\ln i_{0}-\left(\frac{-U^{*}}{R\left(T_{c}-T_{\infty}\right)}\right)-\frac{-16 \sigma \sigma_{e} \Delta \sigma T_{m}^{0}}{k_{B} T\left(\Delta T \Delta h_{f}\right)^{2}} \\
\ln i=\frac{16 \sigma \sigma_{e} \Delta \sigma T_{m}^{0}}{k_{B} T\left(\Delta T \Delta h_{f}\right)^{2}}+\text { constant }
\end{gathered}
$$

From Equation 15, a linear function between $\ln \mathrm{i}$ and $1 / \mathrm{T} \Delta \mathrm{T}^{2}$ can be obtained, where the slope is $\frac{16 \sigma \sigma_{e} \Delta \sigma T_{m}^{0}}{k_{B} \Delta h_{f}^{2}}$. However, nucleation rate is difficult to measure as the formation of nuclei on the fiber surface is difficult to measure due to the size 
and amount of nuclei that form. In order to overcome this issue, a simple relation between the nucleation rate and the induction time, $\mathrm{t}_{\mathrm{i}}$, at a given temperature can be made from Equation $16^{42}$

$$
i(T) * t_{i}(T)=\text { constant }
$$

resulting in $\mathrm{i}$ equal to the reciprocal of $\mathrm{t}_{\mathrm{i}}$. As a result, the $\ln \left(1 / \mathrm{t}_{\mathrm{i}}\right)$ is a function of $1 / \mathrm{T} \Delta \mathrm{T}^{2}$ as seen in Equation 17

$$
\ln \left(\frac{1}{t_{i}}\right)=\frac{16 \sigma \sigma_{e} \Delta \sigma T_{m}^{0}{ }^{2}}{k_{B} T\left(\Delta T \Delta h_{f}\right)^{2}}+\text { constant }
$$

which can be used to solve for $\Delta \sigma$. With the $\sigma_{e}$ and $\Delta \sigma$ calculated, the formation of transcrystals over rGO and CNT fibers can be compared in terms of the energy required to form folds and the nucleating ability of the surfaces. 

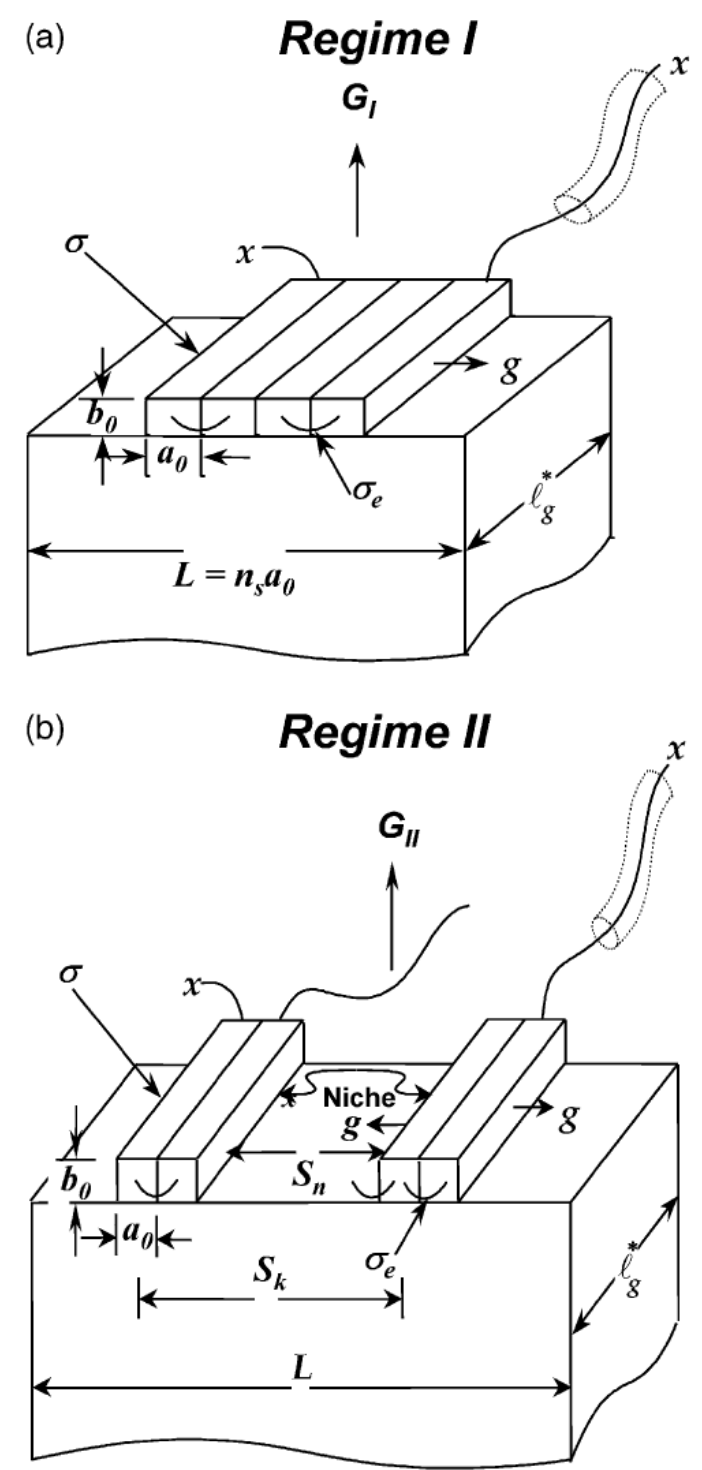

(c)

Regime III

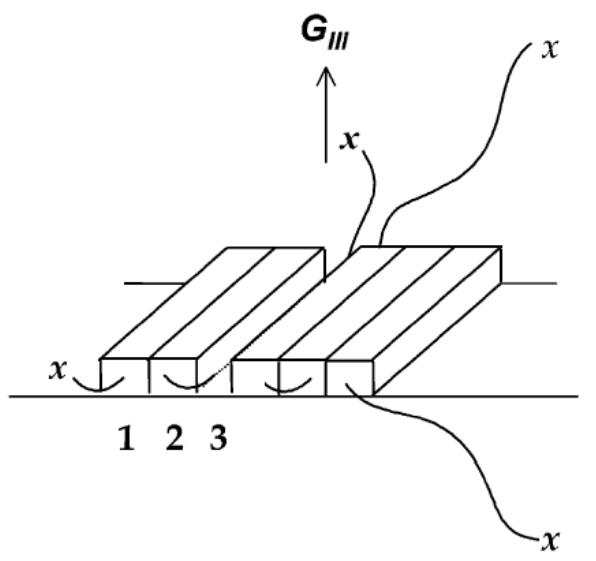

Figure 14. Diagrams of three regimes from Lauritzen-Hoffman theory. ${ }^{36}$ 


\subsection{Motivation and Research Plan}

The purpose of our research is to study iPP transcrystallization of rGO and CNT fibers. By studying the kinetics and structure of the transcrystals grown for rGO fibers, we can gain a better understanding of this unreported process and see how it compares to similar fillers. Furthermore, we use transcrystals to observe the interactions of graphene to the polymer, providing a framework for future graphene-polymer composite development. Lastly, the fiber-reinforced composites produced have potential direct applications in creating stronger automotive components among other applications.

Our study starts with the preparation of transcrystallization samples by introducing fibers into the polymer melt and cooling down to the crystallization temperature using a heat stage. At the crystallization temperature, transcrystallization is induced and we can observe the growth of the transcrystals over time with varying temperatures by placing the heat stage under a polarized optical microscope connected to a camera. These kinetics studies will be carried out over crystallization temperatures ranging from $124^{\circ} \mathrm{C}$ to $140^{\circ} \mathrm{C}$. After obtaining the kinetics data, we study the sample using scanning electron microscopy to observe the microstructure of the transcrystals as well as the wetting and adhesion of the polymer to the surface of the fiber. Later studies will include directly comparing the mechanical strength and other properties of the composites. 


\section{Experiments and Methods}

Graphene oxide (GO) was synthesized as an aqueous dispersion from graphite flakes. The resulting GO was processed into fibers and then reduced. Characterization by Fourier transform infrared (FTIR) spectroscopy, thermogravimetric analysis (TGA), and polarized optical microscopy confirmed the successful production of GO and reduction to reduced graphene oxide (rGO). rGO and CNT fibers were introduced to an isotactic polypropylene (iPP) melt to prepare transcrystallization samples and then cooled to a crystallization temperature using a heating stage. Polarize optical microscopy (POM) was used to study the dynamic process. Scanning electron microscopy (SEM) and X-ray diffraction (XRD) were then employed to study the microstructure.

\subsection{Materials}

All materials that were used in this thesis work were purchased from commercially available sources by Zhang's Research Group. Graphite, isotactic polypropylene, zinc nitrate, and potassium permanganate were purchased from Sigma Aldrich. Sulfuric acid, nitric acid, and ethanol were purchased from Dow. Multi-walled carbon nanotubes dispersed on propylene glycol were as provided from Georgia Institute of Technology.

\subsection{Synthesis of Graphene Oxide}

GO was synthesized from natural graphite flakes via a modified Hummers method. ${ }^{7,8}$ Typically, graphite flakes $(1.0 \mathrm{~g})$ were mixed with an acid mixture of 
$98 \%$ sulfuric acid $(30 \mathrm{~mL})$ and $70 \%$ nitric acid $(10 \mathrm{~mL})$ at a volume ratio of $3: 1$ under stirring at room temperature for 24 hours. The acid-treated graphite flakes were then rinsed with deionized (DI) water to increase the $\mathrm{pH}$ to 5 and then dried in the oven at $60^{\circ} \mathrm{C}$ for 24 hours to obtain graphite intercalated compounds (GICs). The dried GICs were heat-treated in a furnace at $1050^{\circ} \mathrm{C}$ for 10 seconds to get expanded graphite (EG) flakes. The EG flakes and $98 \%$ sulfuric acid (200 $\mathrm{mL}$ ) were mixed and stirred at $0^{\circ} \mathrm{C}$, in which potassium permanganate $(10 \mathrm{~g})$ was added. The mixture was then heated to $40^{\circ} \mathrm{C}$ and stirred violently until the mixture became very viscous and light brown in color. The system was then transferred to an ice bath and DI water $(200 \mathrm{~mL})$ was added to the mixture, followed by dropwise addition of $30 \%$ hydrogen peroxide $(3 \mathrm{~mL})$. The resulting dispersion was centrifuged with $1.0 \mathrm{M}$ hydrochloric acid solution to produce a bright yellow paste. The paste was further washed with DI water until the $\mathrm{pH}$ became about 5. After centrifugation, a gel-like dispersion of GO was received.

\subsection{Wet spinning of graphene oxide fibers}

Aqueous dispersion of $\mathrm{GO}(10 \mathrm{mg} / \mathrm{mL})$ was loaded into a syringe and extruded by a syringe pump at $3 \mathrm{~mL} / \mathrm{min}$ into the bath of $5 \%$ zinc nitrate in ethanol as shown in Figure 15. The fibers were then collected on a wooden stick outside the bath and dried under infrared (IR) light. The dried GO fibers were immersed into an aqueous solution of $30 \%$ hydroiodic acid at room temperature overnight. The rGO fibers were then rinsed by DI water and ethanol, and dried under IR light. 


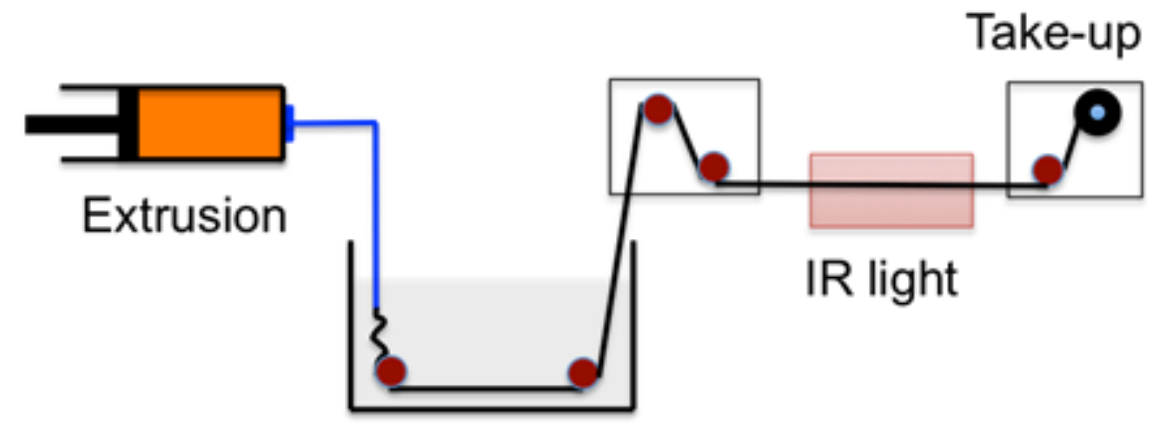

Coagulation bath

Figure 15. Procedure for GO fiber processing.

\subsection{Preparation of carbon nanotube fibers}

CNT fibers were drawn up from the propylene glycol dispersion through rapid removal using a toothpick. Fibers of appropriate thickness were dipped in diethyl ether to dissolve the propylene glycol until no noticeable changes in the diameter of the fiber were observed. The resulting fibers were left to dry at room temperature.

2.5. Preparation of single fiber composites

The rGO and CNT fibers were placed over the compression molded film of iPP on a glass slide and covered with a cover slide. The sample was hot pressed with tweezers at $200^{\circ} \mathrm{C}$ for 5 minutes to erase thermal history of the sample and introduce the fibers into the film. The sample was then cooled at a rate of $20^{\circ} \mathrm{C} / \mathrm{min}$ to the isothermal crystallization temperature $T_{c}$, ranging from $124^{\circ} \mathrm{C}$ to $140^{\circ} \mathrm{C}$. The temperatures of the samples were controlled with a Linkam LTS420 hot-stage. The hot-stage was programmed using the Linksys32 software 
to change the temperature. The process for forming the transcrystals is shown in Figure 16.

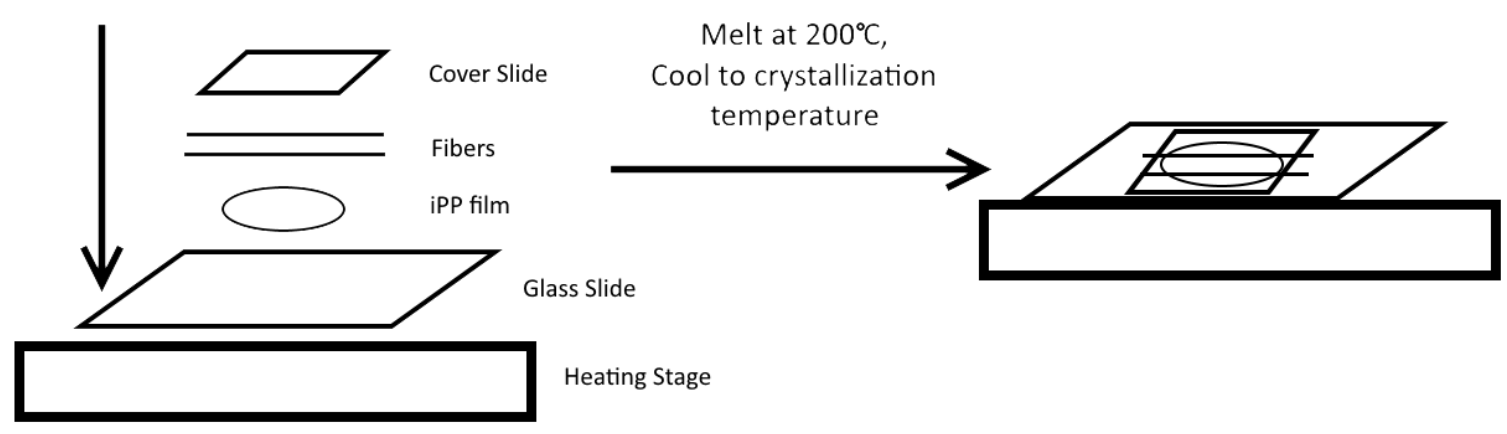

Figure 16. Process for forming iPP transcrystals using melt crystallization.

\subsection{GO and rGO Characterization.}

FTIR spectra provides information on the functional groups to characterize the GO and confirm its reduction to rGO. The FTIR spectra indicates the presence of acidic functional groups in GO and their loss in rGO. Spectra were obtained on a Nicolet iS10 FT-IR spectrometer in an attenuated total reflection (ATR) mode at a resolution of $8 \mathrm{~cm}^{-1}$ of 1000 scans. The samples studied were dried films from 5 mil draw downs of GO along with their reduced forms.

TGA data further confirms the reduction of GO through the comparison of the weight loss of the samples after thermal degradation. GO contains acid functional groups, such as alcohols and ketones, bound to the surface of the sheets. At higher temperatures, these bonds break and result in noticeable weight loss in the sample. The remaining $\mathrm{C}-\mathrm{C}$ bonds remain unbroken and as a result, GO shows much higher weight loss than rGO. The TGA traces were 
collected on a TA Instruments Q500 ramped to $550^{\circ} \mathrm{C}$ at a heating rate of $10^{\circ} \mathrm{C} / \mathrm{min}$. The samples used were dried $\mathrm{GO}$ and $\mathrm{rGO}$ films.

POM was used to observe the liquid crystal texture of GO to confirm its synthesis and neutralization. POM is a widely employed tool for studying liquid crystal textures and provides information about the crystalline ordering of samples. Aqueous dispersions of GO have a commonly observed Schlieren texture, indicating the presence of domains of GO. POM images were obtain from a Leica DM2500P polarized optical microscope connected to an ICC50 HD video camera. The samples observed were drop-casted $20 \mathrm{mg} / \mathrm{mL} \mathrm{GO}$ dispersions on glass slides.

\section{7. iPP Transcrystallization Kinetics}

POM images were captured of the transcrystallization process. The videos recorded from the POM were applied to observe the dynamic transcrystallization process under varying crystallization temperatures. Transcrystallization was observed from the hot-stage under the POM with the sample slides inside of the stage. ImageJ was used to measure the length of the transcrystals over time.

\section{8. iPP Transcrystallization Structure}

XRD data was collected using a Siemens D5000 diffractometer with a $1.54 \AA \mathrm{Cu}$ Ka source over a range of $10^{\circ}$ to $40^{\circ}$ at a scan speed of $10 \mathrm{sec} / \mathrm{step}$ and at $0.01^{\circ}$ increments. XRD data confirms the phase of the iPP transcrystals 
obtained as polypropylene is known to be either in the $\alpha-, \beta-$, or $\gamma$-phase. The characteristic peaks to differentiate between these forms are at $18-19^{\circ}$ for $\alpha, 15$ $16^{\circ}$ for $\beta$, and $19.2-20.5^{\circ}$ for $y$ crystals. ${ }^{43}$ The transcrystal sample films were analyzed from a plastic sample holder.

SEM images were obtained on a FEI Quanta 200 microscope operated at an acceleration voltage of $20 \mathrm{kV}$. SEM uses a high-energy electron beam to obtain high resolution images of the surface of the sample. As a result, SEM images are an effective method to characterize and observe the microstructure and interactions of the transcrystalline layer and its interface with the fiber surface. To reveal the transcrystalline morphology under SEM, the samples were etched for 2 hours with a 1.0 wt\% solution of potassium permanganate in a 2:1 acid mixture of $98 \%$ sulfuric acid and phosphoric acid under ultrasonication. The SEM samples were prepared by applying the etched samples to a carbon tape-covered SEM sample holder and then coated with a fine gold layer by sputtering for 30 seconds. 


\section{Results and Discussion}

\subsection{GO and rGO Characterization}

The GO synthesized and $\mathrm{rGO}$ reduced requires characterization to confirm the formation of the GO and rGO. FTIR, TGA, and POM analysis are employed to confirm the presence and loss of the acidic groups characteristic of GO as well as the liquid crystal phase behavior expected of GO dispersions.

Figure 17 shows the typical FTIR spectra obtained from the GO and rGO produced. In the GO, two spectral peaks at $1700 \mathrm{~cm}^{-1}$ and $3300 \mathrm{~cm}^{-1}$ are found corresponding to the carboxylic acid $-\mathrm{COOH}$ peak and $-\mathrm{OH}$ alcohol peak, corresponding to the acid functional groups found on GO. ${ }^{44}$ On the rGO spectra, these peaks disappear, indicating that the reduction successfully removed the alcohol and ketone groups on the GO.

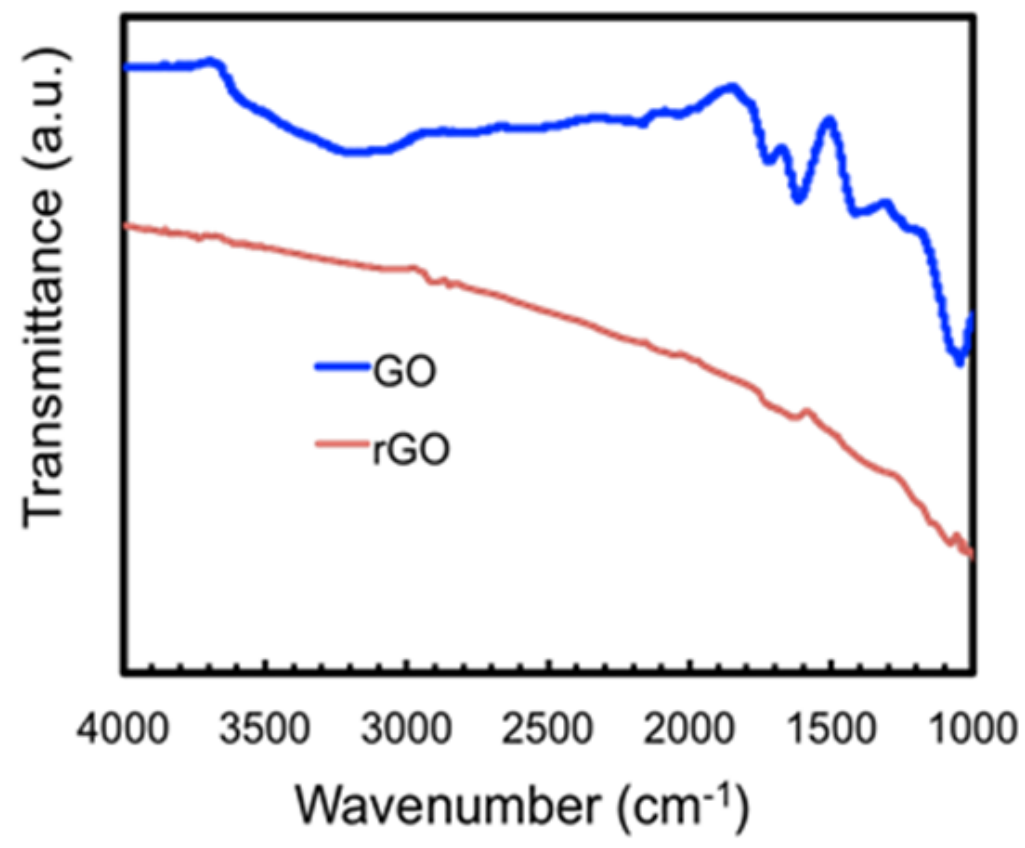

Figure 17. FTIR spectra of GO and rGO. 
Figure 18 shows the typical TGA trace measured from the GO and rGO produced. In the $\mathrm{GO}$, significant weight loss is observed starting at $200^{\circ} \mathrm{C}$, indicating the decomposition of oxygen-containing groups bound to the sheets. ${ }^{45}$ This results in $50 \%$ of the sample mass remaining. In contrast to this, rGO has a less significant drop at $200^{\circ} \mathrm{C}$ and retains $70 \%$ of its mass, indicating a much lower degree of acid functional groups on the surface. However, this indicates that the reduction reaction was not completed as there should be no decomposition at $200^{\circ} \mathrm{C}$ after reduction. ${ }^{45}$ This was likely due to the reduction conditions being insufficient for completion as the reaction was left at room temperature.

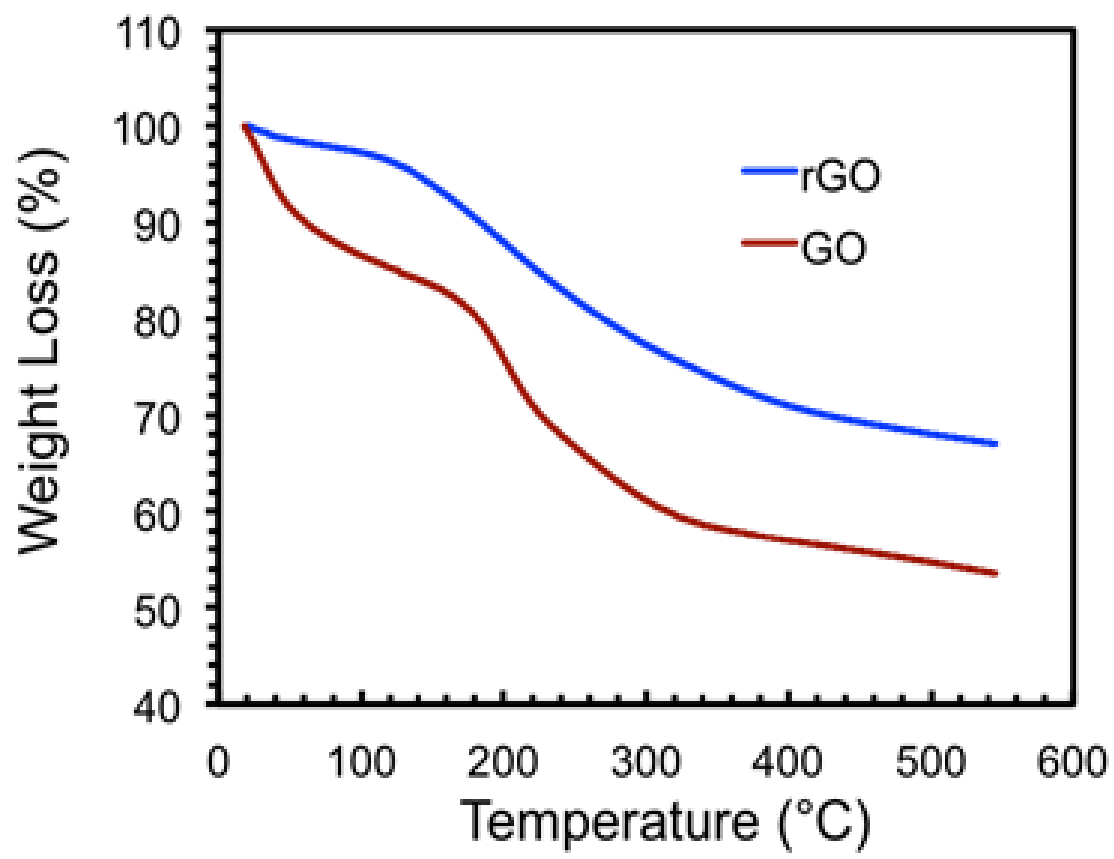

Figure 18. TGA trace of $\mathrm{GO}$ and $\mathrm{rGO}$.

The POM micrographs obtained from the drop-cast GO samples made immediately after completing the Hummers method are shown in Figure 19. The 
liquid crystal (LC) texture shows the expected Schlieren texture of strong optical birefringence, indicating domains of oriented GO sheets, with dark brushes. ${ }^{46,47}$ Upon rotation of the sample to $45^{\circ}$ relative to the crossed polarizers, the bright and dark regions of the GO LC phase switch, indicating the change of the domain orientation being out-of-phase with the transmitted polarized light. These observations are expected of GO in literature..$^{8,47,48}$
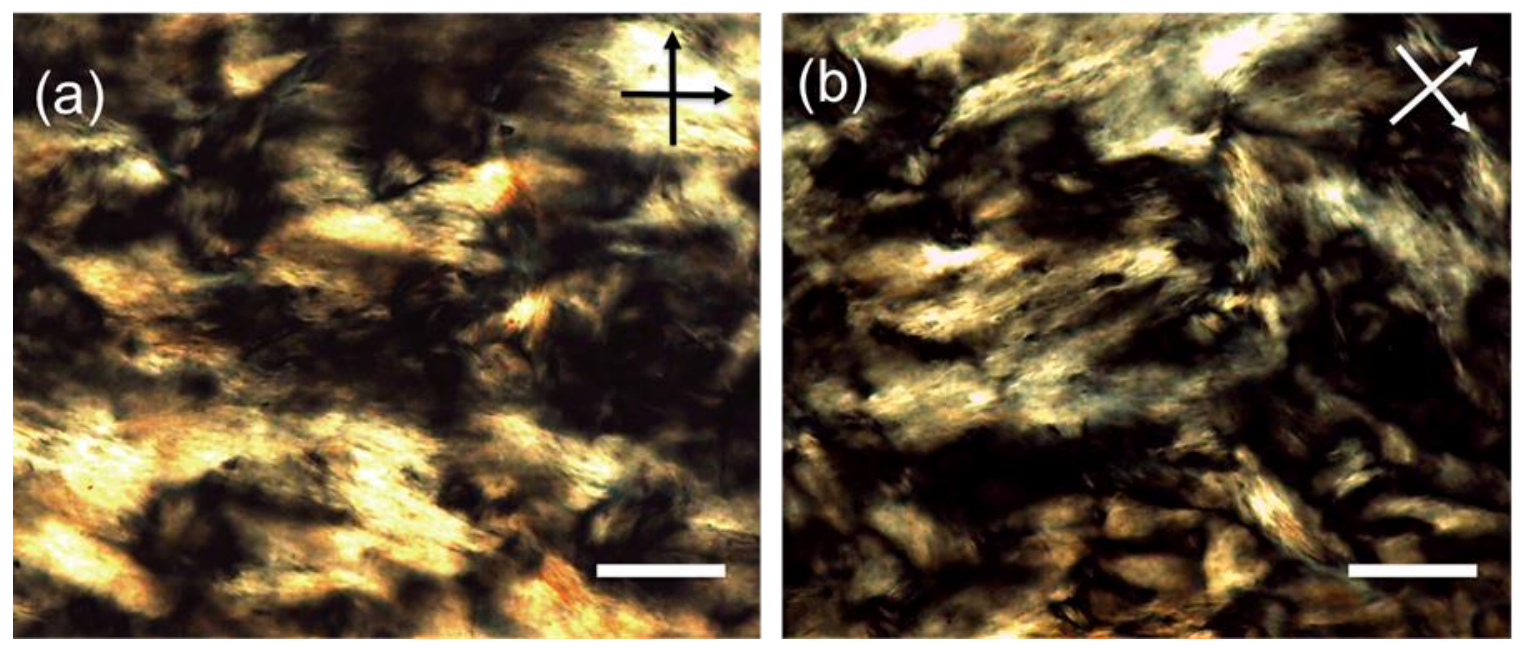

Figure 19. POM micrographs of drop-cast GO LC texture under crossed polarizers rotated at (a) $0^{\circ}$ and (b) $45^{\circ}$. The scale bar represents $200 \mu \mathrm{m} .{ }^{49}$

\subsection{Fiber spinning and structure}

With the GO confirmed, GO fibers to create a fiber for the growth of transcrystals and observed under POM and SEM to observe their surface along with the purchased CNT fibers. GO fibers are spun through extrusion of an aqueous GO dispersion from a syringe into a coagulation salt bath. Due to the shear forces within the syringe and the tubing connected to the needle that leads to the bath, the GO sheets are aligned in the same direction as the flow and form a wet fiber as indicated by the birefringence of the GO domains under the POM 
in Figure 20. Upon entering the salt bath, water diffuses from the GO and ethanol containing salt diffuses into the wet fiber. The cations of the salt forms ionic linkages between the functional groups of the $\mathrm{GO}$, further affecting the mechanical properties of the resulting fiber depending on the salt. ${ }^{10}$ The resulting fiber is then drawn up, dried, and reduced.

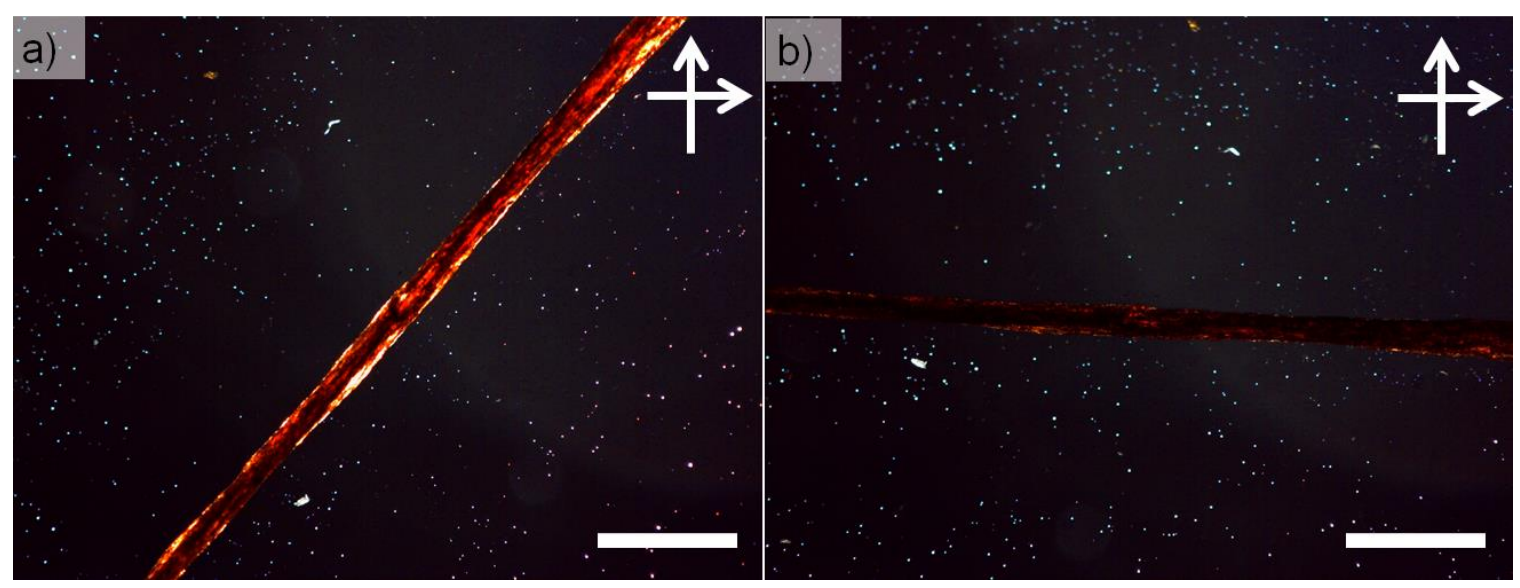

Figure 20. POM micrographs of the GO fiber under crossed polarizers at (a) $0^{\circ}$ and (b) $45^{\circ}$ relative to the transmitted light. The scale bar represents $250 \mu \mathrm{m}$.

The GO fibers produced ranged in diameters from 30-80 $\mu \mathrm{m}$, depending on the processing conditions and the preparation of the GO. Due to the defects of GO, the fiber takes a wrinkled and rough surface as found in Figure 21a. The resulting GO fibers displayed strong mechanical properties as they are able to be twisted and tied into knots as shown in Figures $21 \mathrm{~b}$ and 21c. Twisting the fibers causes the surface to be more uniform, a key factor in transcrystallization, while knotting the fibers indicates its ability to be knitted in textile fiber applications. Figure $21 \mathrm{~d}$ shows the typical structure of the CNT fibers produced. These fibers exhibit a higher degree of smoothness and uniformity than the GO fibers and have diameters ranging from $20-70 \mu \mathrm{m}$. 

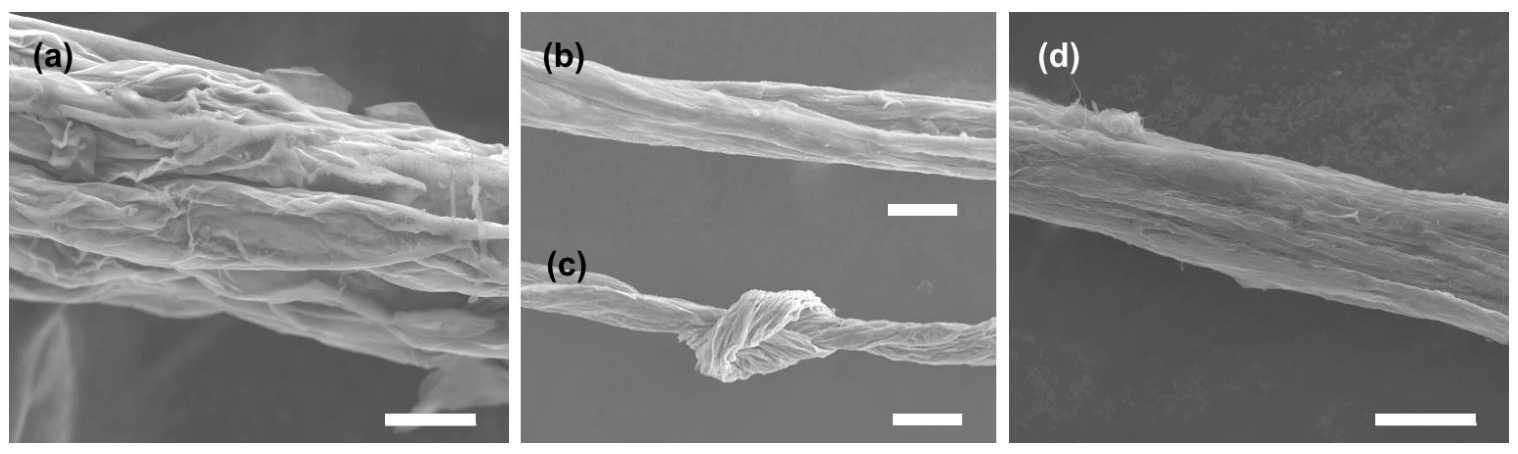

Figure 21. SEM micrographs of (a) GO fiber, (b) twisted GO fiber, (c) tied GO fiber, and (d) CNT fiber. The scale bar represents $25 \mu \mathrm{m}$ in (a) and $20 \mu \mathrm{m}$ in (b), (c), and (d).

\subsection{Transcrystal Structure}

Transcrystallization was studied over CNT and rGO under varying temperatures to observe the formation of the transcrystalline layer. By observing changes in the birefringence, the structures of the transcrystalline lamellae can be confirmed using POM. Furthermore, unique transcrystal structures were also observed, depending on the crystallization conditions. These structures were then studied using the heating stage and the POM to observe their changes in birefringence and differences in melting temperatures.

Transcrystallization was attempted on GO fibers to observe the effects of the chemical structure of the fiber on the transcrystallization. However, no significant transcrystal growth occurred at any crystallization temperatures as shown in Figure 22. The lack of nucleation of transcrystals is likely due to the 
mismatch of surface energies between the hydrophobic iPP $\left(30 \mathrm{~mJ} / \mathrm{m}^{2}\right)$ and hydrophilic GO $\left(62 \mathrm{~mJ} / \mathrm{m}^{2}\right) .{ }^{12,50}$

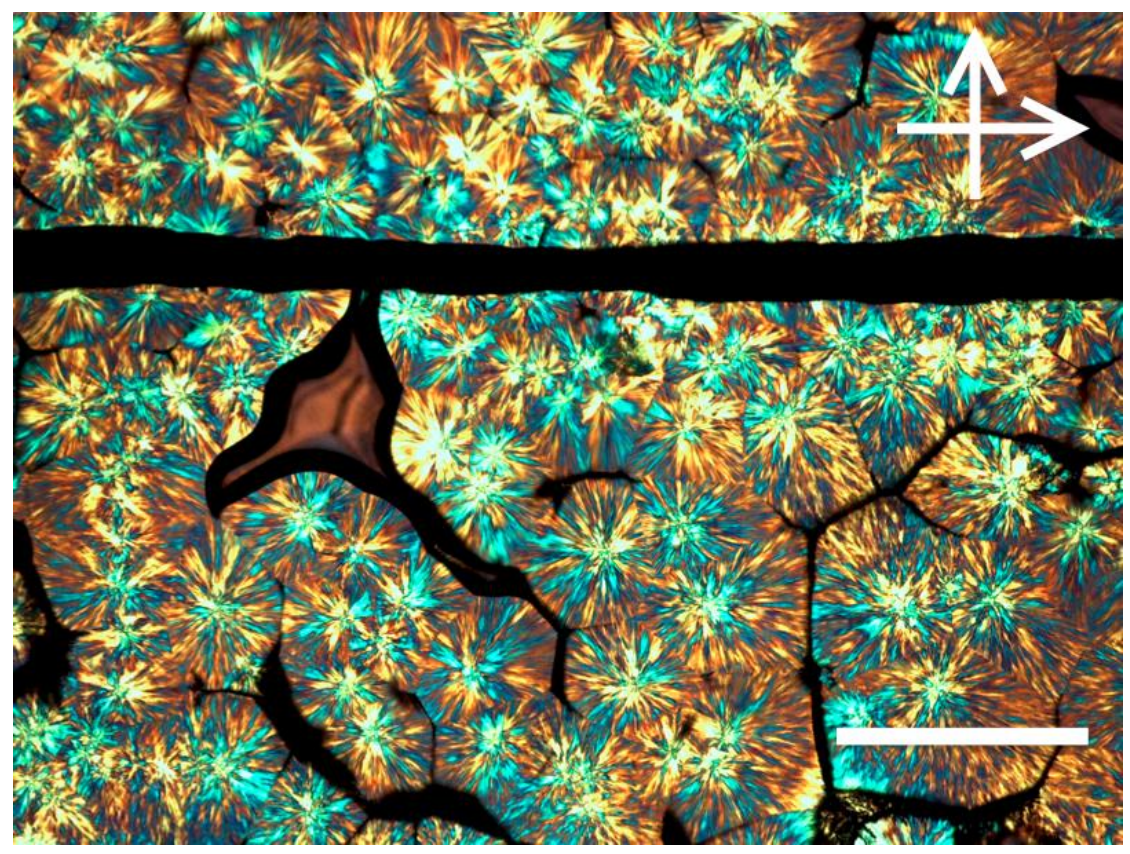

Figure 22. $\mathrm{POM}$ micrograph of iPP crystallized over a $\mathrm{GO}$ fiber at $132^{\circ} \mathrm{C}$ under crossed polarizers. The scale bar represents $250 \mu \mathrm{m}$.

Transcrystal growth was observed on rGO and CNT fibers using POM under crossed polarizers as shown in Figure 23. Transcrystals were observed as bright lamellae surrounding the fibers while spherulites were found a spherical crystals growing in bulk. One noticeable feature distinguishing both fibers is that the rGO transcrystals exhibit a higher degree of alternating blue and yelloworange contrast of a mixed birefringence while the CNT transcrystals predominantly display yellow-orange contrast despite the fact that they underwent the same crystallization conditions. The yellow-orange areas indicate negative birefringence and indicate more organized and parallel, or radial, lamella while the blue areas indicate positive birefringence and indicate more 
disorganized and interconnected, or cross-hatched, lamella as shown in Figure 24. ${ }^{30}$ Positive iPP transcrystals exhibit lower interfacial shear strength and lower melting temperature than negative iPP transcrystals due to the presence of interconnecting lamella disrupting the organization and thermal expansion of the lamella. ${ }^{33}$ The difference in the morphology of the crystals between the two fibers is due to the significantly smoother and more uniform surface of the CNT fiber that creates a flat surface for nucleation. The rough surface of the rGO fiber creates uneven nucleation sites that allows for the transcrystal lamellae to interact and interconnect.
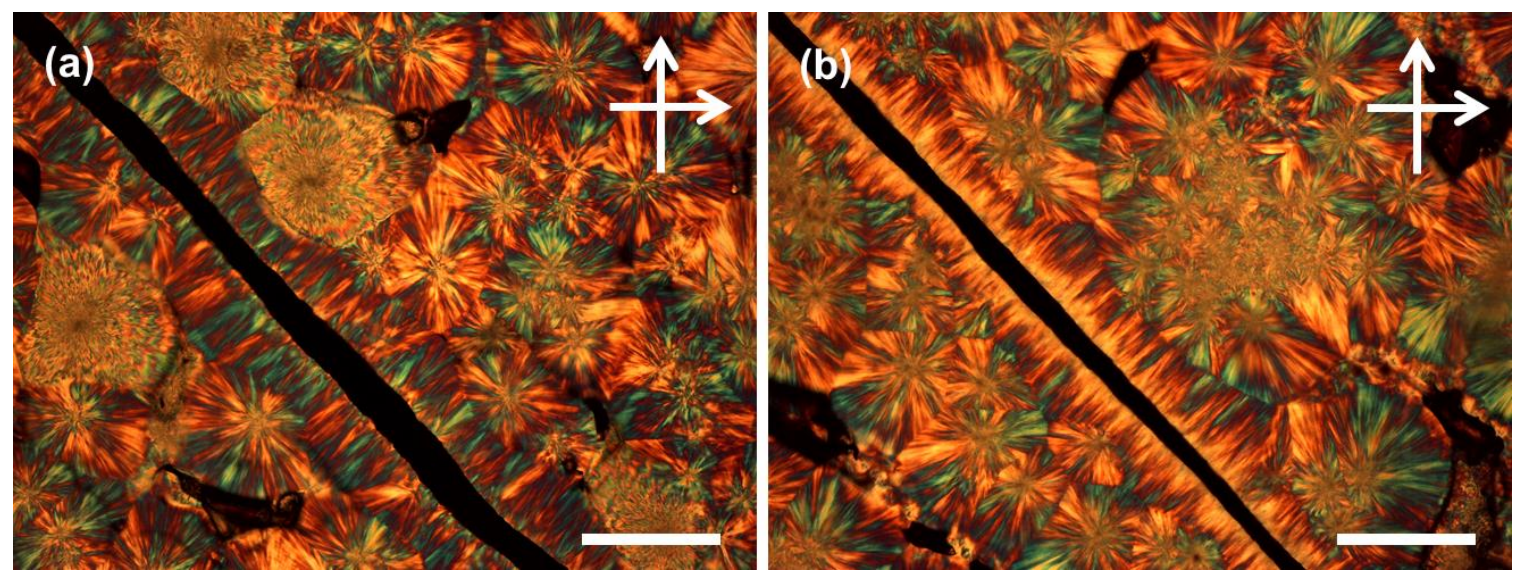

Figure 23. POM micrographs of (a) iPP/rGO transcrystals and (b) iPP/CNT transcrystals under crossed polarizers and crystallized at $130^{\circ} \mathrm{C}$. The scale bar represents $250 \mu \mathrm{m}$. 

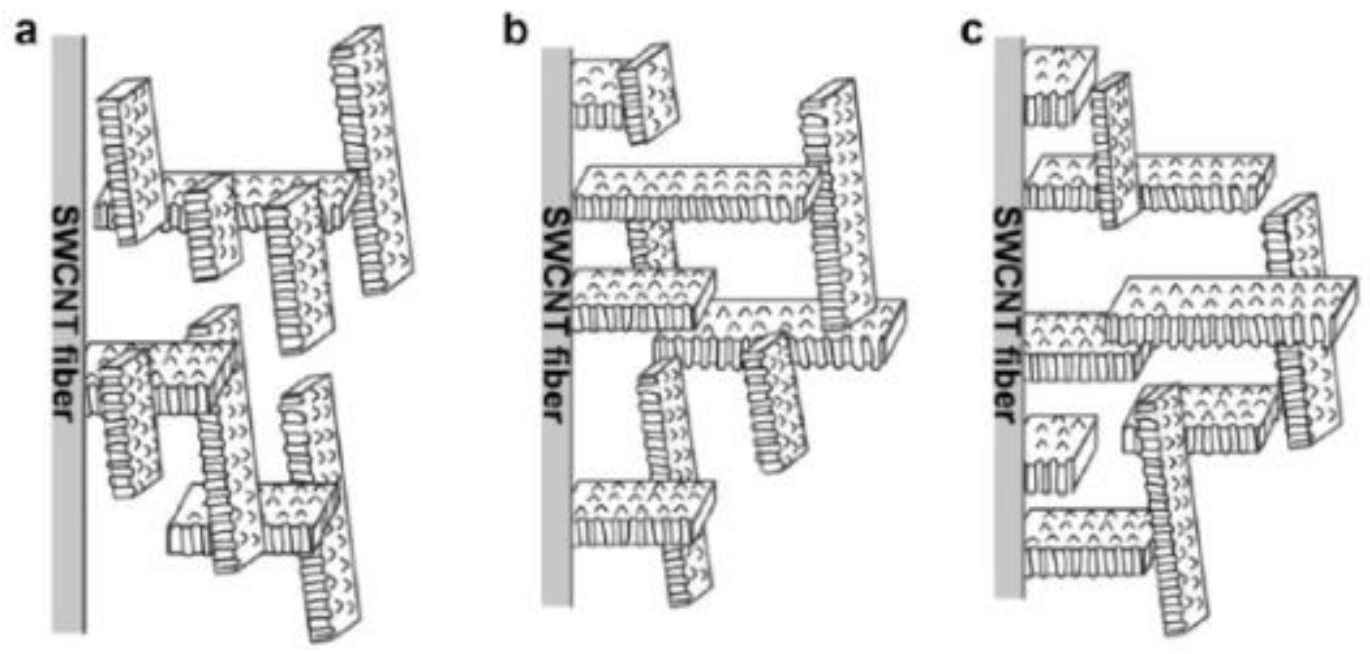

Figure 24. Schemes of the microstructures of (a) positive, (b) mixed, and (c) negative transcrystals. ${ }^{32}$

The dynamic process of polymer transcrystallization has been investigated at $124^{\circ} \mathrm{C}$ using in-situ POM as shown in Figure 25 . It is evident that the iPP nucleation first occurred at the surface of the CNT fiber, forming a bright layer of transcrystal nuclei as seen in Figure 25a. This shows the high nucleating capacity of the fiber toward the iPP matrix. Over time, the transcrystal lamellae grew perpendicular to the fiber axis, forming a bright transcrystalline interphase that surrounds the CNT fiber as seen in Figures 25b-d. At the end of the transcrystallization process, the growth of the transcrystals becomes mostly impeded by the spherulites grown in the bulk seen in Figure $25 \mathrm{~d}$. 

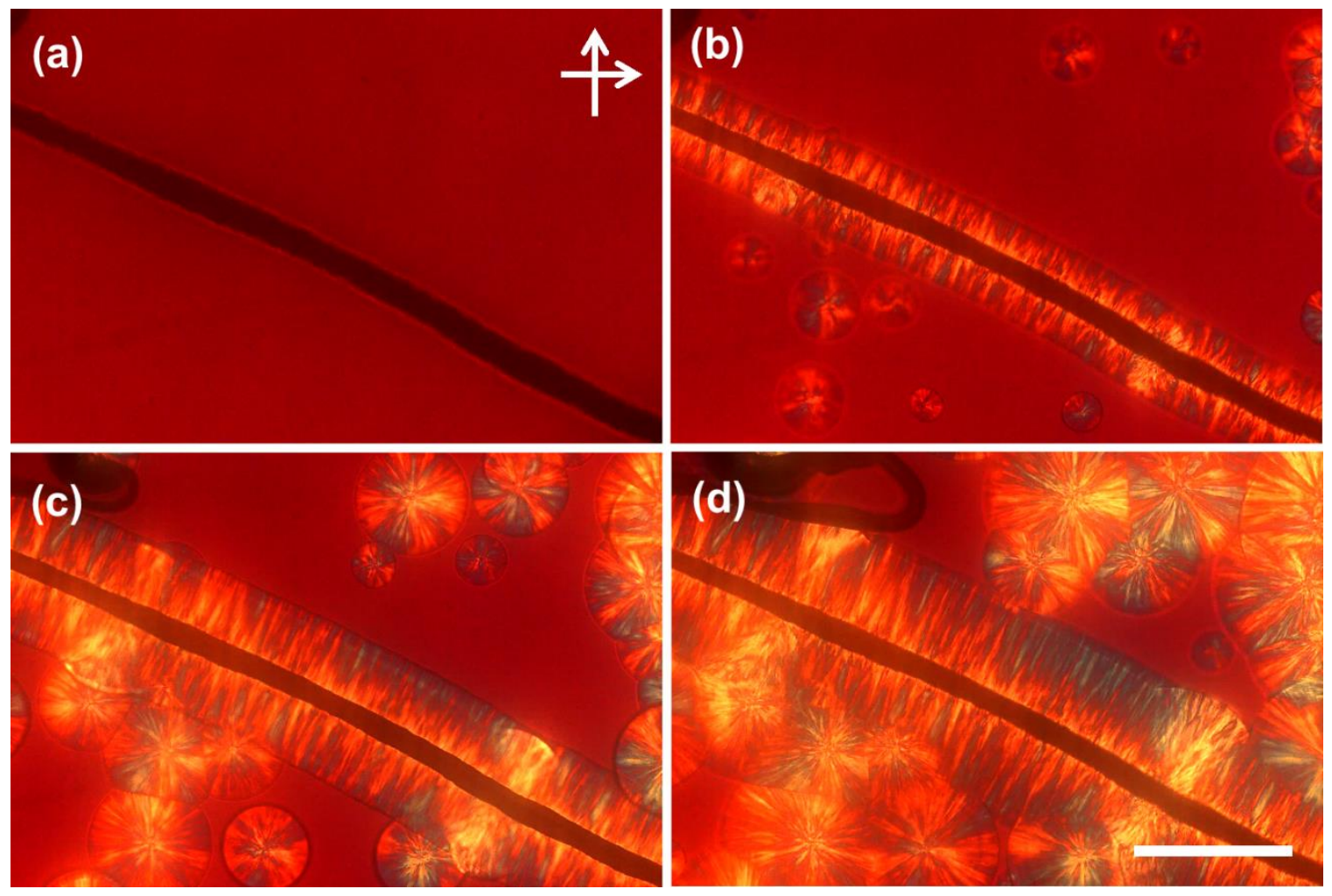

Figure 25. $\mathrm{POM}$ micrographs of $\mathrm{iPP} / \mathrm{CNT}$ transcrystals crystallized at $124^{\circ} \mathrm{C}$ at crystallization times of (a) $0 \mathrm{~min}$, (b) $1.5 \mathrm{~min}$, (c) $3 \mathrm{~min}$, and (d) $4.5 \mathrm{~min}$ under crossed polarizers. The scale bar represents $250 \mu \mathrm{m}$.
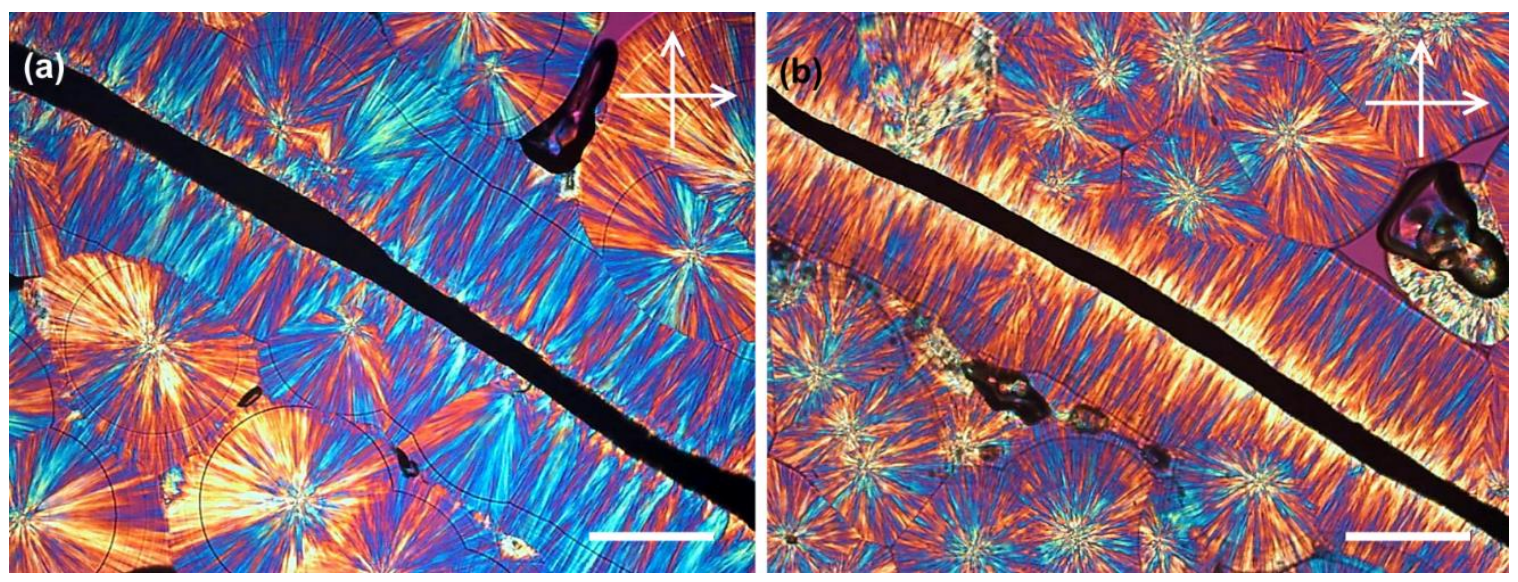

Figure 26. POM micrographs of iPP/CNT transcrystals crystallized at (a) $124^{\circ} \mathrm{C}$ and (b) $132^{\circ} \mathrm{C}$ under crossed polarizers. The scale bar represents $200 \mu \mathrm{m}$. 

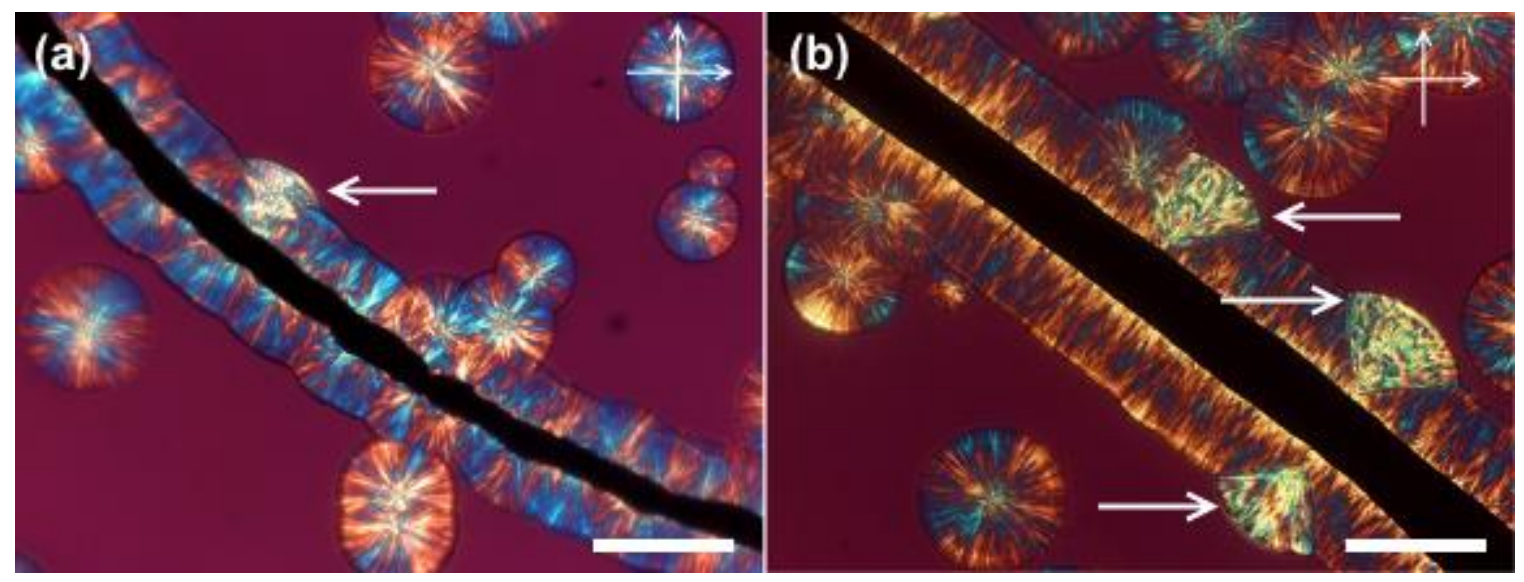

Figure 27. POM micrographs of (a) iPP/rGO transcrystals and (b) iPP/CNT transcrystals crystallized at $132^{\circ} \mathrm{C}$ under crossed polarizers. $\beta$-transcrystals indicated by the arrows. The scale bar represents $250 \mu \mathrm{m}$.

The transcrystal structure is not only affected by the interface, but by the crystallization temperatures as well. At lower temperatures, crystallization is more disorganized and features mixed birefringence while crystals formed at higher temperatures have primarily negative birefringence (Figure 26). This is due to the fact that transcrystallization occurs at higher growth rates at lower temperatures. At higher growth rates, polymer chains have a higher tendency to form cross-hatched lamellae, causing the resulting structures to be more disordered.

Another notable structural feature observed on both fibers is the presence of fan-shaped crystals with strongly negative birefringence as observed in Figure 27. These structures are thought to be $\beta$-phase crystals. iPP crystals can assume an $\alpha$ - (monoclinic), $\beta$ - (trigonal), or $\gamma$ - (orthorhombic) phase, which affects the physical and mechanical properties of the crystals. ${ }^{51} \alpha$-phase is the commonly observed form of iPP crystals and makes up the majority of the 
transcrystal structures while $\beta$-phase transcrystals exhibit low crystal density, low melting temperatures, and improved impact strength in comparison to the other crystal forms. ${ }^{52}$ In order to confirm the formation of $\beta$-transcrystals, XRD analysis was performed at the areas of the film where the fan-shaped crystals were found. Preliminary results of the iPP/CNT transcrystals were taken in Figure 28. A small peak found at $16.2^{\circ}$ coincides with the reported value for (300) reflection of $\beta$ crystals, indicating a small amount of $\beta$-crystals within the sample. ${ }^{53}$ As seen in Figure 27, CNT fibers has much higher density of $\beta$-crystal formation than rGO fibers. In general, $\beta$-crystal formation was uncommon on the rGO fibers with a single $\beta$-crystal observed at most over a $1 \mathrm{~mm}$-length of fiber. In contrast, more than $3 \beta$-crystals can be found over the same length of CNT fiber. $\beta$-crystal formation is commonly promoted through shear-induced crystallization or the use of nucleating agents. ${ }^{52-54}$ However, none of these conditions can be applied to improved $\beta$-nucleation of CNT fibers over rGO fibers. Furthermore, it has been noted that the $\beta$-transcrystals shift positions along the fiber with subsequent crystallizations, indicating that the fiber surface chemistry and structure does not play a role in the formation of the $\beta$-phase. These fiber-induced $\beta$-crystals require further study to better understand their nucleation. 


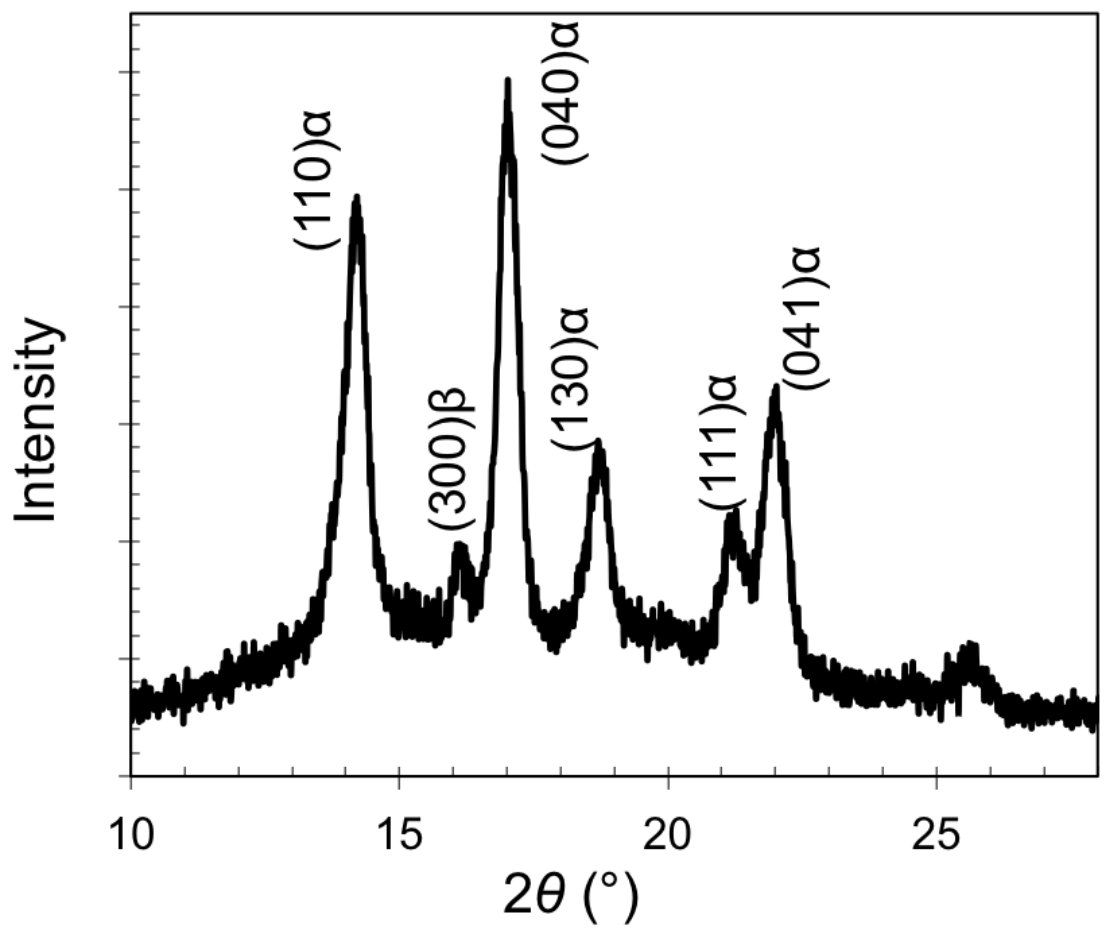

Figure 28. XRD patterns of the transcrystallized iPP with indexed peaks.

The transitions of the $\beta$-crystals over both fibers during melting was observed using the hot-stage to gradually increase the temperature of the samples. $\beta$-crystals are known to have a lower melting temperature than the $\alpha$ form. ${ }^{52}$ This process is depicted in Figures 29 and 30 . At room temperature, the typical negative birefringence of $\beta$-crystals is observed in Figures 29a and 30a. The transcrystals undergo a transition at $155^{\circ} \mathrm{C}$ in which the optical birefringence increases and the contrast transitions from a mixed orange and blue to orange contrast in the a-crystals as seen in Figures $29 \mathrm{~b}$ and $30 \mathrm{~b}$. This is attributed to the reorganization of the tangential lamellae to radial lamellae in the transcrystalline layer. ${ }^{33}$ Upon raising the temperature to $161^{\circ} \mathrm{C}$ for $\mathrm{iPP} / \mathrm{rGO}$ 
transcrystals and to $160^{\circ} \mathrm{C}$ for iPP/CNT transcrystals, the $\beta$-crystals melt while the spherulite and a-crystals remain as evident by Figures $29 c-d$ and $30 c-d$.

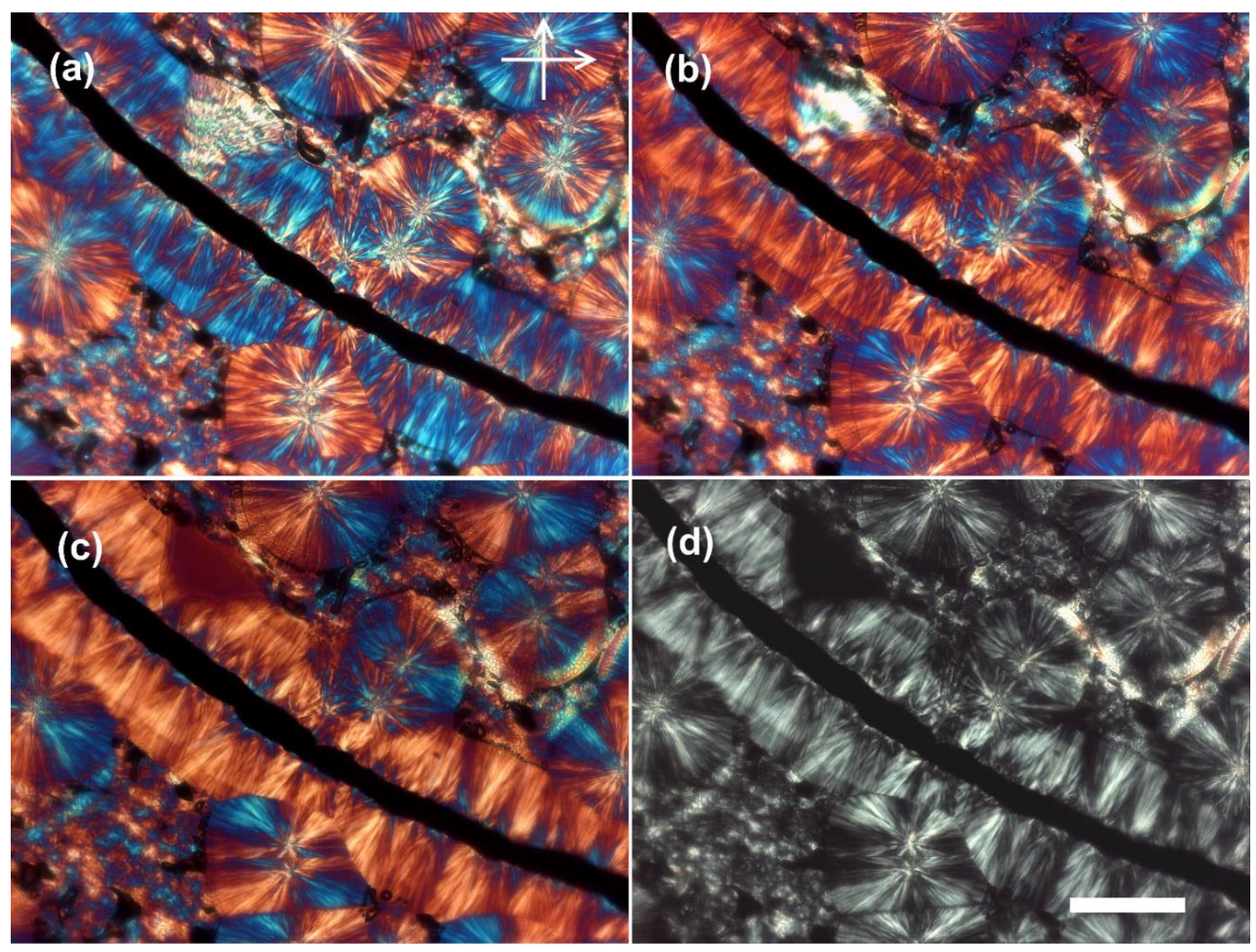

Figure 29. POM micrographs of the melting of iPP $\beta$-transcrystals over an rGO fiber crystallized at $132^{\circ} \mathrm{C}$. Sample at (a) room temperature with retarding plate, (b) $155^{\circ} \mathrm{C}$ with retarding plate, (c) $161^{\circ} \mathrm{C}$ with retarding plate, and (d) $161^{\circ} \mathrm{C}$ without retarding plate. The scale bar represents $250 \mu \mathrm{m} .{ }^{49}$ 


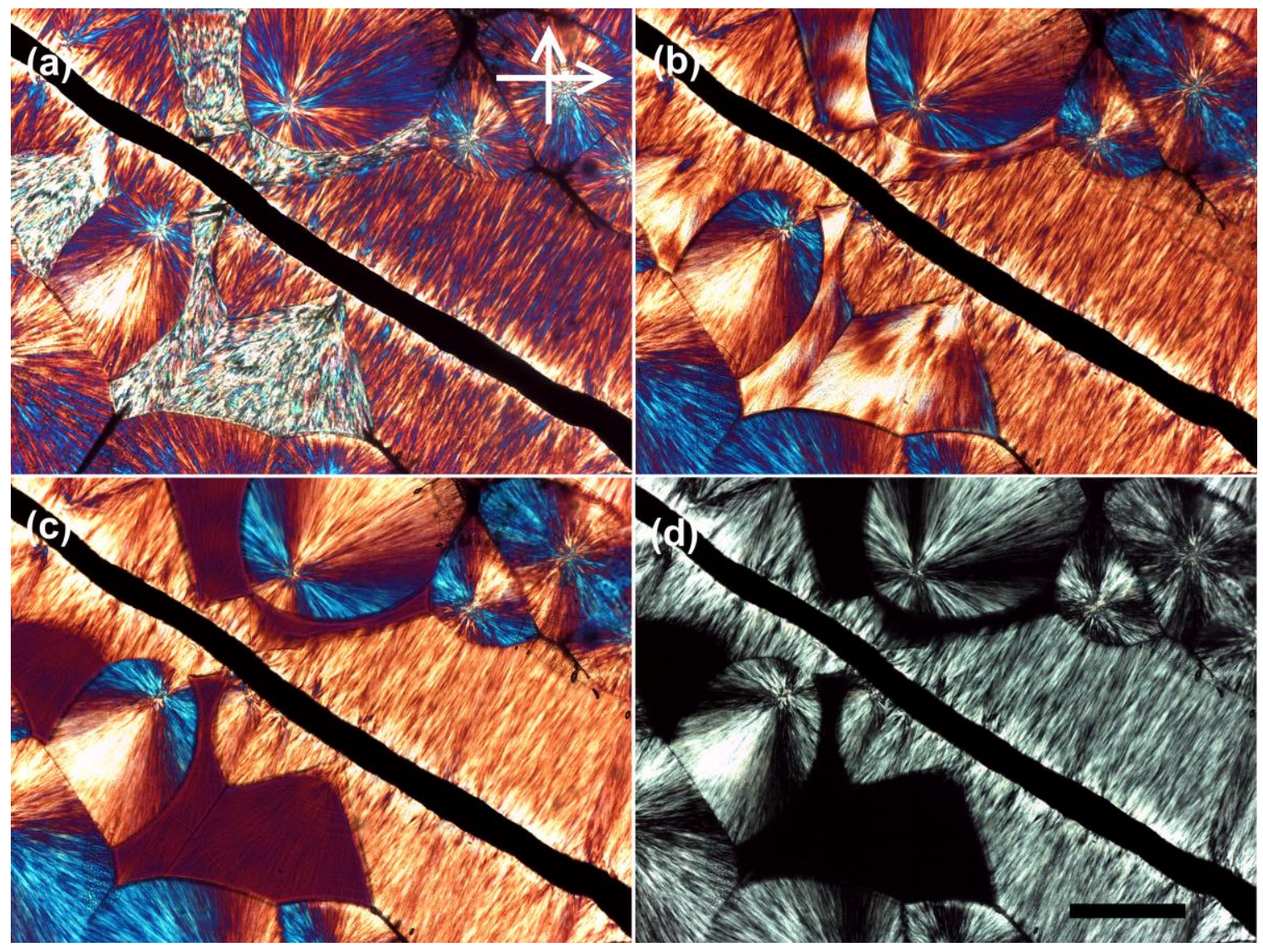

Figure 30. POM micrographs of the melting of iPP $\beta$-transcrystals over a CNT fiber crystallized at $132^{\circ} \mathrm{C}$. Sample at (a) room temperature with retarding plate, (b) $155^{\circ} \mathrm{C}$ with retarding plate, (c) $160^{\circ} \mathrm{C}$ with retarding plate, and (d) $160^{\circ} \mathrm{C}$ without retarding plate. The scale bar represents $250 \mu \mathrm{m}$.

Another noteworthy feature of Figure 26a and 31a is the presence of a second layer of predominantly positive transcrystals surrounding the initial layer around the fiber. This double layer is caused by the rapid quenching of the melt crystallization to room temperature, caused by the disorganized orientation of polymer crystals due to the cooling of the polymer. Figure 31 shows the melting process of this double layer on iPP/CNT transcrystals. The positive birefringence in the second layer undergoes the same transition as the initial transcrystalline 
layer transit at $165^{\circ} \mathrm{C}$ due to the reorganization of the cross-hatch lamellae to radial lamellae as shown in Figure 31b. The negative birefringence increases at $170^{\circ} \mathrm{C}$ so that both layers are similar in color to each other, indicating the completion of the reorganization of the second layer to the same orientation of the initial layer (Figure 31c). The melting of the crystals begins to occur at $175^{\circ} \mathrm{C}$ as the spherulite begin to lose their structure as found in Figure $31 \mathrm{~d}$. At $180^{\circ} \mathrm{C}$, the double layer along with surrounding spherulites melt first (Figure 31e), followed by the initial transcrystalline layer (Figure 31f). This may be due to the transfer of heat to the fiber from the initial layer that the second layer does not have access to or the second layer may remain more disordered despite what the birefringence indicates. 

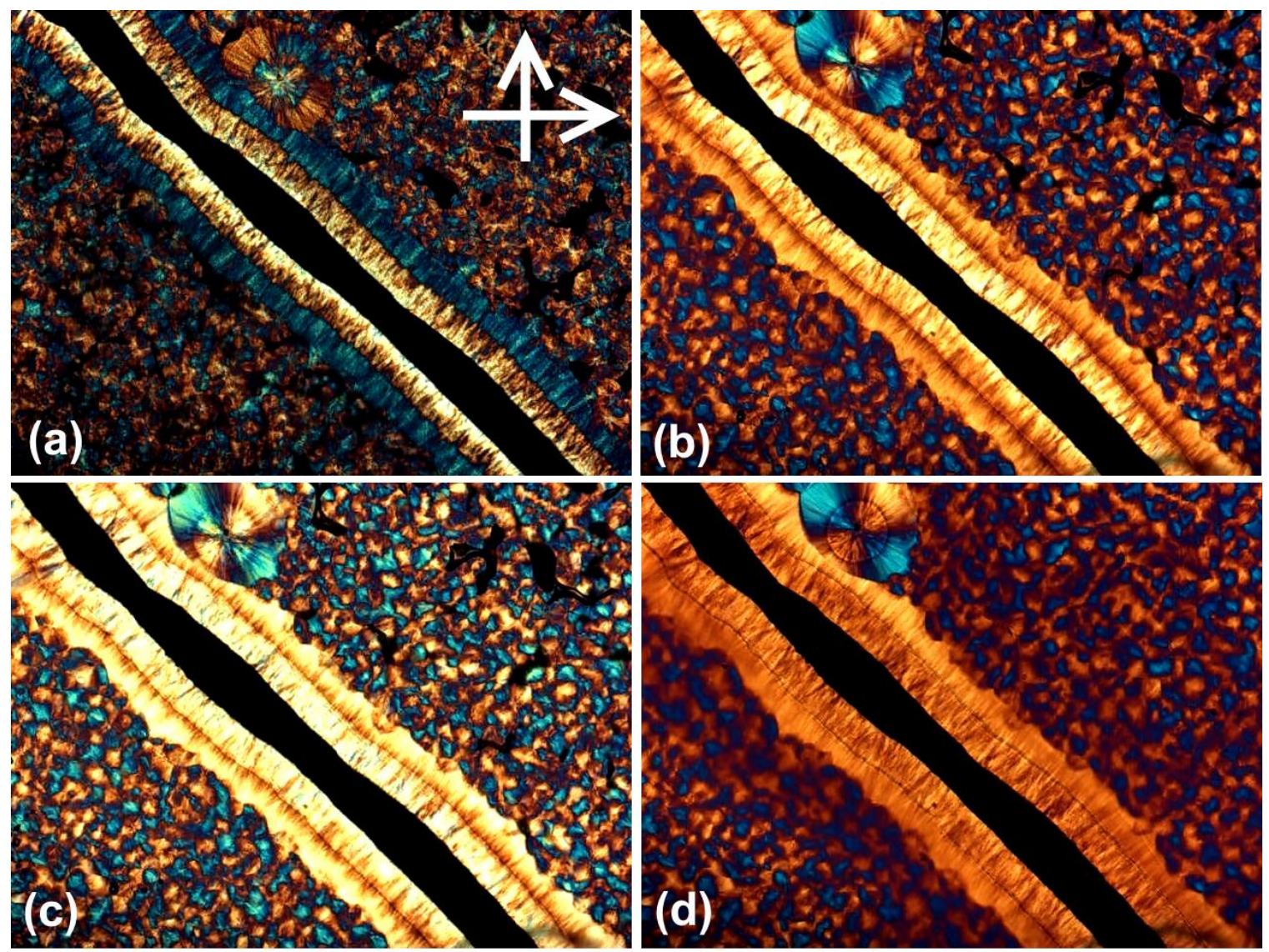

(e)

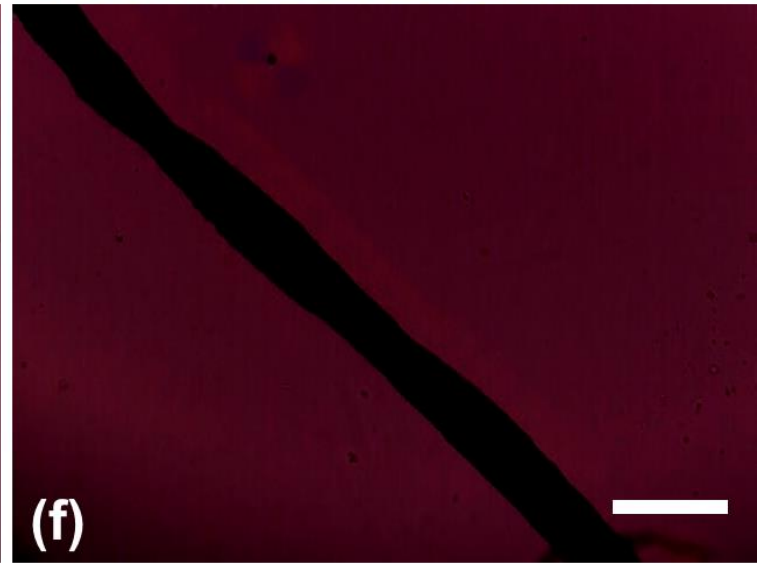

Figure 31. POM micrographs of the melting of $\mathrm{PPP} / \mathrm{CNT}$ transcrystalline double layer crystallized at $132^{\circ} \mathrm{C}$. Sample at (a) room temperature, (b) $165^{\circ} \mathrm{C}$, (c) $170^{\circ} \mathrm{C}$, and (d) $175^{\circ} \mathrm{C}$, and (e-f) $180^{\circ} \mathrm{C}$. The scale bar represents $200 \mu \mathrm{m}$. 


\subsection{Transcrystallization Kinetics}

With the transcrystal structure studied, the dynamic process of transcrystal growth can be measured. The thickness of the transcrystalline layer was observed over time with varying crystallization temperatures for both fibers using POM and the heating stage. With the growth rates of the transcrystals calculated, the fold surface free energy of the transcrystals can be calculated using Lauritzen-Hoffman theory of secondary nucleation. The fold surface free energy measures the energy to form a folded chain. Furthermore, the interfacial free energy difference is calculated from measurements of the induction times, the time required for the formation of transcrystals at the crystallization temperature. The interfacial free energy difference serves as a measure for the nucleating ability of each fiber.

The growth of the TC interphase over time at crystallization temperatures ranging from $124^{\circ} \mathrm{C}$ to $140^{\circ} \mathrm{C}$ is shown in Figure 32 . At each temperature, the thickness of the transcrystalline layer has a linear relationship to time so that the growth rate, $\mathrm{G}$, of the transcrystals is obtained from the slopes of the fitted lines. The growth rates increase with decreasing temperature because lower temperatures promote nucleation, resulting in faster crystal growth. ${ }^{55}$

According to the Lauritzen-Hoffman theory, the growth rate, G, as a function of temperature, T, can be expressed by Equation 18

$$
G=G_{0} \exp \left(\frac{-U^{*}}{R\left(T_{c}-T_{\infty}\right)}\right) \exp \left(\frac{-K_{g}}{T_{c} \Delta T}\right)
$$


The first exponential term in Equation 18 represents the diffusion of the polymer chain segments in melt to the interface while the second exponential term is associated with the thermodynamically-driven chain folding during the heterogeneous nucleation process. ${ }^{38}$ For polymer transcrystallization, the second exponential term is predominant over the first one. ${ }^{31,55}$ As a result, the first term in Equation 1 can be expressed as a constant, resulting in a linear relation of $\ln G$ to $1 / T \Delta T$ as shown in Equation 19

$$
\ln G=-\frac{K_{g}}{T_{c} \Delta T}+\text { constant }
$$

Following Equation 2, Figure 33 shows the plot of In $G$ versus $1 / T \Delta T$ with the best-fit straight line calculated. From the slope of the straight line, the calculated $\mathrm{K}_{\mathrm{g}}$ of $\mathrm{iPP} / \mathrm{rGO}$ and iPP/CNT transcrystals were equal to each other at $2.81 \times 10^{5} \mathrm{~K}^{2}$. The $\mathrm{K}_{\mathrm{g}}$ is the nucleation parameter and a function of the fold and lateral surface free energies as expressed in Equation 20

$$
K_{g}=\frac{4 b_{0} \sigma \sigma_{e} T_{m}^{0}}{k_{B} \Delta h_{f}}
$$

The parameters for $\alpha$-form crystals of iPP have been reported to be: $b_{0}$ is $6.26 \AA, \sigma$ is $1.10 \times 10^{-2} \mathrm{~J} / \mathrm{m}^{2}, T_{m}{ }^{0}$ is $458 \mathrm{~K}$, and $\Delta h_{f}$ is $209 \mathrm{~J} / \mathrm{g} .{ }^{41}$ From these values and Equation 3, the $\sigma \sigma_{e}$ of $\mathrm{PPP} / \mathrm{rGO}$ and iPP/CNT crystals was calculated to be $6.68 \times 10^{-4} \mathrm{~J}^{2} / \mathrm{m}^{4}$ and the $\sigma_{\mathrm{e}}$ was $5.81 \times 10^{-2} \mathrm{~J} / \mathrm{m}^{2}$. Because these fold surface free energy values are the same value, this indicates that fold formation is not favored for one interface over another. These values are also is in good agreement with reported literature values of $6.8-7.6 \times 10^{-2} \mathrm{~J} / \mathrm{m}^{2}$ of iPP/CNT fiber transcrystals ${ }^{31,32}$ and of $4-11 \times 10^{-2} \mathrm{~J} / \mathrm{m}^{2}$ for iPP/carbon fiber transcrystals. ${ }^{35}$ 


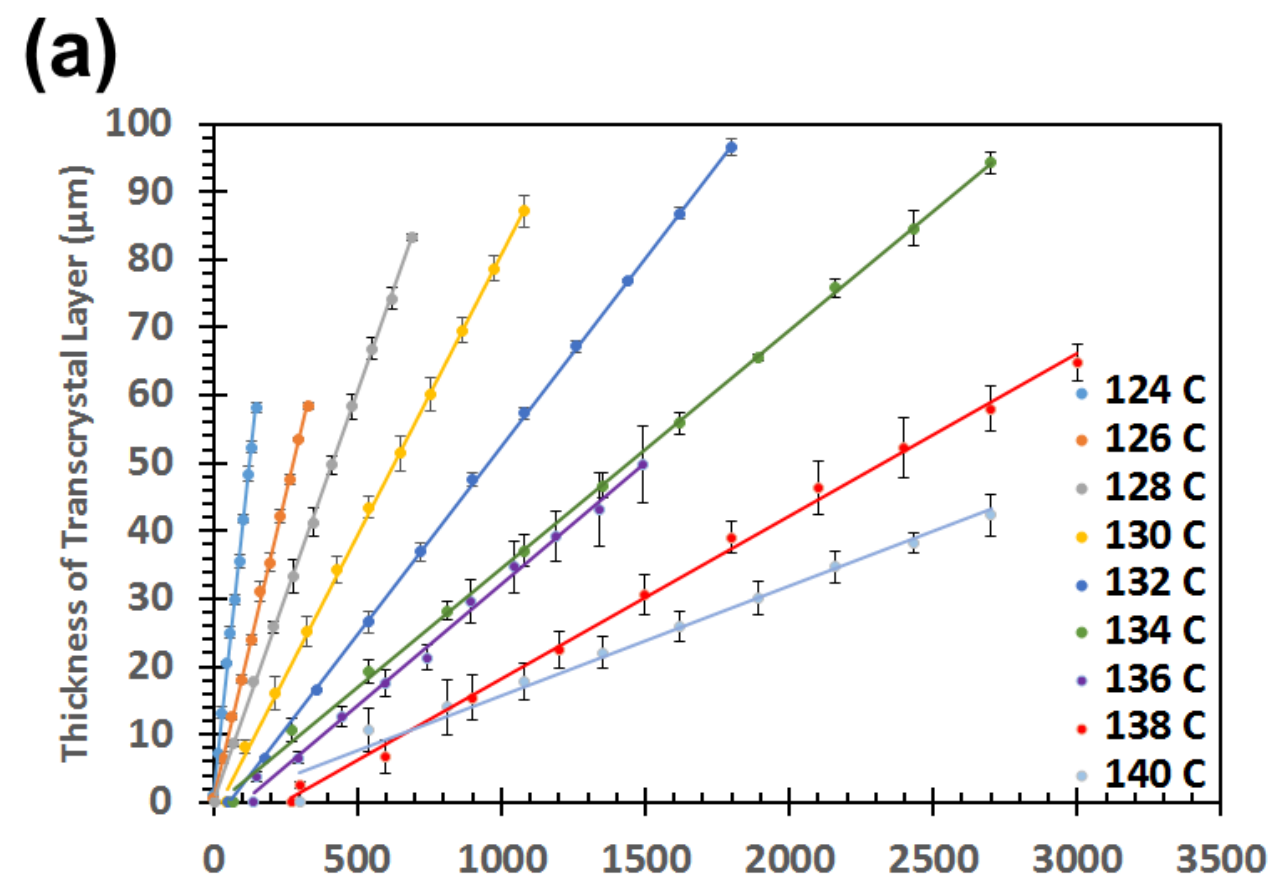

(b) Time (s)

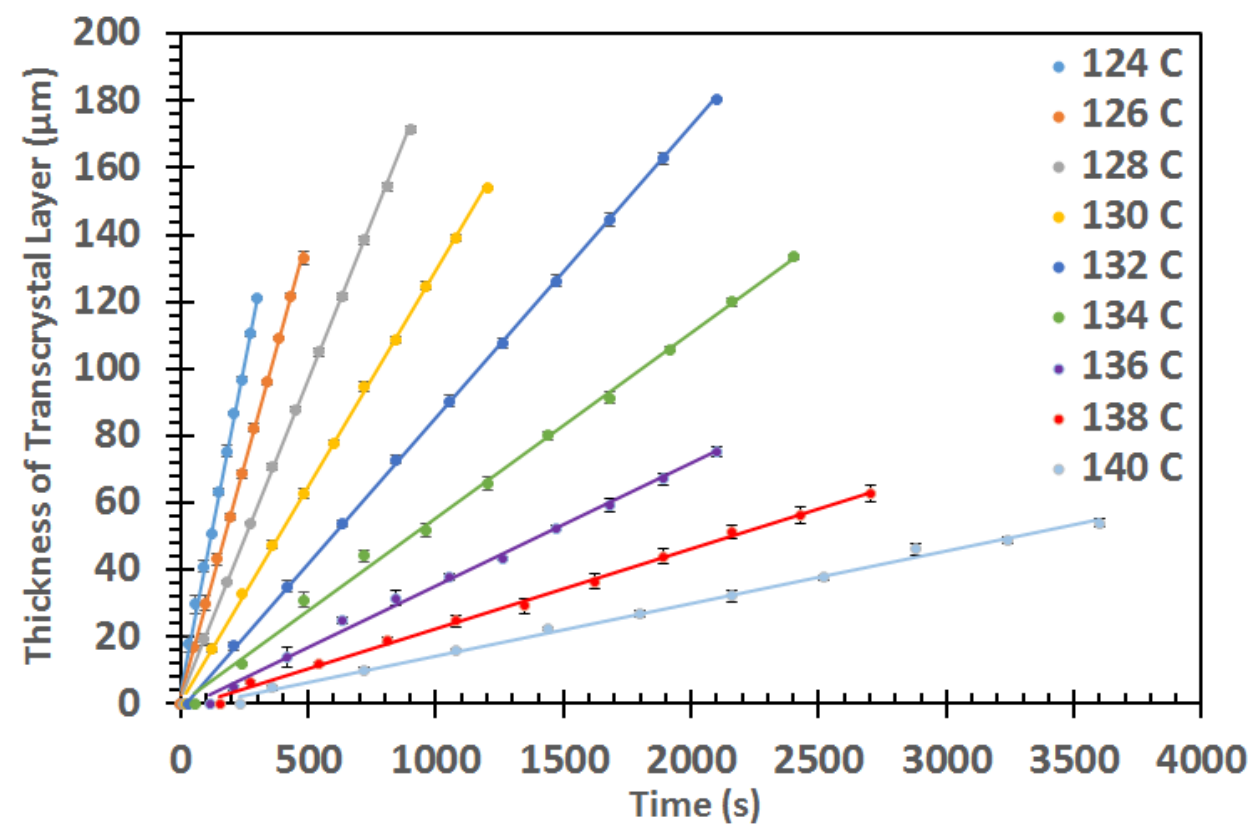

Figure 32. The plots of (a) rGO and (b) CNT transcrystal (TC) thickness versus time at different crystallization temperatures. 


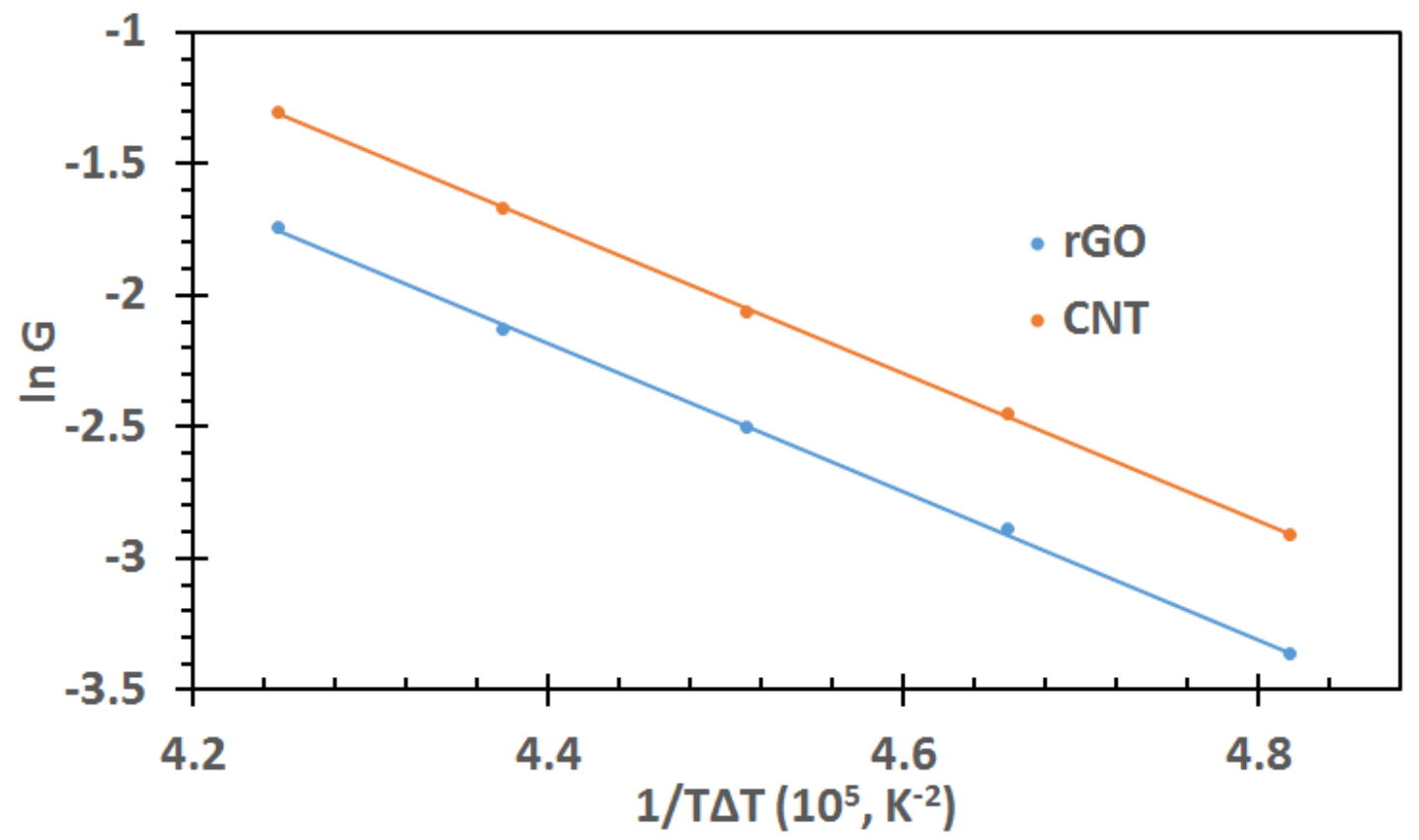

Figure 33. Plot of $\ln (G)$ of transcrystals on $r G O$ and $C N T$ fibers versus $1 /(T \Delta T)$.

The induction times, $\mathrm{t}_{\mathrm{i}}$, of the transcrystals can be used to determine the likelihood of transcrystals forming at the fiber-polymer interface. By plotting $t_{i}$ versus the crystallization temperature as in Figure 34, direct comparison can be made on the nucleation ability of both fibers. Due to the decreased induction times for the iPP/CNT transcrystals relative to the iPP/rGO transcrystals, it seems that CNT will act as a more favorable nucleation site. In order to confirm this, the interfacial free energy difference, $\Delta \sigma$, is calculated to provide a quantitative means to evaluate the nucleating ability of the fibers. $\Delta \sigma$ is calculated from Equation $21^{32}$

$$
\ln i=\ln i_{0}-\left(\frac{-U^{*}}{R\left(T_{c}-T_{\infty}\right)}\right)-\frac{16 \sigma \sigma_{e} \Delta \sigma T_{m}^{0}}{k_{B} T\left(\Delta T \Delta h_{f}\right)^{2}}
$$


where $i$ is the nucleation rate and $i_{0}$ is the constant nucleation rate. The reciprocal of the induction time equals to the nucleation rate as given in Equation $22^{42}$

$$
i(T) * t_{i}(T)=\text { constant }
$$

resulting in $\mathrm{i}$ equal to the reciprocal of $\mathrm{t}_{\mathrm{i}}$. Using Equations 21 and 22 , the $\ln \left(1 / \mathrm{t}_{\mathrm{i}}\right)$ can be plotted as function of $1 / T \Delta T^{2}$ as seen in Figure 35 . The plot does not include values at 124 and $126^{\circ} \mathrm{C}$ because transcrystals required no induction time at these crystallization temperatures. The best-fit straight line was obtained for both fibers. The slope of this line can be used to calculate $\Delta \sigma$ through Equation $23^{32}$

$$
m=-\frac{16 \sigma \sigma_{e} \Delta \sigma T_{m}^{0}}{k_{B} \Delta h_{f}^{2}}
$$

The calculated $\Delta \sigma_{\mathrm{rGO}}$ is $1.77 \times 10^{-3} \mathrm{~J} / \mathrm{m}^{2}$ while the $\Delta \sigma_{\mathrm{CNT}}$ is $1.76 \times 10^{-3} \mathrm{~J} / \mathrm{m}^{2}$. According to these results, the CNT fiber is a more favorable nucleation site, but the nucleation measurements for rGO fibers have high variation and the difference in slopes between the plots of both fibers in Figure 35 show no major differences. In conclusion, the induction time studies indicate that rGO and CNT fibers are comparable in nucleation ability, but further work will have to be done to confirm these results. These values are lower than reported results for electrospun carbon fibers $\left(5.12 \pm 0.56 \times 10^{-3} \mathrm{~J} / \mathrm{m}^{2}\right)^{34}$, but greater than the values reported for SWNT fibers $\left(1.09-1.11 \times 10^{-3} \mathrm{~J} / \mathrm{m}^{2}\right){ }^{32}$ 


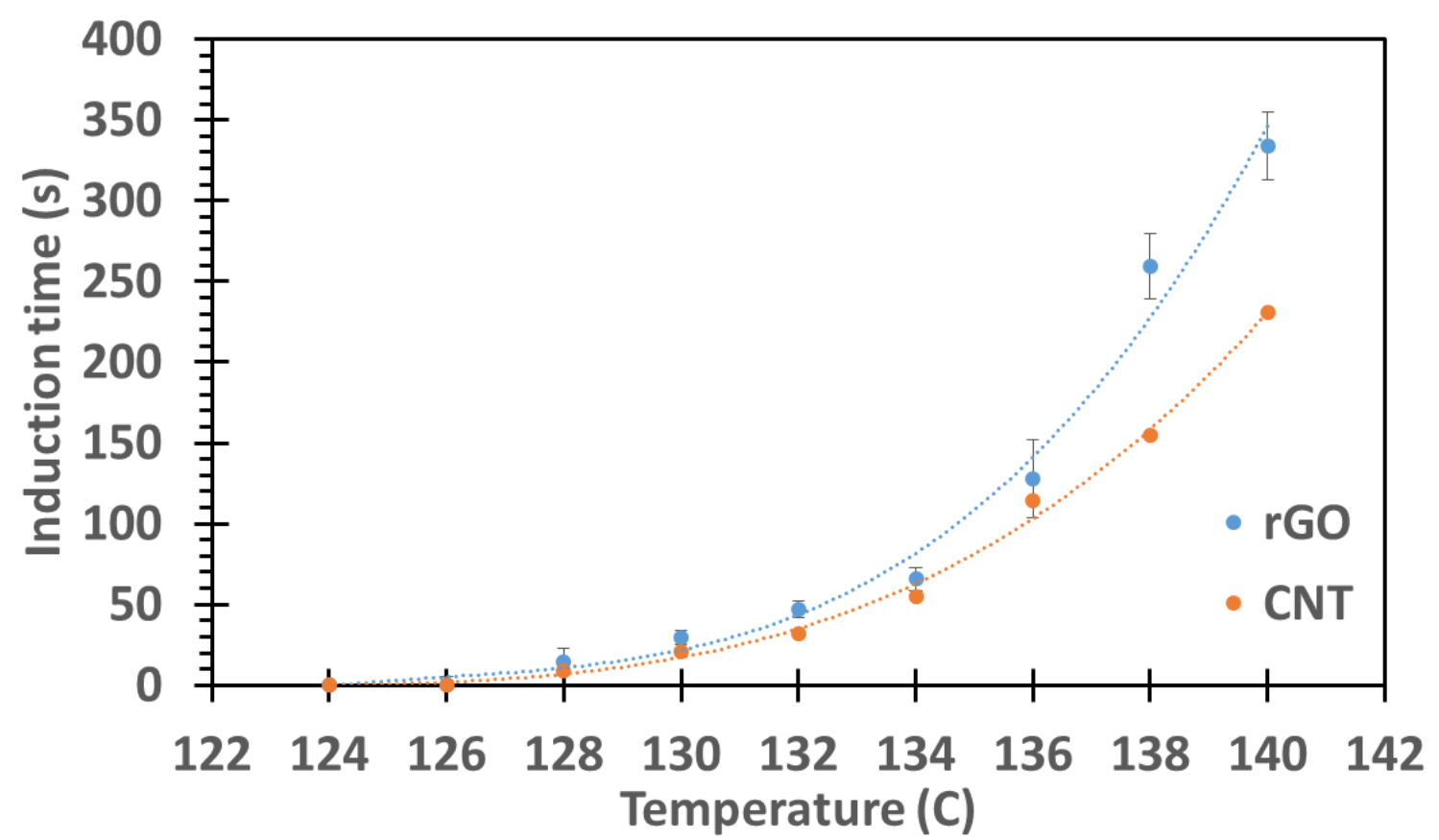

Figure 34. Induction times of iPP transcrystals on rGO and CNT fibers at different crystallization temperatures.

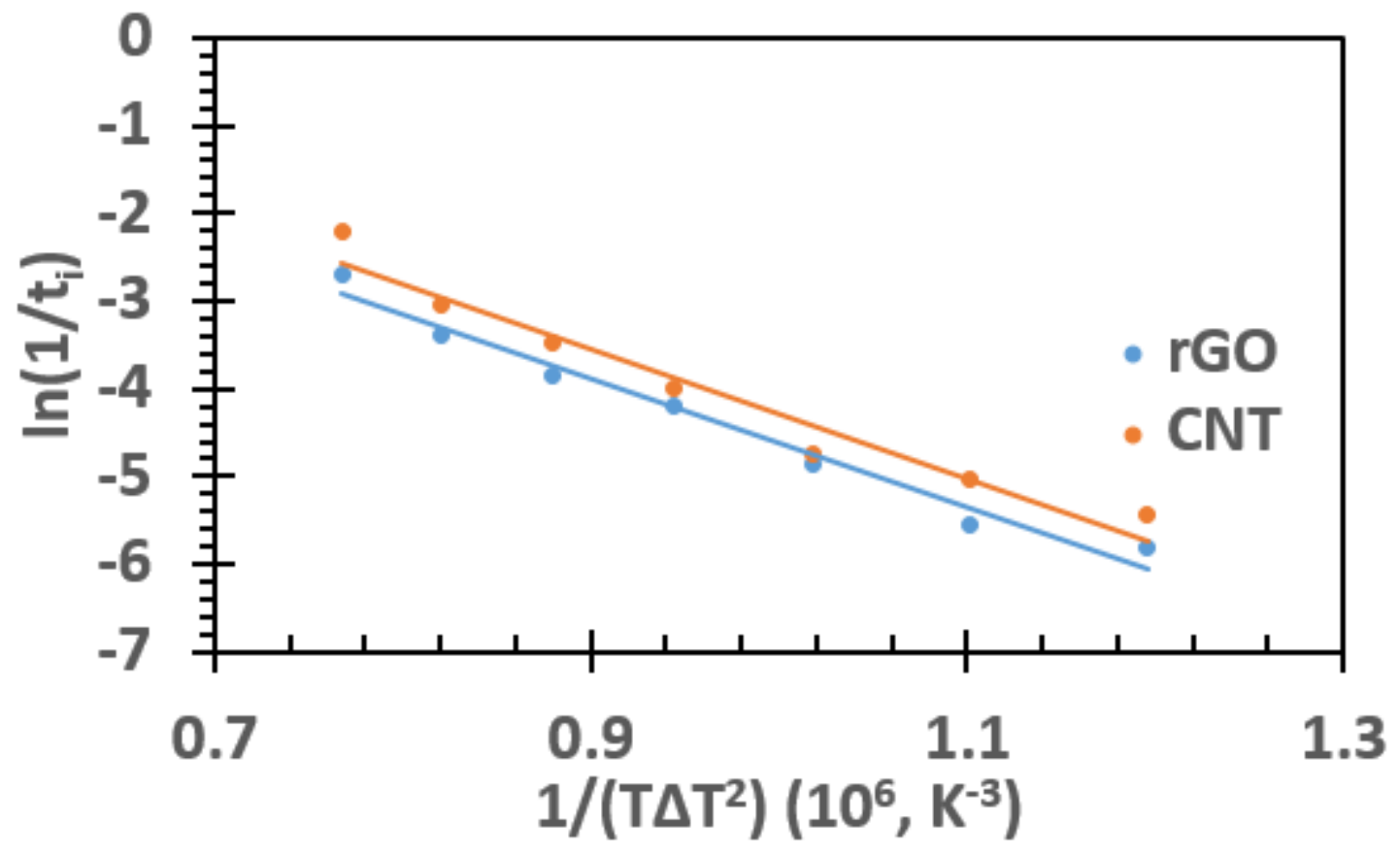

Figure 35. Plot of $\ln \left(1 / \mathrm{t}_{\mathrm{i}}\right)$ versus $1 /\left(\mathrm{T} \Delta \mathrm{T}^{2}\right)$ for $\mathrm{rGO}$ and $\mathrm{CNT}$ transcrystals. 


\subsection{Transcrystal Interface and Morphology}

When the samples have been studied for their structure and kinetics, the microstructures of the transcrystals can be observed using SEM. The structure of the transcrystals need to be studied at higher magnifications to confirm the transcrystalline structure based on literature. Furthermore, the interactions of the iPP and rGO can only be studied using a high magnification imaging technique, like scanning electron microscopy or atomic force microscopy. SEM images show how the transcrystalline lamellae are organized and how well they adhere to the fiber surface.

Figure 36a shows an SEM micrograph of the overall structure of the rGO fiber, transcrystalline layer, and spherulites. The transcrystalline layer and spherulites are differentiated by their differences in orientation with the transcrystal lamellae growing perpendicularly from the fiber surface while the spherulite lamellae grow radially outward from the center of nucleation. The interphase between the transcrystalline layer and the fiber shows overall favorable interactions as indicated by the wetting and adhesion of the polymer to the fiber surface. However, spacing can be found between the polymer and fiber as indicated by the arrows in Figure 36a. This is due to the disparity between the thermal expansion of the iPP and the rGO as the iPP shrinks during the cooling after transcrystallization and dewets the surface of the fiber.

In order to confirm the microstructure and morphology of the crystals, high magnification images were taken of the transcrystal lamellae in Figure 36b and of the boundary between the transcrystal and spherulite lamellae in Figure 36c. 
The transcrystal lamellae shows the lamellae originating from the fiber, referred to as mother lamellae, and the lamellae interconnecting the mother lamella, indicated by the arrows in Figure $36 \mathrm{~b}$ and referred to as daughter lamellae. The mother lamellae are known to grow in the radial direction from the fiber while the daughter lamellae grow tangentially to create a cross-hatched morphology that has been observed in iPP transcrystals as shown in Figure $37 .^{31}$ The angle the daughter lamellae grow from the mother lamellae is approximately $80^{\circ}$. The boundary between the transcrystal and spherulite in Figure 36c further illustrates the changes in orientation between the lamellae of both crystals.
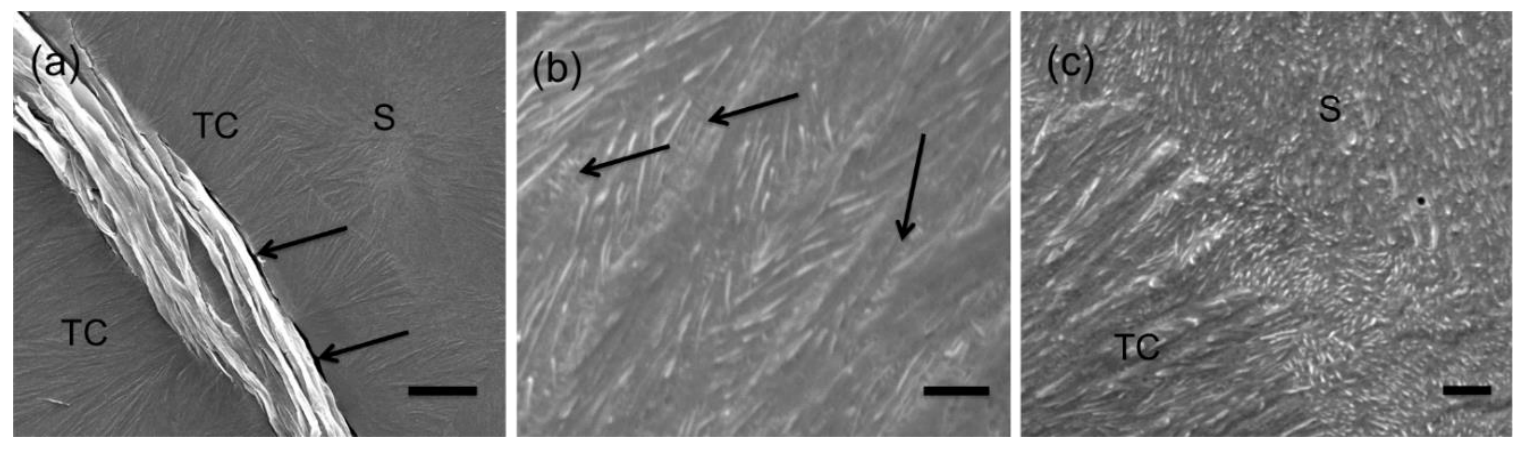

Figure 36. SEM micrographs of (a) the overall structure of the $\mathrm{iPP} / \mathrm{rGO}$ transcrystals and spherulites, (b) the transcrystalline lamellae, and (c) the boundary between the transcrystalline layer and spherulites. TC and S denotes transcrystals and spherulites, respectively. The scale bar represents $10 \mu \mathrm{m}$ in

(a) and $800 \mathrm{~nm}$ in (b) and (c). ${ }^{49}$

Similar images have been obtained from iPP/CNT transcrystals as seen in Figure 38. The overall structure on Figure 38a shows a high degree of adhesion of the iPP crystals to the CNT fiber. However, bubbling has occurred in the iPP film around the fiber, which may be due to the buildup of pressure in the film 
when heated. Figure 38b provides a high magnification image of iPP transcrystals/CNT fiber interphase. The lamellae can be more clearly seen oriented perpendicular to the fiber and the presence of smaller holes between the polymer and fiber can be observed. Similar to the rGO fibers, these holes occur due to the mismatch in thermal expansion between polymer and fiber. To reduce this from occurring, lower cooling rates from the crystallization temperature must be done to ensure that the iPP does not shrink too rapidly and break from the fiber.

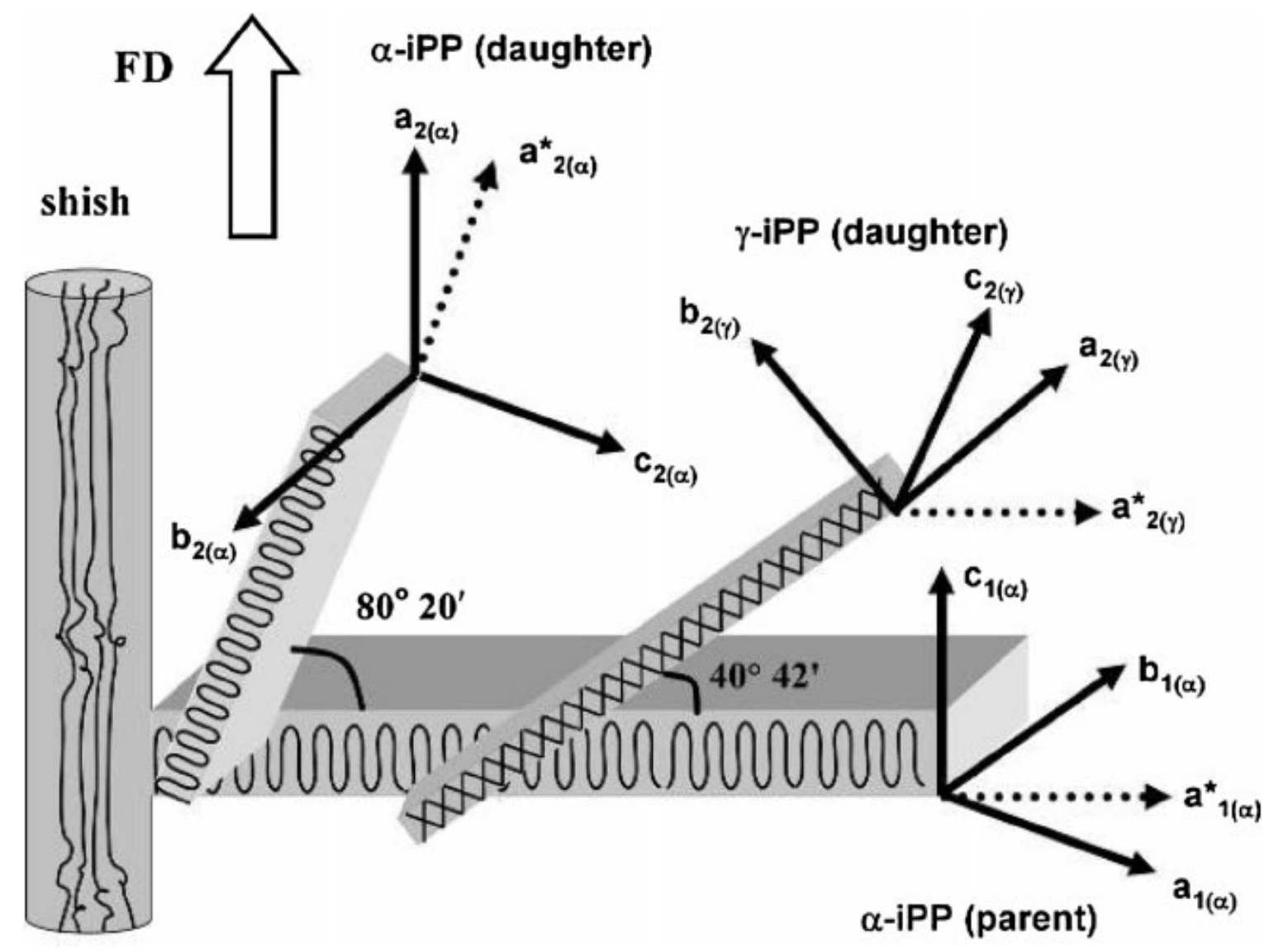

Figure 37. Scheme of the microstructures of iPP transcrystalline lamellae. ${ }^{54}$ 


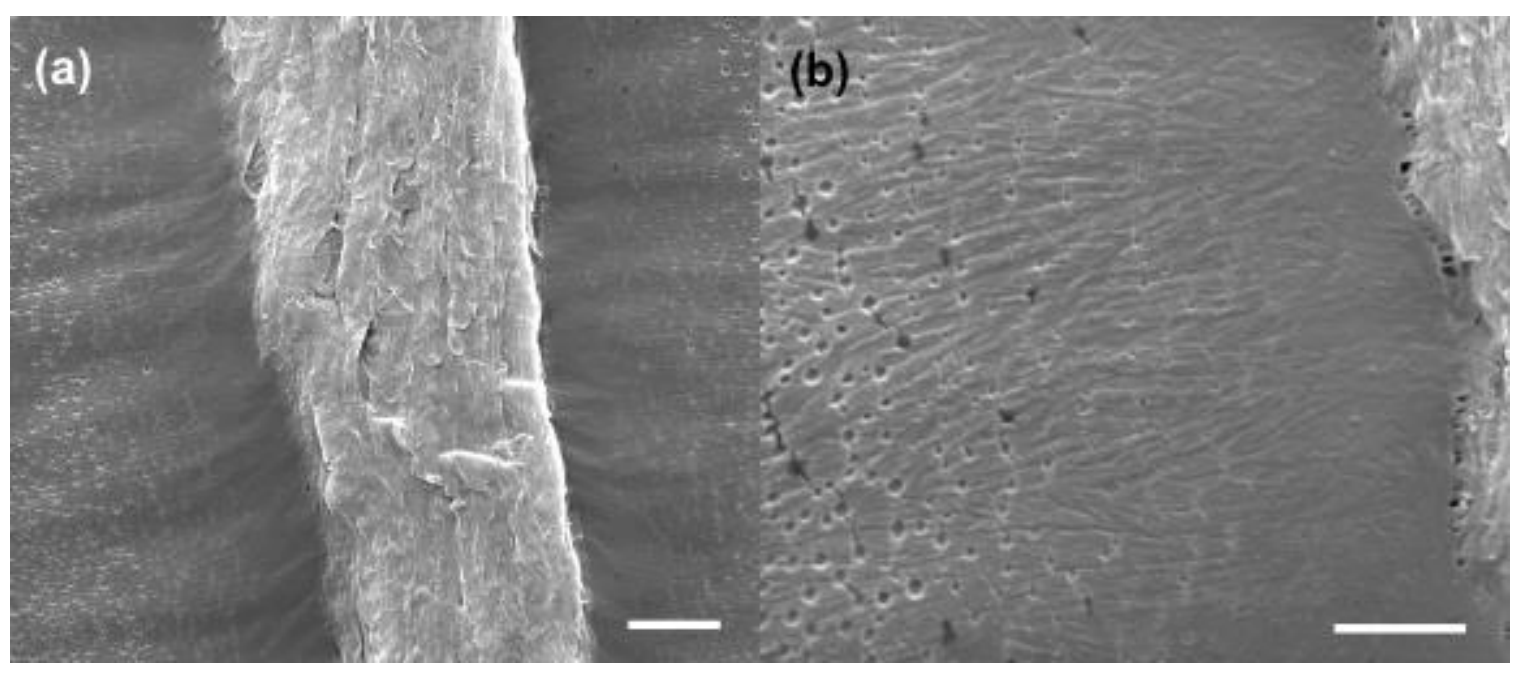

Figure 38. SEM micrographs of (a) the overall structure of the iPP/CNT transcrystals and (b) the iPP/CNT transcrystalline lamellae. The scale bar represents $10 \mu \mathrm{m}$ in (a) and $5 \mu \mathrm{m}$ in (b). 


\section{Conclusion}

In summary, the structure and kinetics of iPP transcrystals on rGO and CNT fibers has been investigated. Upon induction of crystallization at certain temperatures, transcrystals have been observed to grow perpendicularly outward from both fibers. The fiber interface exhibits great changes on the transcrystalline structure as the smoother surface of the CNT fibers allow for more radial lamellae growth. At higher temperatures, radial lamellae are predominant over tangential lamellae due to the increased time for organization because of the slower growth rates.

Unique transcrystalline structures were also studied in both fibers with the formation and melting of $\beta$-phase transcrystals and transcrystalline double layers. The growth of $\beta$-phase transcrystals was observed on both fibers, but to a higher degree on CNT fibers. The double transcrystalline layer was obtained with the rapid quenching of the sample films from crystallization temperature after the induction of transcrystals.

The kinetics results show that both fibers are comparable in nucleating ability with the fold surface free energy and interfacial free energy difference of rGO transcrystals being $5.81 \times 10^{-2} \mathrm{~J} / \mathrm{m}^{2}$ and $1.77 \times 10^{-3} \mathrm{~J} / \mathrm{m}^{2} \mathrm{~J} / \mathrm{m}^{2}$ and for CNT

transcrystals, $5.81 \times 10^{-2} \mathrm{~J} / \mathrm{m}^{2} \mathrm{~J} / \mathrm{m}^{2}$ and $1.76 \times 10^{-3} \mathrm{~J} / \mathrm{m}^{2} \mathrm{~J} / \mathrm{m}^{2}$. Studies of the microstructure of the transcrystals showed the strong interactions between rGO and CNT fibers with some spacing found at certain points through the fiber surface due to the mismatch of thermal expansion between the polymer and 
fiber. The cross-hatched morphology and changes in the orientation of the lamellae between the transcrystals and spherulites was also confirmed.

The results of this study provide the framework for better understanding of the structure and interfacial adhesion of graphene-polymer nanocomposites as well as how they compare with carbon nanotube nanocomposites. Furthermore, the transcrystals produced from this work have direct applications as high strength materials due to the load transfer from the iPP to the rGO or CNT fibers. 


\section{Future Work}

With the transcrystallization dynamic process and structure studied and compared, we can begin testing the differences in mechanical and thermal properties of both transcrystals. In particular, the mechanical reinforcement of the transcrystals has yet to be investigated fully. Judging from the birefringence found under the POM, CNT transcrystals should be the stronger material due to the apparent increased organization of the polymer chains relative to the rGO transcrystals. Making use of dynamic mechanical analysis (DMA) and fiber pullout tests, the tensile strength, Young's modulus, and interfacial shear strength of the transcrystals can be compared. Furthermore, the thermal properties of the transcrystals can be compared using differential scanning calorimetry (DSC) to obtain more accurate melting temperature data and TGA can be performed to observe the changes in thermal degradation for both samples.

Lastly, transcrystallization can be performed on other polymers to create composites for other applications. Poly(lactic acid) (PLA) has been another

matrix studied for transcrystals to create environmentally-friendly composites. ${ }^{56,57}$ rGO fibers can be implemented to create high-strength, biodegradable products. Studies have begun on creating and studying these composites, starting with CNT fibers as seen in Figure 39.

Poly(3-butylthiophene) (P3BT) can also solution crystallize under controlled vapor pressure conditions. ${ }^{58,59}$ With rGO and CNT fibers present in the solution while it anneals, it is possible for semiconducting polymer transcrystals to be made with enhanced conductivity due to the increased 
ordering of the polymer chains ${ }^{60}$ Early results have shown alignment of P3BT as shown in Figure 40. However, no crystalline layer was observed. This is due to the difficulties in controlling the vapor pressure conditions for P3BT. Furthermore, after drop-casting the polymer solution onto the fibers, the solution tends to dewet from the surface of the fiber while drying. Adjusting the concentration of the polymer solution and the vapor pressure during the crystallization will be key to improving the crystallization results of P3BT.

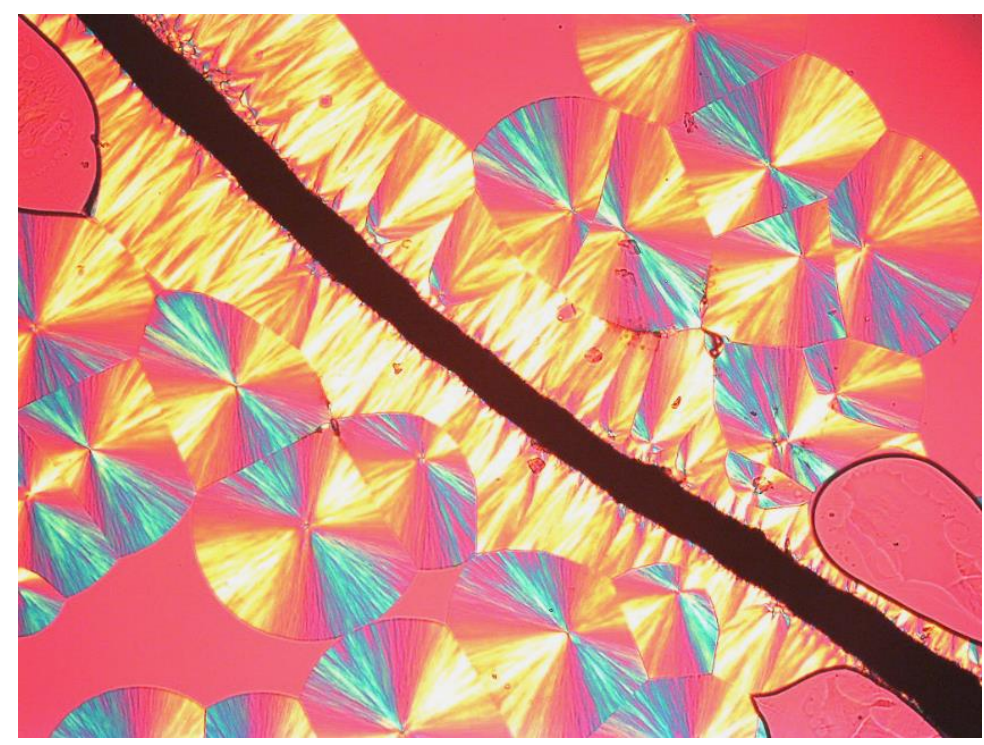

Figure 39. PLA/CNT transcrystals.
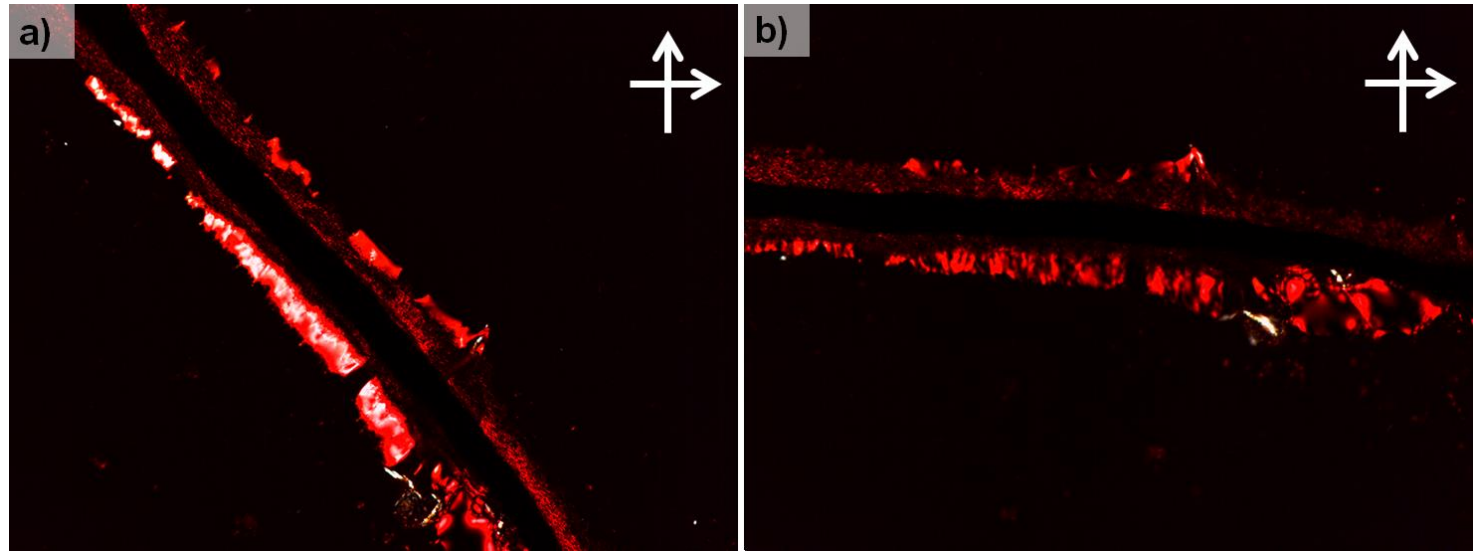

Figure 40. P3BT oriented on an rGO fiber at (a) $0^{\circ}$ and (b) $45^{\circ}$. 


\section{REFERENCES}

(1) Geim, A. K. Nobel Lecture: Random Walk to Graphene. Rev. Mod. Phys. 2011, 83 (3), 851-862.

(2) Weiss, N. O.; Zhou, H.; Liao, L.; Liu, Y.; Jiang, S.; Huang, Y.; Duan, X. Graphene: An Emerging Electronic Material. Adv. Mater. 2012, 24 (43), 5782-5825.

(3) Geim, a K.; Novoselov, K. S. The Rise of Graphene. Nat. Mater. 2007, 6 (3), 183-191.

(4) Geim, a K. GRAPHENE: STATUS AND PROSPECTS A. K. Geim Manchester Centre for Mesoscience and Nanotechnology, University of Manchester, Oxford Road M13 9PL, Manchester, UK. Prospects 2009, 324 (6), 1-8.

(5) Sun, X.; Sun, H.; Li, H.; Peng, H. Developing Polymer Composite Materials: Carbon Nanotubes or Graphene? Adv. Mater. 2013, 25 (37), 5153-5176.

(6) Wang, C.; Liu, C.-R. Transcrystallization of Polypropylene Composites: Nucleating Ability of Fibres. Polymer 1999, 40 (2), 289-298.

(7) William S. Hummers, J.; Offeman, R. E. Preparation of Graphitic Oxide. J. Am. Chem. Soc 1958, 80 (1937), 1339.

(8) Luo, Y.; Braggin, G. A.; Olson, G. T.; Stevenson, A. R.; Ruan, W. L.; Zhang, S. Nematic Order Drives Macroscopic Patterns of Graphene Oxide in Drying Drops. Langmuir 2014, 30 (48), 14631-14637.

(9) Cruz-Silva, R.; Morelos-Gomez, A.; Kim, H. I.; Jang, H. K.; Tristan, F.; Vega-Diaz, S.; Rajukumar, L. P.; Elías, A. L.; Perea-Lopez, N.; Suhr, J.; et al. Super-Stretchable Graphene Oxide Macroscopic Fibers with Outstanding Knotability Fabricated by Dry Film Scrolling. ACS Nano 2014, 8 (6), 5959-5967.

(10) Xu, Z.; Sun, H.; Zhao, X.; Gao, C. Ultrastrong Fibers Assembled from Giant Graphene Oxide Sheets. Adv. Mater. 2013, 25 (2), 188-193.

(11) Huang, G.; Hou, C.; Shao, Y.; Wang, H.; Zhang, Q.; Li, Y.; Zhu, M. Highly Strong and Elastic Graphene Fibres Prepared from Universal Graphene Oxide Precursors. Sci. Rep. 2014, 4, 4248. 
(12) Wang, S.; Zhang, Y.; Abidi, N.; Cabrales, L. Wettability and Surface Free Energy of Graphene Films. Langmuir 2009, 25 (18), 11078-11081.

(13) Reilly, R. M. Carbon Nanotubes: Potential Benefits and Risks of Nanotechnology in Nuclear Medicine. J. Nucl. Med. 2007, 48 (7), 10391042.

(14) Vasileiou, A. a.; Kontopoulou, M.; Docoslis, A. A Noncovalent Compatibilization Approach to Improve the Filler Dispersion and Properties of Polyethylene/graphene Composites. ACS Appl. Mater. Interfaces 2014, 6 (3), 1916-1925.

(15) Alexandre, M.; Dubois, P. Polymer-Layered Silicate Nanocomposites: Preparation, Properties and Uses of a New Class of Materials. Mater. Sci. Eng. $R$ Reports 2000, 28 (1), 1-63.

(16) Potts, J. R.; Dreyer, D. R.; Bielawski, C. W.; Ruoff, R. S. Graphene-Based Polymer Nanocomposites. Polymer 2011, 52 (1), 5-25.

(17) Zhao, X.; Zhang, Q.; Chen, D.; Lu, P. Enhanced Mechanical Properties of Graphene-Based Polyvinyl Alcohol Composites. Macromolecules 2010, 43 (5), 2357-2363.

(18) Zhang, K.; Zhang, L. L.; Zhao, X. S.; Wu, J. Graphene/polyaniline Nanofiber Composites as Supercapacitor Electrodes. Chem. Mater. 2010, 22 (4), 1392-1401.

(19) Dalton, A. B.; Collins, S.; Muñoz, E.; Razal, J. M.; Ebron, V. H.; Ferraris, J. P.; Coleman, J. N.; Kim, B. G.; Baughman, R. H. Super-Tough CarbonNanotube Fibres. Nature 2003, 423 (6941), 703.

(20) Yun, D. J.; Ra, H.; Rhee, S. W. Concentration Effect of Multiwalled Carbon Nanotube and poly (3, 4-Ethylenedioxythiophene) Polymerized with poly(4Styrenesulfonate) Conjugated Film on the Catalytic Activity for Counter Electrode in Dye Sensitized Solar Cells. Renew. Energy 2013, 50, 692700.

(21) Goyal, R.; Sharma, M.; Amberiya, U. K. Innovative Nano Composite Materials and Applications in Automobiles. Int. J. Eng. Res. Technol. 2014, 3 (1), 3001-3009.

(22) Zhang, S.; Lin, W.; Wong, C. P.; Bucknall, D. G.; Kumar, S. Nanocomposites of Carbon Nanotube Fibers Prepared by Polymer Crystallization. ACS Appl. Mater. Interfaces 2010, 2 (6), 1642-1647. 
(23) Zhang, S.; Zhu, L.; Wong, C. P.; Kumar, S. Polymer-Infiltrated Aligned Carbon Nanotube Fibers by in Situ Polymerization. Macromol. Rapid Commun. 2009, 30 (22), 1936-1939.

(24) Zhang, S.; Lin, W.; Yu, X.; Wong, C.; Cheng, S. Z. D.; Bucknall, D. G. Surface-Induced Polymer Crystallization in High Volume Fraction Aligned Carbon Nanotube-Polymer Composites. Macromol. Chem. Phys. 2010, 211 (9), 1003-1011.

(25) Ma, J.; Meng, Q.; Michelmore, A.; Kawashima, N.; Izzuddin, Z.; Bengtsson, C.; Kuan, H.-C. Covalently Bonded Interfaces for Polymer/graphene Composites. J. Mater. Chem. A 2013, 1 (13), 4255.

(26) Xu, J.-Z.; Chen, C.; Wang, Y.; Tang, H.; Li, Z.-M.; Hsiao, B. S. Graphene Nanosheets and Shear Flow Induced Crystallization in Isotactic Polypropylene Nanocomposites. Macromolecules 2011, 44 (8), 28082818.

(27) Xu, P.; Loomis, J.; Bradshaw, R. D.; Panchapakesan, B. Load Transfer and Mechanical Properties of Chemically Reduced Graphene Reinforcements in Polymer Composites. Nanotechnology 2012, 23 (50), 505713.

(28) Jang, H.-K.; Kim, H.-I.; Dodge, T.; Sun, P.; Zhu, H.; Nam, J.-D.; Suhr, J. Interfacial Shear Strength of Reduced Graphene Oxide Polymer Composites. Carbon N. Y. 2014, 77, 1-8.

(29) Xu, J. Z.; Liang, Y. Y.; Zhong, G. J.; Li, H. L.; Chen, C.; Li, L. Bin; Li, Z. M. Graphene Oxide Nanosheet Induced Intrachain Conformational Ordering in a Semicrystalline Polymer. J. Phys. Chem. Lett. 2012, 3 (4), 530-535.

(30) Quan, H.; Li, Z. M.; Yang, M. B.; Huang, R. On Transcrystallinity in SemiCrystalline Polymer Composites. Compos. Sci. Technol. 2005, 65 (7-8), 999-1021.

(31) Zhang, S.; Minus, M. L.; Zhu, L.; Wong, C. P.; Kumar, S. Polymer Transcrystallinity Induced by Carbon Nanotubes. Polymer 2008, 49 (5), 1356-1364.

(32) Gao, Y.; Xie, M.; Liu, L.; Li, J.; Kuang, J.; Ma, W.; Zhou, W.; Xie, S.; Zhang, Z. Effect of Supra-Molecular Microstructures on the Adhesion of SWCNT fiber/iPP Interface. Polymer 2013, 54 (1), 456-463.

(33) Wu, C.-M.; Chen, M.; Karger-Kocsis, J. Effect of Micromorphologic Features on the Interfacial Strength of iPP/Kevlar Fiber Microcomposites. Polymer 2001, 42, 199-208. 
(34) Wang, C.; Liu, F. H.; Huang, W. H. Electrospun-Fiber Induced Transcrystallization of Isotactic Polypropylene Matrix. Polymer 2011, 52 (5), 1326-1336.

(35) Assouline, E.; Pohl, S.; Fulchiron, R.; Gérard, J.-F.; Lustiger, A.; Wagner, $\mathrm{H}$. .; Marom, G. The Kinetics of A and B Transcrystallization in FibreReinforced Polypropylene. Polymer 2000, 41, 7843-7854.

(36) Cheng, S. Z. D.; Lotz, B. Enthalpic and Entropic Origins of Nucleation Barriers during Polymer Crystallization: The Hoffman-Lauritzen Theory and beyond. Polymer 2005, 46 (20), 8662-8681.

(37) Ratta, V. Crystallization, Morphology, Thermal Stability and Adhesive Properties of Novel High Performance Semicrystalline Polyimides, 1999, Vol. PhD.

(38) Hoffman, J. D.; Miller, R. L. Kinetic of Crystallization from the Melt and Chain Folding in Polyethylene Fractions Revisited: Theory and Experiment. Polymer 1997, 38 (13), 3151-3212.

(39) Lauritzen, J. I.; Hoffman, J. D. Extension of Theory of Growth of ChainFolded Polymer Crystals to Large Undercoolings. J. Appl. Phys. 1973, 44 (10), 4340-4352.

(40) Hoffman, J. D.; Lauritzen, J. I.; Passaglia, E.; Ross, G. S.; Frolen, L. J.; Weeks, J. J. Kinetics of Polymer Crystallization from Solution and the Melt. Kolloid-Zeitschrift und Zeitschrift für Polymere 1969, 231 (1-2), 564-592.

(41) Clark, E. J.; Hoffman, J. D. Regime $\{$ III $\}$ Crystallization in Polypropylene. Macromolecules 1984, 17, 878-885.

(42) Ishida, H.; Bussi, P. Surface-Induced Crystallization in Ultrahigh-Modulus Polyethylene Fiber Reinforced Polyethylene Composites. Macromolecules 1991, 24 (12), 3569-3577.

(43) Mezghani, K.; Phillips, P. J. Г-Phase in Propylene Copolymers at Atmospheric Pressure. Polymer 1995, 36 (12), 2407-2411.

(44) Naebe, M.; Wang, J.; Amini, A.; Khayyam, H.; Hameed, N.; Li, L. H.; Chen, Y.; Fox, B. Mechanical Property and Structure of Covalent Functionalised Graphene/epoxy Nanocomposites. Sci. Rep. 2014, 4, 4375.

(45) Park, S.; An, J.; Potts, J. R.; Velamakanni, A.; Murali, S.; Ruoff, R. S. Hydrazine-Reduction of Graphite- and Graphene Oxide. Carbon N. Y. 2011, 49 (9), 3019-3023. 
(46) Zhang, S.; Majewski, P. W.; Keskar, G.; Pfefferle, L. D.; Osuji, C. O. Lyotropic Self-Assembly of High-Aspect-Ratio Semiconductor Nanowires of Single-Crystal ZnO. Langmuir 2011, 27 (18), 11616-11621.

(47) Xu, Z.; Gao, C. Aqueous Liquid Crystals of Graphene Oxide. ACS Nano 2011, 5 (4), 2908-2915.

(48) Kim, J. E.; Han, T. H.; Lee, S. H.; Kim, J. Y.; Ahn, C. W.; Yun, J. M.; Kim, S. O. Graphene Oxide Liquid Crystals. Angew. Chemie - Int. Ed. 2011, 50 (13), 3043-3047.

(49) Abdou, J. P.; Braggin, G. a.; Luo, Y.; Stevenson, A. R.; Chun, D.; Zhang, S. Graphene-Induced Oriented Interfacial Microstructures in Single Fiber Polymer Composites. ACS Appl. Mater. Interfaces 2015, 7, 13620-13626.

(50) Ning, N.; Zhang, W.; Yan, J.; Xu, F.; Wang, T.; Su, H.; Tang, C.; Fu, Q. Largely Enhanced Crystallization of Semi-Crystalline Polymer on the Surface of Glass Fiber by Using Graphene Oxide as a Modifier. Polymer 2013, 54 (1), 303-309.

(51) Liu, Q.; Sun, X.; Li, H.; Yan, S. Orientation-Induced Crystallization of Isotactic Polypropylene. Polymer 2013, 54 (17), 4404-4421.

(52) Sun, X.; Li, H.; Wang, J.; Yan, S. Shear-Induced Interfacial Structure of Isotactic Polypropylene (iPP) in iPP/fiber Composites. Macromolecules 2006, 39 (25), 8720-8726.

(53) Zhao, S.; Cai, Z.; Xin, Z. A Highly Active Novel B-Nucleating Agent for Isotactic Polypropylene. Polymer 2008, 49 (11), 2745-2754.

(54) Phillips, A. W.; Bhatia, A.; Zhu, P. W.; Edward, G. Polymorphism in Sheared Isotactic Polypropylene Containing Nucleant Particles. Macromol. Mater. Eng. 2013, 298 (9), 991-1003.

(55) Luo, Y.; Santos, F. a.; Wagner, T. W.; Tsoi, E.; Zhang, S. Dynamic Interactions between poly(3-Hexylthiophene) and Single-Walled Carbon Nanotubes in Marginal Solvent. J. Phys. Chem. B 2014, 118 (22), 60386046.

(56) Xu, H.; Xie, L.; Jiang, X.; Li, X. J.; Li, Y.; Zhang, Z. J.; Zhong, G. J.; Li, Z. M. Toward Stronger Transcrystalline Layers in Poly(I-Lactic Acid)/natural Fiber Biocomposites with the Aid of an Accelerator of Chain Mobility. $J$. Phys. Chem. B 2014, 118 (3), 812-823. 
(57) Wen, T.; Zhang, X.; Xiong, Z.; de Vos, S.; Wang, R.; Wang, F.; Wang, D. Study on Fracture Behavior of PLLA Transcrystallization: Effect of Crystalline Morphology. J. Appl. Polym. Sci. 2015, 132 (2), 41273.

(58) Lu, G.; Li, G.; Yang, X. Morphology and Crystalline Transition of poly(3Butylthiophene) Associated with Its Polymorphic Modifications.

Macromolecules 2008, 41 (6), 2062-2070.

(59) Lu, G.; Li, G.; Yang, X. Achieving Perpendicular Alignment of Rigid Polythiophene Backbones to the Substrate by Using Solvent-Vapor Treatment. Adv. Mater. 2007, 19 (21), 3594-3598.

(60) Crossland, E. J. W.; Tremel, K.; Fischer, F.; Rahimi, K.; Reiter, G.; Steiner, U.; Ludwigs, S. Anisotropic Charge Transport in Spherulitic Poly(3Hexylthiophene) Films. Adv. Mater. 2012, 24 (6), 839-844. 